Portland State University

PDXScholar

Summer 7-26-2016

\title{
South Korean Teachers' Beliefs about Diversity: the Impact on Practice of Multicultural Education
}

Marie Yeo

Portland State University

Follow this and additional works at: https://pdxscholar.library.pdx.edu/open_access_etds

Part of the Bilingual, Multilingual, and Multicultural Education Commons, Korean Studies Commons, and the Teacher Education and Professional Development Commons Let us know how access to this document benefits you.

\section{Recommended Citation}

Yeo, Marie, "South Korean Teachers' Beliefs about Diversity: the Impact on Practice of Multicultural Education" (2016). Dissertations and Theses. Paper 3120.

https://doi.org/10.15760/etd.3116

This Dissertation is brought to you for free and open access. It has been accepted for inclusion in Dissertations and Theses by an authorized administrator of PDXScholar. Please contact us if we can make this document more accessible: pdxscholar@pdx.edu. 
South Korean Teachers' Beliefs about Diversity:

The Impact on Practice of Multicultural Education

by

Marie Yeo

A dissertation submitted in partial fulfillment of the requirements for the degree of

Doctor of Education

in

Educational Leadership: Curriculum and Instruction

\author{
Dissertation Committee: \\ Micki M. Caskey, Chair \\ Dannelle D. Stevens \\ Anita Bright \\ Yves Labissiere
}

Portland State University

2016 
(C) 2016 Marie Yeo 


\begin{abstract}
Teachers in South Korean schools have begun to pay attention to the importance of multicultural education as Korea transforms into a multicultural society from a historically monoculture society. Because of Koreans' pride in the homogeneity of their race, language, and culture, multiculturalism is an idea that is hard for many to accept. Education needs to play a key role in fostering and retaining the value of diversity. Studies suggest that teachers' positive beliefs about diversity play a significant role to develop their multicultural competence and eventually to practice better multicultural education. The problem is little evidence exists in the literature about Korean teachers' beliefs about diversity. The purpose of this study was to examine South Korean teachers' beliefs about diversity, the factors that influence those beliefs, and the impact of those beliefs on their practice of multicultural education teaching. I used a mixed methods research approach which included surveys among a group of elementary teachers in South Korea and interviews with six teachers to examine their beliefs about diversity in more depth. Results indicated that for teachers in this study: (a) intercultural experiences positively influenced Korean teachers' beliefs about diversity; and (b) teachers' beliefs about diversity had a significant impact on their practice of multicultural teaching. Based on the findings, I suggest that teacher education programs provide meaningful intercultural experiences and support teachers to develop positive beliefs about diversity, and eventually, to practice better multicultural education in South Korea.
\end{abstract}




\section{Acknowledgements}

It took two villages to finish my doctoral work: One village in Portland and the other one in Korea. Without supports from people of the two villages, I would not been able to complete my doctoral study. In Portland, I have been extremely lucky to meet the most amazing people. Thanks to them, I have opened my eyes toward the value of diversity, generosity, tolerance, and mutual respects.

First and foremost, I would like to express my deepest gratitude for my two advisors. Dr. Dannelle Stevens was the one who first invited me to this program. In our tea time conversation several years ago, Dannelle suggested me, "Why don't you start our doctoral program?” My response was “Can I?" Back then, I was wondering myself if I would ever start the program, however, the conversation ignited a small fire of hope in my mind and now I am finishing my doctoral study!

Dr. Micki Caskey, the chair of my dissertation committee, literally she held my hand and led me to each step to the completion of the program. She read each line of dissertation for many times, gave me the most thoughtful and timely feedbacks, and always responsive to any of my questions and needs. I always remember she read my dissertation and gave me valuable feedbacks even during hard times in her personal life. I learned tremendously from my both advisors as a scholar, educator, mentor, and woman.

I wish to express my sincere gratitude to my dissertation committee members for dedicating time and energy to be engaged in my dissertation committee. Dr. Anita Bright always sent me encouraging words, responsive to my requests, and provided me significant perspectives on my dissertation that I could have missed. I wish to thank Dr. 
Labissiere for his support as my Office of Graduate Studies representative and for providing me feedbacks that contributed to make my dissertation more comprehensible.

Dr. Moti Hara deserves my gratitude for our discussions to find proper statistical tests and to analyze results to answer my research questions. I was not familiar with the statistical analysis at the beginning, thanks to Moti's patience and advice; I was able to provide clearer evidences to examine my research assumptions and to answer my questions.

I would like to thank my cohort members for creating such a safe and helpful learning community. My cohort members respected different perspectives that I brought to and encourage each other at each the important stage of the program. Knowing that I was not alone in this long journey was a great help particularly, for an international student like me.

Outside of school, many friends volunteered to be my cheerleaders. My friend, Philip Ochs, read numerous edits of my dissertation and encouraged me to use correct English grammar, particularly proper prepositions. I most appreciate that he taught me the American wisdom "Don't be shy to ask for what you want."

Back in Korea, my family has supported me unconditionally throughout the last four years. My husband, Inyong Na, generously and patiently supported me and took care of family in Korea while I have been away from them. My children, Yongbin and Yewon, I thank them for having been there by my side for last four years. They followed me to America and adjusted amazingly well, studied hard and played hard. My mom and dad have sent me continuous trust that I would succeed in my study and make a 
meaningful contribution when I come back. My mother in law has shown understanding of my having been absent from all family events and duties for the last several years.

My friends in Korea have been my cheerleaders. They helped me to find study participants and encouraged me that what I was doing is not an easy, but an important work. I sincerely appreciate the participating teachers in my study for sharing their honest thoughts. I respect the participating teachers' knowledge on multicultural education and their passion to improve it.

Finally, I am privileged to be a student, friend, and family of the ones that I acknowledged. They made it possible for me to attain my goal, and I thank them all from the bottom of my heart. 
Table of Contents

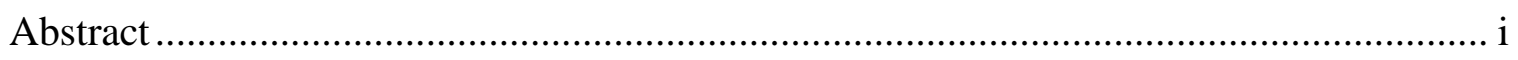

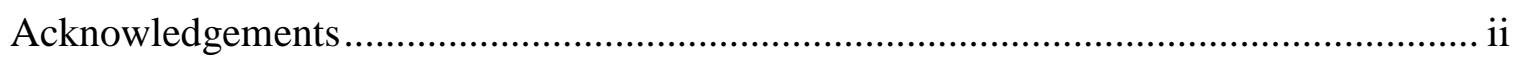

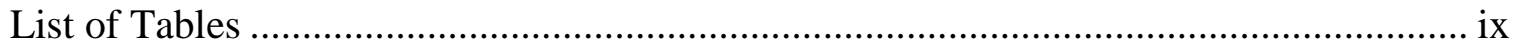

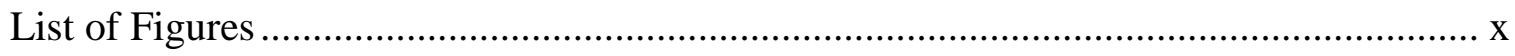

Chapter 1: Problem Statement .................................................................................................. 1

Background of the Problem ...........................................................................

Increasing diversity in South Korea.....................................................1

Issues from the emerging diversity in South Korea ................................. 3

Statement of the Research Problem ....................................................................4

Barriers to teachers developing beliefs about diversity ...........................4

Lack of research on teachers' beliefs about diversity ..............................6

Significance of the Research Problem .............................................................. 7

Teachers' beliefs about diversity in multicultural education .....................8

Elementary teachers' beliefs about diversity in South Korean multicultural

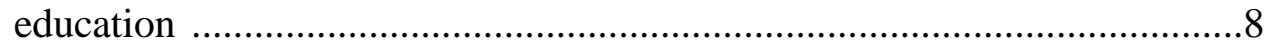

Presentation of Methods and Research Questions ..........................................10

Research paradigm .....................................................................11

Research questions ..................................................................11

Research methods .................................................................. 12

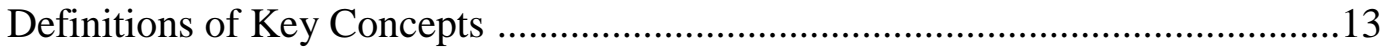

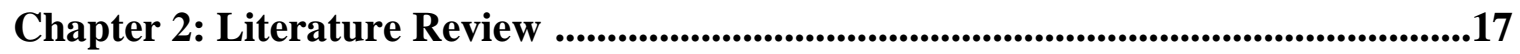

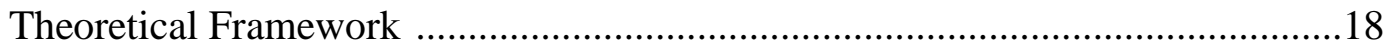

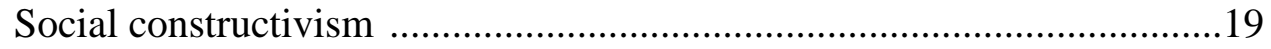

Application of social constructivism ................................................19

Critique of the theoretical framework .................................................21

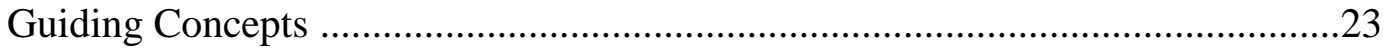

Perspectives in multicultural education .............................................23

Definitions of multicultural education .....................................24

Different perspectives in multicultural education .......................25 
Critical approaches to multicultural education ...........................25

Current multicultural education in South Korea ...........................30

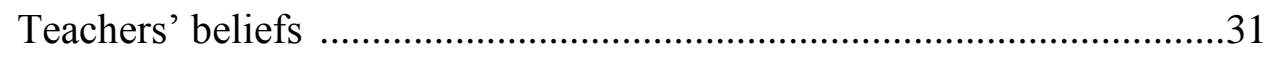

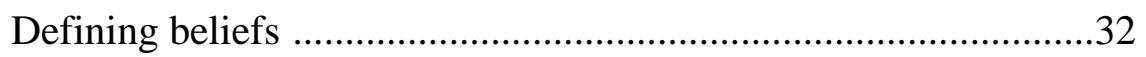

Teachers' beliefs and practice of teaching ...................................33

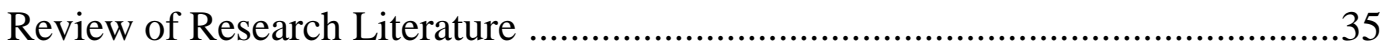

Research on multicultural education research in South Korea .................36

Research genres in multicultural education ...........................................38

Multicultural competence research ...........................................40

Teachers' beliefs about diversity .........................................................44

Korean teachers' perspectives about multicultural education ..................48

Critique of research literature ............................................................52

Review of Methodological Research Literature ...........................................53

Measuring teachers' beliefs about diversity .........................................53

Quantitative instruments ......................................................54

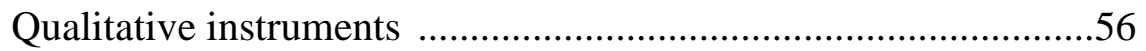

Summary of Research Literature and Application to the study ...........................59

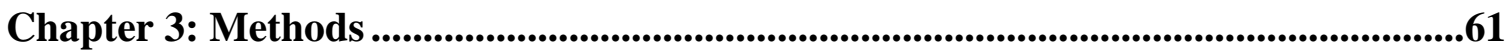

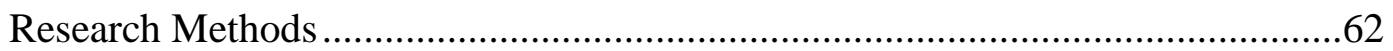

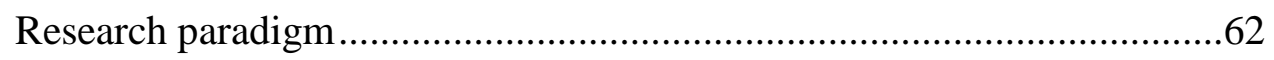

Mixed methods approach ..........................................................64

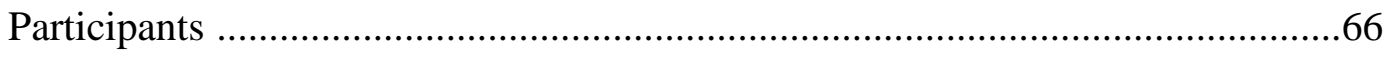

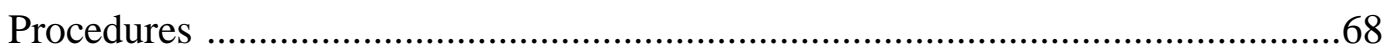

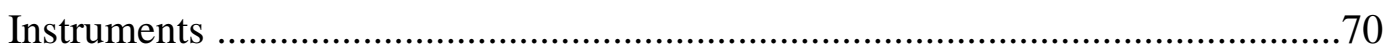

Instrument for the quantitative data collection ..................................71

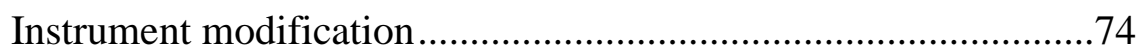

Instrument for the qualitative data collection .....................................75

Role of the Researcher ................................................................................ 76

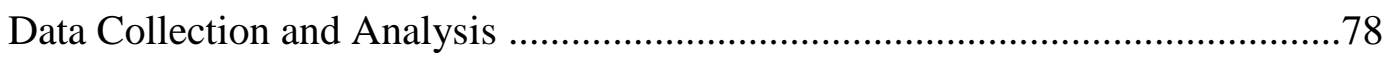

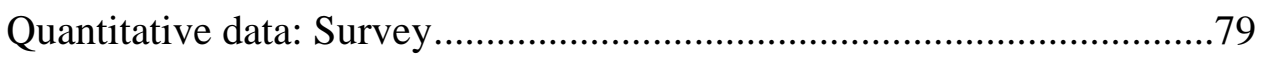

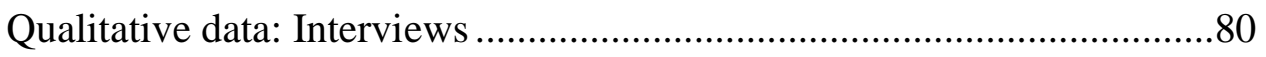


Chapter 4: Analysis and Results..............................................................................................82

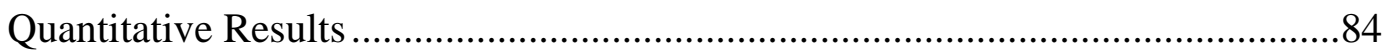

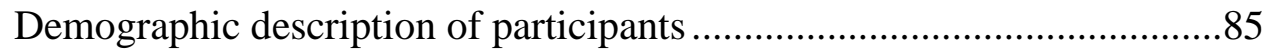

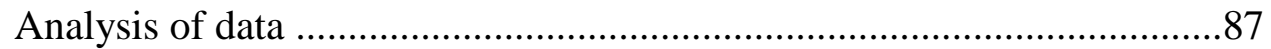

Korean teachers' beliefs about diversity in personal contexts ......87

Korean teachers' beliefs about diversity in professional contexts 90

The difference between teachers' beliefs about diversity in personal and professional contexts

The influence of demographics and experiences on teachers'

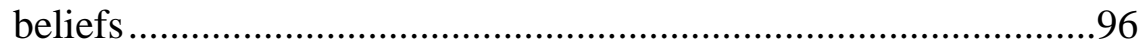

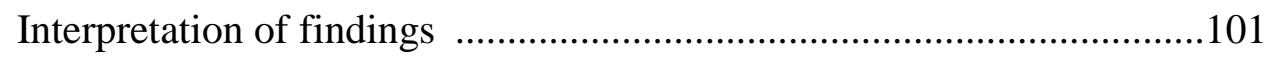

South Korean teachers' beliefs about diversity .............................101

Diversity in personal contexts...........................................104

Diversity in professional contexts......................................104

Difference between teachers' beliefs about diversity in personal and professional contexts

Influence of demographics and experiences on teachers' beliefs 106

Qualitative Results 108

Analysis of data 109

Categories developed from qualitative analysis

Teachers' experiences with multicultural family.............113

Effect of intercultural experiences .....................................115

Impact of teachers' beliefs on multicultural education....116

Challenges in multicultural education ..............................117

How to support multicultural education ...........................118

Multicultural teacher education program ..........................119

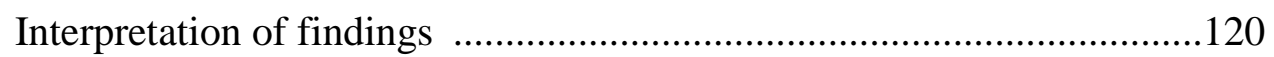

Themes identified from qualitative data analysis ........................121

Prejudice about multicultural family ................................121

Intercultural experiences help teachers to understand

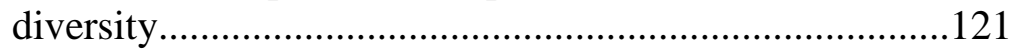

Teachers' beliefs affect their teaching 
Multicultural education is challenging but there is a way to support it

Multicultural teacher education though experiences .......124

The bigger picture: lessons learned .........................................124

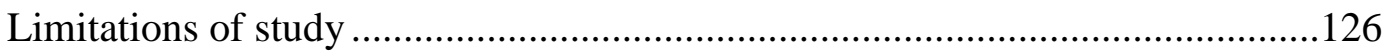

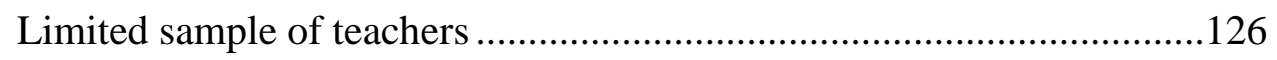

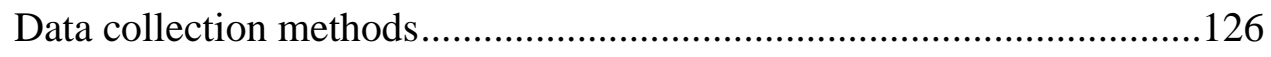

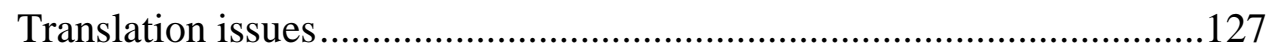

Researcher bias and reactivity ................................................... 128

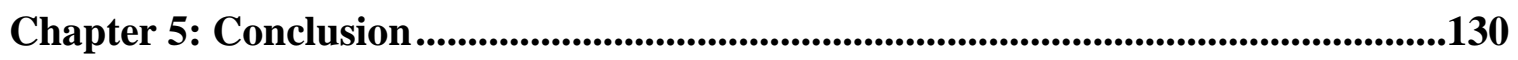

Synthesis of findings and the larger context .................................................131

Korean teachers' beliefs about diversity in personal contexts................132

Korean teachers' beliefs about diversity in professional contexts...........134

Differences between Korean teachers' beliefs about diversity in personal and professional contexts .............................................................136

Factors that influence teachers' beliefs .............................................138

Impact of beliefs on practice.............................................................141

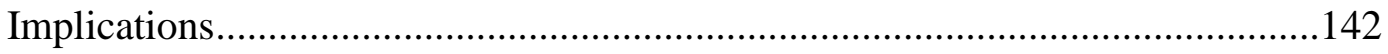

Recommendations for practice ................................................... 142

Recommendations for research ......................................................... 145

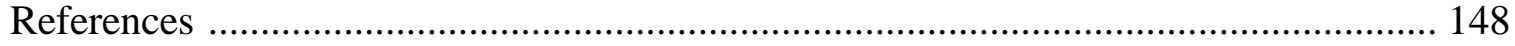

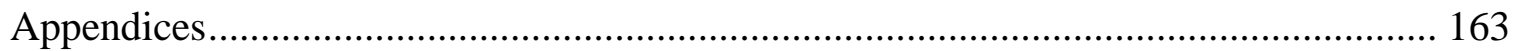

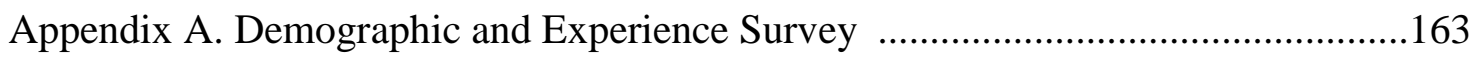

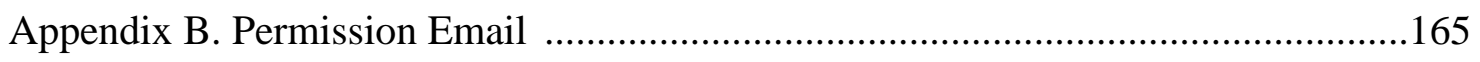

Appendix C. Personal Beliefs about Diversity Scale (modified) ..............................166

Appendix D. Professional Beliefs about Diversity Scale (modified).........................168

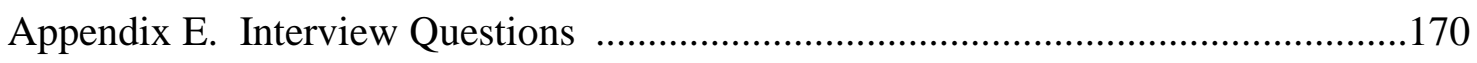

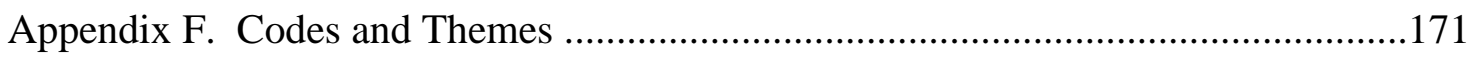




\section{List of Tables}

Table 1: Quantitative Instrument Example: Brief Scenario Description .............................57

Table 2: Reasons for Mixed Methods Research ............................................................65

Table 3: Research Procedure ………………………...........................................69

Table 4: Overview of Data Collection Measures and Analysis Methods ...........................80

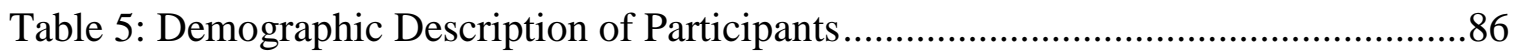

Table 6: Percentage of Agreement in the Personal Diversity Beliefs Scale .......................88

Table 7: Percentage of Agreement in the Professional Diversity Beliefs Scale ................91

Table 8: Paired Samples Statistics of Individual Personal and Professional Scales Sum

Table 9: Paired Samples Correlations of Individual Personal and Professional Scales Sum

Table 10: Paired Samples t-Test of Individual Personal and Professional Scales Sum

Table 11: Regression Coefficient for Personal Beliefs Sum Score ...................................98

Table 12: Regression Coefficient for Professional Beliefs Sum Score ..............................99 


\section{List of Figures}

Figure 1: A Conceptual Framework of Research Genres in multicultural education........39

Figure 2: Data collection instruments and analysis methods. .84

Figure 3: A visual display of correlation between Personal and Professional Sum Scores

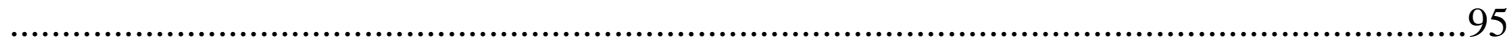

Figure 4: Qualitative data analysis suggested by Seidman (2013) ...............................111

Figure 5: Themes identified from qualitative data analysis ............................................112 


\section{Chapter 1: Problem Statement}

The recent Korean national curriculum standards are said to have replaced monoethnicism with the notion of cultural diversity and multiculturalism (Moon, 2010). This indicates a significant change in South Korean education policy that acknowledges the emerging diversity in Korean society. However, research reveals that most South Korean teachers feel they are not prepared to teach diversity and to practice multicultural education (Jang \& Jeon, 2013; Lee, H., 2014; Park, 2011). Living in a society like Korea, where a particular racial and cultural unity is important makes it very hard to acknowledge and recognize the value of cultural diversity in society. Moreover, South Korean teachers deal with a high level of responsibility and accountability for their students' academic performance. Thus, for many Korean teachers, practice of multicultural education is just another task to perform whether they believe in it or not. If educators do not understand and value diversity and do not have positive beliefs about diversity, they will not attend to it, and ultimately, they cannot practice multicultural education to support the needs and interests of all students.

\section{Background of the Problem}

In the following section, I describe the South Korean background that forms the basis of the research problem in this study. I explain the increasing demographic diversity in South Korea and the emerging issues from the rapid transformation into a multicultural society.

\section{Increasing Diversity in South Korea}

Since the 1980s, because of the increasing number of immigrant workers and international marriages, the South Korean society has transformed rapidly into a 
multiethnic and multicultural society. In 1995, the total number of registered foreign residents in South Korea was only 110,028. By 2014, that number had grown to 1,378,000. The number increased by $14.1 \%$ between 2013 to 2014 , and in the most recent five years, the number has grown average of 9.3\% each year (Korean National Indicators System, 2016). In 2014, concerning the demographics of the registered foreigners' nationality, the largest groups were Chinese (50.0\%), American (7.6\%), Vietnamese (7.2\%), Thai (5.2\%), Filipino (3.0\%), and Japanese (2.7\%). Regarding the purpose of their registration, $34.3 \%$ was for employment, $16.1 \%$ was for residency for Korean with foreign citizenship, $8.4 \%$ was for marriage. Foreign residents compose $3 \%$ of the total South Korean population, which may not be a large number by international standards, but this rapid change is a significant issue in the South Korean context.

Above all, because multiculturalism is not consistent with Korean traditional culture and values, the increasing ethnic and cultural diversity and interaction among different cultures in Korea is fraught with problems. Koreans have a great pride in their long history of homogeneity and unique culture which implies superiority of Korean ethnicity and culture (Kim, 2010; Kymlicka, 1995; Tschong, 2009; Won, 2008). While Koreans may see how their country is transforming into an ethnically and culturally diverse society in work places, schools, and on the street, it is still hard for Koreans to include someone who looks different and speaks a different language within the boundary of being a legitimate "Korean." 


\section{Issues from the Emerging Diversity in South Korea}

The two key areas where problems exist are in the workplace and in the schools. First, many immigrant workers suffer from basic human right violations such as wages below the legal minimum level, compulsory over time and holiday work, and facing frequent industrial accidents, as well as violence from employers (Han, 2007). To protect foreign workers from this dehumanization, legislation titled "Trainee Employment System" was set up in 2003. Still, immigrant workers are discriminated against in their workplace as well as in their everyday lives (Kang, 2010).

Another area where the emerging diversity presents problems is in education. As stated by the Korean Ministry of Education (2016), the number of multicultural students has increased from $31,778(0.44 \%)$ in 2010 to 82,536 in 2015 representing $1.35 \%$ of the total students. To put the nationality of their foreign parents in context, the largest percentage of them (34\%) are Chinese; Vietnamese and Japanese are the next largest groups. This number indicates a $260 \%$ increase of total multicultural students in five years. Considering the total number of students in elementary and secondary schools in Korea has decreased each year, it is significant that the number of multicultural students has increased roughly more than 10,000 in each year for the last five years.

Based on the realization of a need to support the increasing diversity in schools, the Korean government has emphasized the educational needs of students from multicultural families since the seventh national curriculum. Yet still, the children from multicultural families deal with prejudice and exclusion by their classmates, teachers, and community because they look different than native Korean children and their parents 
cannot speak fluent Korean language (Bae, 2006; Choi, Yoon, \& Park, 2006; Kang, 2010; Kim, Lee, Bae, \& Hu, 2005).

Given this background, multicultural education is a growing expectation for teachers in South Korean society (Hong, 2010; Kang, 2010; Lee, J., 2008). Education is an important place to address the problem of the lack of multicultural understanding because education takes a key role for fostering and retaining the value of diversity. Evidence has suggested that Korean teachers have potential for a better practice of multicultural education in South Korea. Researchers noted that Korean teachers are required to have a multicultural competence to teach students the value of diversity and the attitude of respect toward culturally diverse people. (Lee, J. Y., 2013; Park, 2007).

\section{Statement of the Research Problem}

Researchers argued that personal beliefs are a greater predictor of personal behavior than professional knowledge (Nelson \& Guerra, 2014; Nespor, 1987; Pajares, 1992). Pohan and Aguilar (2001) asserted that, particularly, teachers' positive beliefs about diversity play a critical role to develop multicultural competence and to practice a better multicultural teaching. Yet, South Korean teachers experience barriers when forming beliefs on issues of diversity, and furthermore little research exists about Korean teachers' beliefs about diversity.

\section{Barriers to Teachers Developing Beliefs about Diversity}

The problem is that barriers exist for teachers to develop positive beliefs about diversity in the South Korean context. First, South Korean multicultural education policy has focused on assimilating those of different cultural backgrounds into Korean culture 
(Choi, 2010; Hong, 2010; Kang, 2010; Kim \& Kim, 2008; Yoon, 2009). Choi (2010) argued that current South Korean multicultural education is a one-way culture education in which immigrants or foreigners adjust themselves to the Korean mainstream society. In other words, Korean multicultural education has been limited to teaching multicultural students Korean culture instead of valuing the diverse cultures that they can bring to schools. For example, in special after school programs designed for supporting multicultural children, mainly Korean language and culture are instructed and introduced. Actually this type of special program results in further isolating multicultural students from native Korean students, and gives them yet another message that we are different than you (Kang, 2010).

Another barrier for developing teachers' beliefs about diversity is that South Korean multicultural education policies have been mostly initiated by the government (Olneck, 2011; Park, 2007; Watson, 2010). According to Park (2007), the percentage of Korean multicultural educational policies created by the central government and office of education reached $66 \%$, followed by local government initiated policies at $21 \%$. So, central and local governments have promoted multicultural education programs and activities predominantly, and those programs have been deemed appropriate. With this top-down method of policy initiation and implementation, teachers have viewed multicultural education as something they "have to teach" rather than "want to teach" (Watson, 2010). In other words, many Korean teachers practice multicultural education because it is required in the national and local curriculum rather than because they have 
developed the positive beliefs about diversity and have found motivation to teach multicultural education based on those beliefs.

\section{Lack of Research on Teachers' Beliefs about Diversity}

Another hindrance is the lack of research about South Korean teachers' beliefs about diversity. Teachers' beliefs about diversity are essential in the sense that the beliefs serve as a foundation for determining their multicultural practice. While studies revealed that teachers' beliefs and attitude about diversity play critical roles in their teaching practice (Castro, 2010; Kumar \& Hamer, 2012; Kyles \& Olafson, 2008; Nadelson et al., 2012; Nelson \& Guerra, 2014; Silverman, 2010), there remains an insufficient understanding of South Korean teachers' beliefs about diversity.

Increasingly, researchers are studying Korean teachers' recognition, awareness, and perception about multicultural education in South Korea. A body of research has reported that South Korean teachers are aware of the importance of multicultural education and are highly concerned about their practice of it (Bae, 2012; Jang \& Jeon, 2013; Kim \& Kim, 2008; Lee, J. Y., 2013). Other research has revealed that Korean teachers are acknowledging the importance of the teachers' role in multicultural education, but largely teachers feel a lack of knowledge and competence about multicultural teaching (Jang \& Jeon, 2013; Lee, H., 2014; Park, 2011).

Yet, a lack of research still remains about Korean teachers' beliefs on issues of diversity. In other words, the studies have not explored what beliefs about diversity Korean teachers hold and how those beliefs affect their actual recognition and practice of multicultural teaching. Furthermore, there has been little attempt to investigate how 
teachers' personal beliefs are related to their professional beliefs about diversity which can provide a fundamental and comprehensive explanation of Korean teachers' understanding and practice of multicultural education.

In essence, the problem are the hindrances to Korean teachers' developing beliefs on issues of diversity in South Korean context. Second, little research has discussed South Korean teachers' beliefs about diversity, how teachers are developing their beliefs about diversity, and how teachers' beliefs about diversity influence their classroom implementation of multicultural education.

The purpose of this study was to examine South Korean teachers' beliefs about diversity in personal and professional contexts, factors that influence teachers' beliefs about diversity, and the impact of those beliefs on their practice of multicultural teaching. Eventually, the study provide suggestions for South Korean educators and administrators on how to support teachers to develop positive beliefs about diversity so that they can play a better role in accommodating diversity in the classroom and helping all students to foster attitudes of respect and tolerance about diversity.

\section{Significance of the Research Problem}

Examining teachers' beliefs on the issues of diversity is important because teachers' beliefs play a critical role in their practice of multicultural education. In addition, examining elementary school teachers' beliefs is significant because $73 \%$ of multicultural students are attending elementary schools in South Korea (Korean Ministry of Education, 2016). 


\section{Teachers' Beliefs about Diversity in Multicultural Education}

As Hong (2010) asserted, when educators develop multicultural awareness and cross-cultural ability, inclusive teaching and necessary social changes become possible. To teach students the value of diversity and foster multicultural competence, educators must first develop positive beliefs about diversity and multiculturalism. Research has found that teachers' beliefs and attitude have significant impact on their teaching practice (Castro, 2010; Kumar \& Hamer, 2012; Kyles \& Olafson, 2008; Nadelson et al., 2012; Nelson \& Guerra, 2014; Silverman, 2010). Researchers like Nelson and Guerra (2014) contended that personal beliefs are a greater predictor of behaviors than professional knowledge. Pohan and Aguilar (2001) asserted that particularly educators' beliefs serve as filters for their knowledge bases and ultimately affect their actions. Particularly, teachers' personal beliefs about diversity significantly influence their educational practice in schools.

To teach Korean students the value of diversity and the respect toward diverse cultures, Korean teachers' beliefs about diversity need to be examined and identified first. A clear understanding Korean teachers' current beliefs about diversity and factors that influence them is the first step towards supporting teachers to develop positive beliefs about diversity and eventually to practice better multicultural teaching in their classrooms.

\section{Elementary Teachers' Beliefs about Diversity in South Korean Multicultural}

\section{Education}

Particularly, in the changing ethnic and cultural landscape of South Korea, the elementary teacher's role in multicultural education has become very important. Recent 
statistics reveals that the majority (73\%) of total multicultural students are enrolled at the elementary school level in South Korea (Korean Ministry of Education, 2016). In addition, more than half of $(62.1 \%)$ children from multicultural families are younger than six years old, the age at which formal school education starts in South Korea. Consequently, in the near future the number of multicultural students entering elementary school will grow rapidly.

Through my own experience, I have found teachers' attitudes and beliefs on particular issues can influence their students in elementary levels more significantly than at older levels of their education. Jeon's (2010) research supports my position. In her study about elementary teachers' perception and practice of multicultural education in South Korea, Jeon (2010) found that the teachers' multicultural perception and practice affect students' multicultural awareness. At the elementary level, students actively develop their personal and social intelligence, and their capacity to communicate with people around them. Thus, Korean elementary school teachers are given a particularly critical role to teach in an increasingly diverse environment.

My research may contribute to the professional literature by becoming a resource that describes the extent of beliefs about diversity among practicing South Korean teachers in personal and professional contexts. In addition, my study may reveal whether there are differences in diversity beliefs between the personal context and professional contexts. Furthermore, the findings from my study may uncover the relationship between teachers' intercultural experiences and their beliefs about diversity. 
Finally, the findings from my study may explain the impact teachers' beliefs about diversity have on their multicultural practice.

The benefits for teachers who participated in my study include: (a) examining and acknowledging diversity beliefs in personal and professional contexts, (b) understanding factors that influence the development of beliefs about diversity, (c) becoming aware of the importance of positive beliefs about diversity in multicultural education.

For school leaders and administrators, the findings from my study may provide more information and insight on how to support the development of positive beliefs about the issues of diversity. Particularly, for those who organize teacher multicultural teacher education programs, it is important to examine the effectiveness of the programs on influencing teachers' attitudes and beliefs about diversity. For example, based on the finding of this study that teachers' traveling abroad experience affected their diversity beliefs positively, having more meaningful intercultural experiences in a teacher education program would be an effective means to help change teachers' beliefs.

\section{Presentation of Methods and Research Questions}

The pragmatic research paradigm (Morgan, 2007; 2014) guided my study. Consequently, I adopted a mixed methods approach to use multiple solutions to my research problem. In the following section, I explain the pragmatic research paradigm (Morgan, 2007; 2014) and present research questions, and describe a mixed methods approach that adopted in my study. 


\section{Research Paradigm}

My research design is framed by a pragmatic approach (Morgan, 2007; 2014).

The pragmatic paradigm in research emphasizes the practical rather than the philosophical aspects of knowledge. It places the research problem as central and applies

all approaches to understanding the problem (Creswell, 2003). I found that Morgan's pragmatic approach is appropriate to guide my research. The pragmatic world view encourages sharing of understandings and the following behaviors as a consequence from research. The purpose of this research was to investigate South Korean teachers' beliefs about diversity and seek a common understanding about the importance of the teachers' beliefs for the practice of multicultural education. Based on shared understanding, teachers are expected to value diversity and foster cultural competence. In addition, in methodology, the pragmatic approach can combine the strengths of qualitative and quantitative methods. Korean teachers' beliefs about diversity is a multi-dimensional and complex topic, thus I found combining the strengths of two methods would be appropriate to investigate Korean teachers' beliefs about diversity.

\section{Research Questions}

In the process of identifying South Korean teachers' beliefs about multicultural education, the following five research questions guided my research.

1. What are South Korean teachers' beliefs about diversity in personal contexts?

2. What are South Korean teachers' beliefs about diversity in professional contexts? 
3. How do South Korean teachers' beliefs about diversity differ between personal and professional contexts?

4. How do South Korean teachers' beliefs about diversity in personal and professional contexts differ based on their demographics, and teaching and intercultural experiences?

5. What impact do South Korean teachers' beliefs about diversity have on their practice of multicultural education?

\section{Research Methods}

To investigate South Korean teachers' beliefs, I used a mixed methods approach that combines quantitative surveys and qualitative interviews methods. In addition, I employed a sequential explanatory design in which quantitative surveys are advanced, and followed by qualitative interviews.

In the first phase of my study, I conducted surveys. The participants were 110 teachers in public elementary schools in a Metropolitan city, South Korea. The first part of the survey was used to examine participants' demographic information, and teaching and intercultural experiences such as gender, age, the number of years taught, experiences of taking multicultural training courses and teaching multicultural students, experience traveling and living abroad, and friendships with culturally diverse others. The second part of survey was administered to investigate South Korean teachers' general beliefs about diversity in personal and professional contexts. 
In the second phase, I conducted in-depth interviews with six teachers. The interviewees were selected from the survey participants by convenient sampling. The interviews helped to clarify and elaborate on responses from the initial survey.

To establish validity and increase credibility in my research, I applied triangulation strategy which includes collecting data from diverse ranges of individuals and settings, and using multiple methods. The data in my research were collected from teachers from four different school districts and 10 elementary schools in a Metropolitan city in south eastern Korea, and the data were obtained through multiple research methods such as quantitative surveys and qualitative interviews. Additionally, to check the translation of Korean to English and the interpretation of survey measures, I had two peer reviewers who are knowledgeable of Korean language and the educational context. I also conducted a pilot test with a group of five teachers to check if survey questions were clear and made sense to Korean teachers. Then, in Chapter 4, I clarified the possible biases and limitation of study.

\section{Definitions of Key Concepts}

In this section, I identify the key concepts that characterize my research. Each concept can be defined in various ways according to the context to which the concepts are applied. Here, I provide an explanation of each term in my study context.

\section{Cultural Diversity}

According to Sleeter (1991), cultural diversity is the difference in race, ethnicity, language, nationality, religion and the like among various groups within a community. Yet, the concept of diversity is most frequently associated with race and /or ethnicity and it has been the one of the central concerns in multicultural education field (Pohan \& 
Aguilar, 2001). While the broader concept of diversity including sociocultural issues like social class, gender, religion, languages, and sexual orientation is included, in this research study, the diversity related with race and ethnicity is the core focus.

\section{Multicultural Education}

Multicultural education is a type of education that includes a set of concepts and an educational reform movement that promotes democracy while responding to many educational issues created by current globalization (Banks, 2010). It promotes the ideas of tolerance about differences, social justice, equity, and human rights in all educational settings (Gollnick \& Chinn, 1986). It respects the cultural diversity and pluralism each learner brings to class (Banks, 2008) and ensures the highest level of academic achievement for all students (Banks, 2010).

Multicultural education in each country should be defined within its own unique historical, social, cultural, and political background. For example, in the South Korean context, multicultural education should value the ethnic and racial minority groups' educational right, and help all students to increase their cultural awareness, develop positive attitudes toward racial, ethnical, and cultural diversity (Lee, J., 2008).

\section{Multicultural Family}

In this study, multicultural family refers to the family where one or both parents are of a different ethnicity than Korean. In South Korea, multicultural family mainly includes the family formed by international marriages and the family consists of foreigners working or living in Korea. In addition, multicultural students refer to elementary and secondary school students who are from multicultural families. 
According to Korean Ministry of Education (2016), in 2015, the number of multicultural students in elementary and secondary schools in South Korea was 82,536 which comprise $1.35 \%$ of the total students. To put the nationality of their foreign parents in context, the largest percentage of them were Chinese (34\%); and Vietnamese (21\%) and Japanese (16\%) were the next largest groups. I chose to use the term "multicultural family" and "multicultural student" instead of "immigrant family" and "immigrant student," because the term multicultural, which is damunhwa in Korean, is more commonly used in South Korea since the mid-2000s.

\section{Teachers' Beliefs}

Regarding teachers' beliefs, Pajares (1992) argued that there has been no specific working definition about beliefs in the educational research community; however it can be better understood through a comparison with knowledge. Belief is based on evaluation and judgment; knowledge is based on objective fact. Numerous researchers have argued that the beliefs teachers hold influence their perceptions and judgments, eventually affecting their teaching practice (Kyles \& Olafson, 2008; Nelson \& Guerra, 2013; Nespor, 1987: Pajares, 1992; Pohan, 1996; Pohan \& Aguilar, 2001). They conclude that beliefs are one of the most significant predictors of how teachers respond to diversity in the classroom.

\section{Multicultural Competence}

Multicultural competence is an ability to interact with and understand people who are ethnically, racially, and culturally different from themselves (Gay, 1995). Bennett (2006) anticipated that multicultural competence soon will become one of the 
fundamental skills that schools are required to teach. Multicultural competence includes the dispositions of open-mindedness, absence of racial or cultural prejudice, knowledge about various cultural groups, and diversity within and across ethnic groups (Bennett, 2001). In this study, I argue that Korean teachers are expected to prepare themselves with multicultural competence to function effectively in increasingly diversifying schools.

\section{Intercultural Experience}

Intercultural experience refers to the interaction and mutual acts that occur between culturally different people. The term is differentiated from "cross-cultural." "Cross-cultural" implies something covers more than one culture, so, in usage, it focus on the comparison and contrast between different cultures. On the other hand, "intercultural" pays attention to the interaction between different cultural groups (Fries, 2009; Garmon, 2005). Grounded by social constructivism, this research is based on the assumption that teachers' intercultural experiences, in other words, their interaction with people from different cultures might influence their beliefs about diversity. 


\section{Chapter 2: Literature Review}

In Chapter 1, I explained the increasing ethnical and cultural diversity in a traditionally homogeneous South Korean society and the issues from the emerging diversity. Followed by the background, I presented the research problems in two parts: (a) the barriers for South Korean teachers in developing beliefs about diversity, (b) the lack of research to identify South Korean teachers' beliefs on diversity issues. While identifying these problems, I found a need for a study to explore South Korean elementary teachers' beliefs about diversity in personal and professional contexts, factors that influence those beliefs, and to examine the impact of their beliefs on classroom teaching practice.

I emphasized the importance of elementary teachers' beliefs about diversity in South Korean multicultural education based on the rationale that, presently, the majority of multicultural students are at the elementary level in South Korea and elementary teachers have a strong influence on their students' change of attitude and beliefs. Furthermore, I recommended an examination of South Korean teachers' beliefs in both personal and professional contexts and the existing discrepancy between the beliefs in each context. I believe that clear understandings of South Korean teachers' beliefs about diversity eventually will provide insight for improving multicultural competence in South Korean teachers.

In Chapter 2, I employ the framework of social constructivism to guide the investigation of teachers' beliefs related to their classroom teaching practice. Particularly, through this framework, I elaborate the importance of sociocultural factors and interactions with others on the teachers' beliefs development. I also explain major 
concepts that inform and guide my research, which include: (a) perspectives in multicultural education, and (b) teachers' beliefs

Followed by the guiding concepts, I provide a comprehensive review of relevant literature and issues that highlights the limitations in South Korean multicultural education and the assessment of teachers' beliefs about diversity in relationship to actual practice of multicultural education. The topics in my review of the literature include: (a) multicultural education research in South Korea, (b) research genres in multicultural education, (c) teachers' beliefs about diversity, (d) South Korean teachers' perception about multicultural education, and (e) critiques of the research literature. Finally, I review the literature on methodologies that attempt to examine teachers' beliefs about diversity.

\section{Theoretical Framework}

My study draws on the theoretical framework of social constructivism (Lee \& Greene, 1999; McMahon, 1997; Palincsar, 1998; Prawat \& Floden, 1994; Richardson, 1997) regarding teachers' beliefs about diversity and their practice of multicultural education. Social constructivism helps to elaborate and analyze the concepts and issues of my research as it assumes that knowledge is constructed in sociocultural contexts through interactions with others. In other words, social constructivism guides my study by focusing on how Korean teachers are developing beliefs about diversity from their experiences and interaction with others. 


\section{Social Constructivism}

Constructivism is based on the idea that knowledge is actively constructed by the learners (Akar \& Yildirim, 2010; Prawat \& Floden, 1994). Various proponents of constructivism have their own unique views about how best to facilitate the knowledge

construction process. Social constructivism is based on the assumption that "knowledge is a social product" (Prawat \& Floden, 1994, p. 37). Knowledge is developed through engagement in discourses and social activities, and it is influenced by historical and cultural factors. Scholars in social constructivism emphasize the importance of a social and cultural context in understanding learning and development (McMahon, 1997; Palincsar, 1998; Richardson, 1997). Richardson (1997) argued that individual development derives from social interactions within which cultural meanings are shared by the group and internalized by the individual. Researchers such as Lee and Greene (1999) asserted that because knowledge is socially generated, it can vary over time and across cultural groups with different beliefs about human development. Additionally, some researchers in social constructivism have explained teacher development and teaching practice in diverse classrooms using a theoretical framework of sociotransformative constructivism (Rodriguez \& Berryman, 2002).

\section{Application of Social Constructivism}

The constructivist's view on learning is appropriate to promote multicultural education. Constructivism is grounded in the social and collaborative nature of learning (Akar \& Yildirim, 2010). Constructivist teachers are creators of an authentic studentcentered environment in which shared meaning can be developed (Richardson, 1997). 
Multicultural education deals with ideas, values and attitudes about different cultures. In line with constructivism, teachers are encouraged to create a learning environment in which students engage with social issues through questions that demand discussion, critical analysis, and decision making (Akar \& Yildirim, 2010). Students are expected to be independent learners who are owners of their thinking and who find solutions for issues they encounter. Values and beliefs are not taught by teachers, instead students are asked to connect and question their previous experiences actively with new concepts, and to challenge prevalent assumptions in their societies. In a multicultural teacher education program, teachers are asked to rethink and challenge their own values and attitude toward different cultures and people. Through the process, teachers can reevaluate and transform their beliefs about diversity. Thus, constructivist view corresponds to the concepts of teaching and learning in multicultural education and support the purpose of my study.

Particularly, social constructivism frames and guides the development of teachers' beliefs about diversity. Teachers' belief system, a foundation of their practical knowledge, is also developed from sociocultural influences (Lee \& Dallman, 2008). Accordingly, to understand the development of South Korean teachers' beliefs about diversity in Korean context, we need to understand and relate to Korean social, historical and cultural context. Furthermore, in social constructivism, the interaction with others is the key to learn new knowledge and change one's beliefs. Thus, examining South Korean teachers' intercultural experiences provide a deeper insight about how the teachers' beliefs are constructed. Based on that examination, in multicultural teacher education programs, we can more effectively support teachers to develop positive beliefs. 
In essence, framed by social constructivism that assumes that the formation of one's beliefs is closely related to life experiences, particularly interaction with others, I examine Korean teachers' beliefs about diversity in Korean cultural and historical contexts, and in relation to their intercultural experiences with culturally and ethnically different others.

\section{Critique of the Theoretical Framework}

Social constructivism is based on the idea that knowledge and belief are constructed in sociocultural contexts with interactions with each other and environment. Kyles and Olafson (2008) provided evidence for this assumption by reporting that preservice teachers who have multicultural schooling and life experience are more likely to have positive beliefs and attitudes regarding cultural diversity than preservice teachers with monocultural life experiences.

Yet, barriers exist within the Korean sociocultural context for teachers to develop knowledge and beliefs about diversity. The cultural context in Korean schools including educational policies and curricula may not facilitate interactions among school teachers. Korea has a highly centralized education system in which the educational policies are initiated by national level educational policymakers and the policies are implemented and administered by educational guidelines (Lee, Y., 2013). Furthermore, Korean national educational policies mainly emphasize teaching the multicultural students Korean etiquette, culture, and language. This cultural assimilationist perspective is more likely to result in pride about Korean culture and values, but it may also create prejudice toward students from a multicultural family. 
In a social constructivist view, belief is formulated within a social and historical context. However, South Koreans have a unique background which may hinder Koreans from developing supporting views about diversity. Koreans are proud of their one race, one language, and one heritage country (Tschong, 2009; Won, 2008). This homogeneity myth has united all Koreans as "one" but may interfere with the formation of Koreans' beliefs about diversity. Additionally, as Koreans went through Japanese colonization (1910-1945) and Korean War (1950-1953), they have developed a dual ethnic bias. On one hand, they may be sympathetic toward people from advanced countries and on the other hand, Koreans may feel antagonistic against ethnic minorities from less-developed countries, which results in ethnic exclusivism (Kim, 2007). This dual bias is creating conflict between main stream Koreans and a majority of immigrants from neighboring Asian countries.

To conclude, if there are more hindrances than supports in Korean cultural and historical contexts, the teachers will have difficulty in developing positive beliefs about the issues of diversity. In this case, the socially constructed knowledge and beliefs are more likely negative toward diversity. Thus, it raises a question whether social constructivism framework is suitable to explain the formation of teachers' positive beliefs on issues of diversity in South Korea. Another pitfall in applying the social constructivism lens is that it is possible to overlook other factors in beliefs' construction, such as, individual variables that might also have a significant impact. To overcome this weakness, this study investigates Korean teachers' belief about diversity in both personal and professional contexts. By examining both personal and professional beliefs, the 
research provides deeper and clearer understanding about how teachers' beliefs are constructed and practiced in their classrooms.

In line with social constructivist perspective, Bennett (2001), beliefs and attitudes about diverse people and culture are learned within a context influenced by personal needs and social influence. The premise of this study is that beliefs are learned and developed within social interactions. Therefore, it is imperative to examine South Korean teachers' beliefs about diversity and the factors that influence the beliefs, in order to provide teachers with opportunities to rethink, challenge and improve their own beliefs about diversity.

\section{Guiding Concepts}

In this section, I explain major concepts that inform and guide my research: (a) perspectives in multicultural education, and (b) teachers' beliefs. For perspectives in multicultural education, I introduce and explain definition and different perspectives in multicultural education including the critical approach to multicultural education, as well as current multicultural education in South Korea. For teachers' beliefs, I explain the importance of teachers' beliefs in relation to their practice of teaching, along with various efforts to define beliefs.

\section{Perspectives in Multicultural Education}

In this section, I review the concept of multicultural education and the different perspectives in multicultural education that have been researched in the U.S. U.S. multicultural education theories and perspectives will be applied in the South Korean 
context to provide appropriate foundations for investigating multicultural education issues in South Korea related to the formation of teachers' beliefs about diversity.

Definitions of multicultural education. The term multicultural education has been used by educators and scholars to describe a wide range of programs and activities related to educational equity, ethnicity, race, gender, disability, and socio-economic class (Grant \& Sleeter, 2010). The definition of multicultural education varies considerably among scholars. Banks and Banks (2010) defined multicultural education as:

An idea, an educational reform movement, a process whose major goal is to change the structure of educational institutes so that male and female students, exceptional students, and students who are member of diverse racial, ethnic, language, and cultural groups have an equal chance to achieve academically in school. (p. 1)

Sleeter and Grant (2009) viewed multicultural education as an umbrella concept that examines educational practices in the terms of race, culture, language, social class, gender, and disability. Kahn (2008) defined multicultural education as "a process, a philosophy, a concept, which is dynamic, multi-faceted, polemic" (p. 531).

In line with the definitions of multicultural education, scholars such as Gollnick and Chinn (1986) provided general goals that can be applied to any level of school education. They described six goals of multicultural education, which were to: (a) promote the value of cultural diversity, (b) promote human rights and respect for those who are different from oneself, (c) acquire knowledge of the historical and social realities of society in order to better understand the existing inequalities of racism, sexism, and poverty, (d) tolerate people's alternative life choices, (e) promote social justice and equality, and (f) promote equity in the distribution of power and income among diverse 
ethnic groups. Teachers' acknowledging and acceptance of the goals of multicultural education is critical in a sense that it guides their planning and practice of multicultural teaching.

Another scholar, Banks $(2008,2010)$ asserted that a major goal of current multicultural education is broadened to support all students to develop knowledge, attitude, and skills required to function in their own culture, other diverse cultures, and in the global community. Yet, Banks contended the goal of multicultural education cannot be fully achieved all at once; instead, multicultural education should be viewed as an ongoing process to increase the educational equity for all students.

In sum, multicultural education is defined differently among scholars. Yet, the concept of multicultural education has been expanded to the broader educational reform movement and no longer is just a resistance movement against racial and ethnic inequity. Banks (2010) asserted that the major goal of multicultural education is to reframe schools in order to help all students acquire the knowledge, attitudes, and skills that are required for functioning in a racially and culturally diverse society. The most important part of school reframing will be questioning, challenging, and changing the educators' beliefs, attitudes, and practices.

Different perspectives in multicultural education. Multicultural education developed as a response to the Civil Rights movement in the U.S beginning in the 1960s with its major goal being to eliminate discrimination against a racial and ethnic minority (Bank, 2010; Bennett, 2001). Even though multicultural education started as a resistance against racism, multicultural education has become a broader reform movement that 
extends to other marginalized groups in terms of social class, gender, and disability as well as race and ethnicity (Banks, 2004). During the process of development, different perspectives in the multicultural education field have been introduced according to the multiple ways of defining diversity, and from political and historical perspectives (Lee, Y., 2013).

Duarte and Smith (2000) compared two metaphors that describe different approaches to multicultural education. They pointed out a "melting pot" image of America where the unique culture of particular ethnic or cultural group would be melted together into American culture. The melting process was referred to as assimilation. Yet, "multiculturalism rejects assimilationism because it emphasized cultural sameness rather than cultural diversity" (Duarte \& Smith, 2000, p. 5). Duarte and Smith also suggested the vision of a "salad bowl" in the place of the assimilationist image of a melting pot. According to them, in a salad each ingredient keeps it's the unique appearance while contributing to the overall flavor of the dish. In a multicultural salad bowl, each culture keeps its own distinct qualities while living in the United States. In essence, Duarte and Smith (2000) concluded that opposition to assimilationism is "a primary marker for multiculturalism" (p. 6). In other words, true multiculturalism distinguishes itself by rejecting the "melting pot" assimilationist approach.

McLaren (2000) categorized the forms of multiculturalism as: conservative multiculturalism, liberal multiculturalism, left-liberal multiculturalism, and critical multiculturalism. First, conservative multiculturalism is an assimilationist model of cultural diversity which is based on the concept of "white supremacy." Conservative 
multiculturalism tends to marginalize and dismiss the different experiences of students of color and allows little analysis of the power structure in race and social class (Nylund, 2006). Second, liberal multiculturalism does not acknowledge the existing cultural differences among racial groups. Rather than that, they believe the existing intellectual similarity of all people. Liberal multiculturalists do not necessarily undermine racism or other social inequalities (Nylund, 2006). In the third category, left-liberal multiculturalism pays special attention to cultural differences. The supporters of this approach claim that the focus on equality of races restrains the cultural differences among races that promote diversity in values, behaviors, and ideas. In addition, they contend that mainstream multicultural approaches hinder the differences related to race, gender, class, and sexuality (McLaren, 2000). Finally, critical multiculturalism recognizes the socio-historical construct of race, and intersection with class, gender, nationality, sexuality, and capitalism (Nylund, 2006). For McLaren (2000), multicultural education is not about cultural tradition to be studied or appreciated. More than that critical multiculturalism supports students to participate in the construction of their cultural identity. In the following section, I discuss more dimensions of critical multiculturalism.

Critical approaches to multicultural education. Critical multiculturalism has emerged as an oppositional educational discourse (Lee, Y., 2013). As noted earlier, multiculturalism in general is identified largely by its resistance to assimilationism (Duarte \& Smith, 2000). According to Duarte and Smith (2000), the goal of critical multicultural education is to recognize the potential undemocratic nature of schools with respect to cultural diversity in order to create learning environments in which all students 
are provided the right and resources for the practice of cultural freedom. For that, they argued, the critical multicultural educators must model the diversity and democracy of voices that they want to see in schools.

Grant and Sachs (2000) argued that the currently predominant type of multicultural education in schools is grounded within a "three f's approach: foods, fairs, and festivals" (p. 189). They asserted that this celebratory type of multicultural education actually reinforces the dominant assimilationist view which defines non-European cultural traditions as "exotic, alien, and foreign" (Duarte \& Smith, 2000, p. 174). In many schools, the three f's approach can marginalize those cultures or traditions that are celebrated during special days or weeks.

Similar to Grant and Sachs, Giroux (2000) contended that it is problematic when multicultural education simply aims to promote pluralism by learning to appreciate the diversity. Giroux indicated that, when celebratory multicultural education is implemented, questions concerning "white racism" and the category of "whiteness" are muted. According to Giroux, critical educators should identify the issue of diversity with social injustice and economic inequity. Thus, the concern of multicultural education is not the celebration and appreciation of diversity, but the "unlearning of racial privilege." (Duarte \& Smith, 2000, p. 175). Giroux (2000) stated that insurgent multiculturalism, his critical approach to multiculturalism:

...must address issues regarding group differences and how power relations function to structure racial and ethnic identities. Furthermore, cultural differences cannot be merely affirmed to be assimilated into a common culture or policed through economic, political, and social sphere that restrict full citizenship to dominant groups. (p. 206) 
Linked to Grant and Sachs's perspective, McLaren (2000) defined critical multiculturalism in opposition to multicultural approaches that celebrate diversity. McLaren claimed that conservatives support the three f's approach and use the term diversity to cover up the notion of assimilation. In his view, ethnic groups are reduced to "add-ons" to the dominant culture (p. 217). McLaren (2000) argued that critical multiculturalism is in opposition of both conservative multiculturalism and liberal multiculturalism. He saw in both opposing approaches that sameness and common experiences are emphasized, but the existing cultural differences are ignored. McLaren (2000) insisted that conservative multiculturalism should be rejected for the following reasons. First, conservative multiculturalism refuses to treat whiteness as a form of ethnicity and proposes whiteness as an invisible norm by which other ethnicities are judged. Second, in conservative multiculturalism, the term "diversity" is used to conceal the ideology of assimilation. Third, conservative multiculturalism is basically monolingual and insists that English should be the only official language in the U.S. Fourth, conservative multiculturalists assumed that the standard of achievement of all students are based on an Anglo middle-class, and do not challenge the knowledge that is deemed most valuable by the white middle-class.

In line with the critical perspective, Banks (2008) asserted that multicultural education needs to be a transformative citizen education to help students acquire the knowledge, skills, and values to function effectively in a society. He argued that multicultural education is an educational reform movement designed to change the 
schools and educational institutions so that students from all social classes, genders, races, language and cultural groups will have an equal opportunity to learn.

In essence, critical multiculturalism is against the superficial celebration type of multicultural education. Critical multiculturalism emphasizes an understanding of multicultural education within political context. Also, as a form of resistance to dominant types of schooling, critical multiculturalism attempts to challenge the traditional views on school systems and relationships. As reviewed in the literature, regarding critical multiculturalism, there is no clear consensus among scholars. Although critical multicultural works vary considerably, the main concerns of critical multicultural educators have been to recognize that social inequality exists, and finally to pursue social justice and equity.

Current multicultural education in South Korea. South Korean multicultural education has been largely assimilationist (Hong, 2010; Kang, 2010; Yoon, 2009). In other words, multicultural education in South Korean schools assumed that marginalized groups of citizens would adopt the Korean language, Korean culture, and the values of mainstream Koreans. The final goal of multicultural education has been assimilating the marginalized groups into Korean privileged culture. Thus, South Korean multicultural education has focused on accommodating and assimilating the different cultural backgrounds of students from multicultural families, without an effort to respect the differences that the students bring in to the schools. However, the emphasis on assimilation is problematic because it can lead to the disappearance of cultural respect and diversity. For example, as Kang (2010) noted, South Korean schools, for the support 
of children from multicultural family, have practiced "after school multicultural programs." Yet, in reality, this type of cultural assimilationist program has resulted in an isolation of multicultural students from mainstream Korean students, and has given them another message that they are once again different from Koreans.

The critical approaches to multiculturalism reject cultural assimilationism and the hegemony of the mainstream group's worldview in education. However, looking into South Korean multicultural education issues through the frame of multiculturalism, cultural assimilationist views and assumptions are embedded in the content and form of South Korean multicultural education policy and curriculum as currently implemented. The critical approaches to multicultural education challenge and question assimilationist approaches in policy and their superficial culture celebrations in school curriculum in South Korean schools.

The lack of full understanding and practice of multicultural education may be due to the fact that Korean teachers have a limited view of multicultural education. Here is the reason why the implementation of multicultural education should be based on the positive teachers' beliefs and values so that they confront social inequity, prejudice, stereotype, ethnocentrism, and racism through their professional work in schools (Sleeter \& Grant, 2009).

\section{Teachers' Beliefs}

Researchers agree that teachers' beliefs influence their perception and judgment, which ultimately affect their behavior in the classroom (Eisenhart, Shrum, Harding, \& 
Cuthbert, 1988; Nespor, 1987; Ogletree, 2013: Pajares, 1992). Thus, understanding teachers' beliefs is a starting point from which to reframe their beliefs and practices.

Definition of beliefs. Beliefs refer to an individual's organization and understanding of certain context and situation (Fang, 1996; Nespor, 1987; Pajares, 1992). Nelson and Guerra (2014) asserted that personal beliefs are powerful filters that shape the way an individual sees the world, people, and oneself. However, the meanings of belief are varied according to the study fields in which the beliefs are studied. Beliefs have been described as a "messy construct" with different interpretations and meanings (Pajares, 1992). Particularly the educational research community has been unable to select a sufficient definition of beliefs (Eisenhart et al.1988; Pajares, 1992). With this difficulty of defining belief in studies, Pajares (1992) contended that using a distinction between belief and knowledge is common when attempting to define and understand the meanings of belief.

In a comparison of cognitive knowledge and belief, Pajares (1992) noted, "Belief is based on evaluation and judgment; knowledge is based on objective fact" (p. 313). In other words, while knowledge systems are "open to evaluation and critical examination," belief systems are evaluated purely internally and do not require internal consistency (Nespor, 1987). In their nature, the belief systems are "disputable, more inflexible, and less dynamic than knowledge systems" (Pajares, 1992, p. 311). Yet, researchers agree that beliefs are far stronger influence than knowledge in organizing and defining tasks and problems, and are stronger predicator of behavior (Nespor, 1987; Pohan \& Aguilar, 2001). Even if beliefs lack a logical foundation, personal belief has a strong impact on 
professional practice and is a greater predictor of a person's behavior than professional knowledge. (Pajares, 1992; Pohan, 1996; Pohan \& Aguilar, 2001). Because of the influence of personal beliefs on the professional implementation of teaching, teachers' beliefs have been considered one of the fundamental factors that determine the quality of education.

Teachers' beliefs and practice of teaching. Scholars like Nespor (1987) expanded the research of beliefs into the discipline of education. Pajares (1992) and Eisenhart et al. (1988) particularly attempted to define the beliefs of teachers. According to Pajares, in research, teachers' beliefs refer to teachers' educational beliefs, rather teachers' general, broader beliefs. Pajares continued to write that teachers' educational beliefs are generally:

...beliefs about confidence to affect students' performance (teacher efficacy), about the nature of knowledge (epistemological beliefs), about causes of teachers' or students' performance (attributions, locus of control, motivation, writing appreciation, math anxiety), about perceptions of self and feelings of self-worth (self-concept, self-esteem), about confidence to perform specific tasks (selfefficacy). (p.316)

In their study, Eisenhart, Shrum, Harding, and Cuthbert (1988) noted that the literature about teachers' beliefs was:

The product of long term, generally hidden, and anticipatory socialization pressure; of the intensive interaction among members of a group faced with common problems; of the intersection of the school system structural characteristics and teacher aspiration in that system; and more simply of accumulated teaching experiences. (p. 52)

Like the diverse definitions of beliefs, researchers have different views on definition of teachers' beliefs, however, they have agreed that teachers' beliefs are multi-dimensional, extensive and complex concepts. 
Then, why are the teachers' beliefs important? A number of researchers have investigated the relationship of teachers' personal beliefs and professional practice (Aguirre \& Speer, 2000; Brown, 2004; Fang, 1996; Nespor, 1987; Pajares, 1992; Van Hook, 2002). These researchers found that the beliefs that teachers hold are the best predictors of individual behavior and that the teachers' beliefs influence their perceptions, judgments, and practices (Brown, 2004; Pajares, 1992). They also found that teachers' beliefs and attitude have shown a various impact on the students, such as academic achievement, beliefs, and attitudes of students. For example, Aguirre and Speer (2000) determined that teachers' beliefs interact with the instruction goals and influence teachers' instructional practice in two secondary mathematic teachers.

In line with the research about teachers' beliefs and their professional teaching practice, in the multicultural education field, there have been studies that examine preservice and inservice teachers' beliefs and the impact on the implementation of multicultural education (Kumar \& Hamer, 2012; Kyles \& Olafson, 2008; Nelson \& Guerra, 2013; Pohan, 1996; Pohan \& Aguilar, 1994, 2001; Pohan, Ward, Kouzekanani, \& Boatright, 2009; Silverman, 2010; Van Hook, 2002). These studies are based on the assumption that investigating and understanding teachers' beliefs about diversity is critical because by doing so teachers and teacher educators would gather insight and information to improve multicultural teaching practices. In the literature review section, .I review the details of the research on teachers' beliefs about diversity and multicultural education. 
In essence, scholars would agree that teachers' beliefs have an influence on their perceptions and ultimately their behaviors (Van Hook, 2002). Thus, a clear understanding about teachers' beliefs structures is important to the improvement of teaching practices as well as professional teacher preparation programs.

\section{Review of the Research Literature}

In the previous section, I presented a theoretical framework and two guiding concepts (i.e., perspectives of multicultural education and teachers' beliefs) to investigate problems in South Korean multicultural education and to suggest the possible steps to solve the problems, particularly in relation to the development of teachers' beliefs about diversity. In this section, I review multicultural education research in South Korea since mid-2000s. Particularly, my focus is be on the main topics of the research that has been conducted and the limitation of the research. Next, I review the study of research genres in multicultural education to grasp the systematic categories of multicultural education research in general. Then, I position the significance and relevance of my research within the structure of genres.

Following the multicultural education genre study, I review the research about the teachers' beliefs toward diversity in relation to the practice of multicultural education, which will support the assumption that teachers' beliefs play an important role in their teaching practice. Additionally, I review the recent studies that are related to Korean teachers' perceptions about multicultural education and discuss their significance and limitations. Finally, I close the literature review by reviewing methodological literature- 
research that measured teachers' belief about diversity in two categories: quantitative and qualitative measurements.

\section{Research on Multicultural Education in South Korea}

The South Korean society has transformed rapidly into a multiethnic and multicultural society since the 1980 s because of the increasing number of immigrant workers and international marriages. It is from mid-2000s that damunhwa (multicultural) has begun to receive attention in the news media and the academia in South Korea (Kim, 2010). Thus, it has been just about a decade since multicultural education began to be studied as a major topic in the Korean educational research field. In my search, the research has been limited to specific topics such as the need or significance of multicultural education and the limited critique of current South Korean multicultural education.

One of the most frequently studied topics is the assimilationist approach to multicultural education in South Korea. Scholars have recognized that Korea's cultural assimilation approach is one issue that society needs to resolve to achieve a democratic multicultural society. Hong (2010) pointed out that the most problematic issue in South Korea is that the predominant approach to ethnic minorities has been based on assimilation, requiring minority groups to give up their language and culture and blend into mainstream society. In line with Hong, Choi (2010) addressed this issue by arguing that current South Korean multicultural education is a one-way cultural education by which schools primarily educate immigrants to adjust themselves to the mainstream Korean society. Choi (2010) asserted that multicultural education in South Korea should 
not be limited to teaching Korean language and culture to multicultural students. Beyond the instruction of Korean language and culture, multicultural education should provide all students with opportunities to think critically about of the increasing diversity in society, and to act for promoting multiculturalism therein. Choi and Yoon (2008) suggested that the reflexive socialization approach is one possible solution to the assimilationist method, as a way of critical thinking, which can advance multicultural education in South Korea. They explained reflexive socialization as a process that includes critical self-reflection and examinations of own status and surroundings and active behaviors to overcome obstacles.

The research that explored the problems of South Korean multicultural education provides direction for the improvement of multicultural teaching practice. At the same time, I found some significant gaps and limitations in South Korean multicultural education study. As Y. Lee (2013) indicated, so far little research on Korean multicultural education has dealt with questions related to inequality, social justice or social change which are the major concerns in multicultural education research in western countries. Y. Lee (2013) continued that some researchers like Chang (2008), and Choi and Yoon (2008) addressed the importance of critical thinking, but the purpose of their studies is mainly observational and does not propose any ideas for achieving equity and social justice.

Additionally, the multicultural education research in South Korea limited largely to theories. Research dealt with the multicultural education theories and models from western literature, and the issues in an emerging multicultural country, South Korea, 
along with the significance of multicultural education. Now, the focus needs to shift to practice: how to practice multicultural education that is appropriate within the Korean context. Within this context, researchers have begun to discover the importance of teachers' impact on education and to study the teachers' aspect in multicultural education in South Korea (Jang \& Jeon, 2013; Kim \& Kim, 2008; Lee, J., 2008; Lee, H., 2014). Yet, the research has mainly concentrated on the investigation of South Korean teachers' experiences, perspectives, and attitudes about multicultural education. Little research has studied the deeper aspect of teachers' attitude and perception about multicultural education, such as teachers' value and beliefs about diverse cultures and people.

\section{Research Genres in Multicultural Education}

I argue that a limited scope of research has been studied in South Korean multicultural education. If current multicultural education in Korea has been restricted, it will be helpful to first explore the general map of multicultural education research to get insight about future research direction. To get a broader perspective about the multicultural education research genre and to find the relevance of my research within the larger framework of research, I reviewed Bennett's (2001) study on the genres of research in multicultural education. Looking at the conceptual frame of the research in multicultural education and examining the root and relationships between genres is significant in the way that it "provides researchers and educators with a lens when they design a new, or are rethinking existing inquiry and teacher preparation program" (Bennett, 2001, p. 171). I expect that mapping genres of significant research in multicultural education in western countries could provide a useful lens for Korean 
researchers as they initiate research because there are currently not enough existing research resources and references in South Korea.

Bennett's (2001) conceptual framework of research genres illustrates the root and relevant study fields of multicultural education (see Figure 1). In the upper frame, the genre clusters display the core of the field: curriculum reform, social equity, equity pedagogy, and societal equity. Twelve genres of research have been identified and categorized and they are related and interactive in the broader category of research and each genre represents a particular dimension of multicultural education. For example, in the multicultural competence cluster, three research genres are included: ethnic identity development, prejudice reduction, and ethnic group cultures.

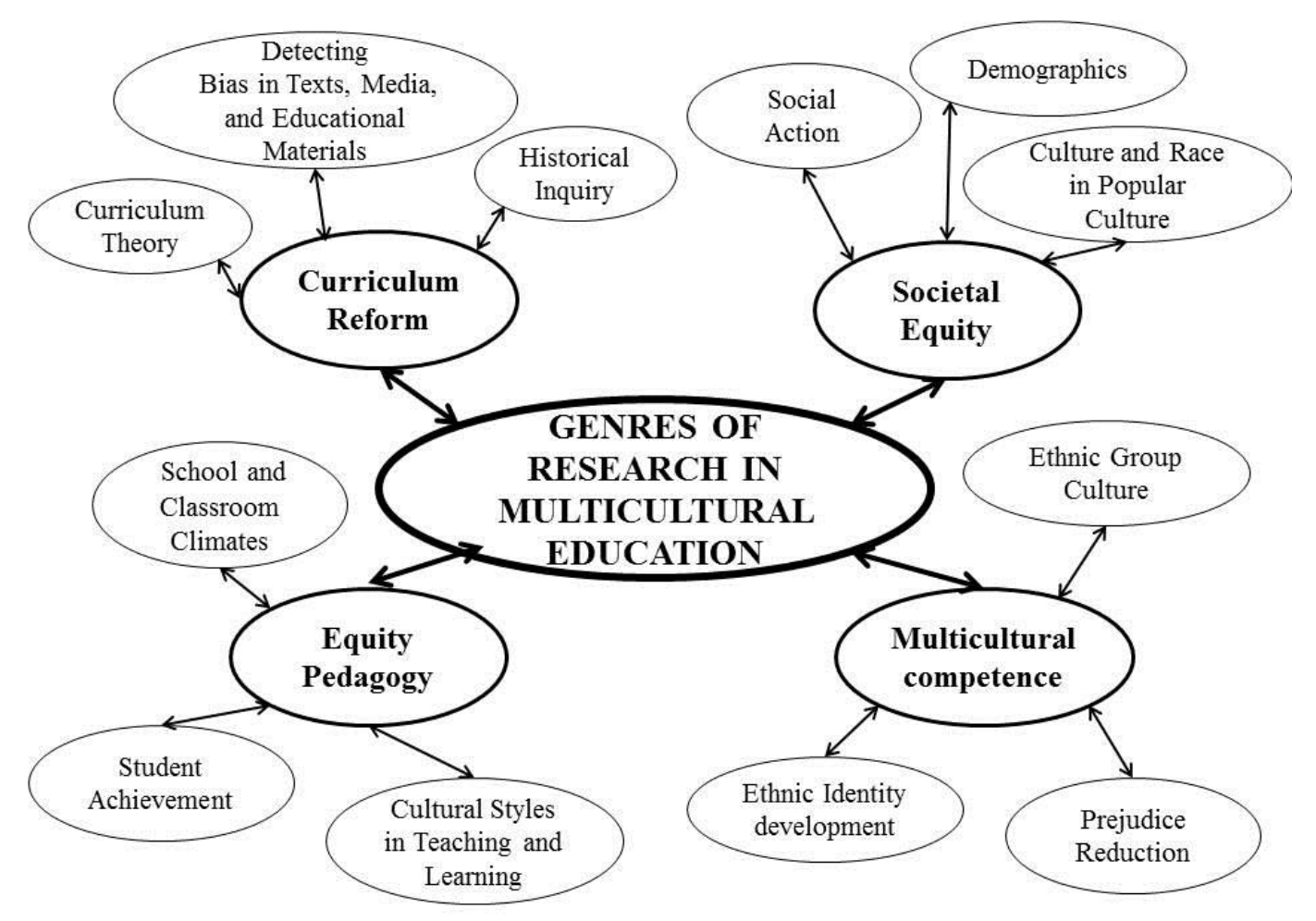

Figure 1. A Conceptual Framework of Research Genres in multicultural education (Bennett, 2001) 
In discussion of each cluster and genres, Bennett (2001) provided a definition and brief history of each theory and research within each cluster and introduces related genres. One or two research examples are also provided to give a fuller understanding of each multicultural education research genre. In the following section, I examine the multicultural competence research cluster as related to multicultural teacher education.

Multicultural competence research. The reason that I pay particular attention to multicultural competence is that I find that multicultural competence is one of the most important abilities that South Koreans need to learn in preparation for living in a diverse society. Plus, little research has been conducted in this genre in the Korean context. Bennett (2006) emphasized the importance of multicultural competence:

Multicultural competence may soon become one of the basic skills that schools are required to teach. Just as some states have recently added decision making or thinking skills to the traditional basics of reading, writing, and computation, so they might require competence in multiple ways of perceiving, evaluating, and doing. (p. xv)

Bennett (2001) anticipated that multicultural competence will become one of the fundamental skills that students living in a diverse society should learn. She continued to argue that the idea of multicultural competence implicitly includes open-mindedness, absence of racial or cultural prejudice, knowledge about various cultural groups, as well as awareness of diversity within and across cultural groups (Bennett, 2004). Furthermore, individuals have a unique multicultural competence because each individual has a different access to multiple cultures, and different experiences and learning opportunities from which one can learn the competence (Bennett, 2001). 
The research in multicultural teacher education is often found in the multicultural competence research cluster, particularly in the prejudice reduction genre. Bennett (2001) defined prejudice as:

an attitude based on preconceived judgments or beliefs that are based on unsubstantiated or faulty information. These attitudes are learned from significant others such as parents and peers, experiences in school, and societal messages in films, television, and the news media. (p. 195)

In other words, no individual is born prejudiced, instead, prejudice is learned within a context and shaped by personal experiences and social influence. If prejudice is learned, there is a need for education that contributes to reduce incorrect beliefs in an individual and replace them with correct and unbiased beliefs.

In prejudice reduction in teacher education research, the knowledge, attitude, and belief of preservice and inservice teachers has been studied in relation to the impact of teacher education program (Aguirre \& Speer, 2000; Kumar \& Hamer, 2012; Kyles \& Olafson, 2008; Nelson \& Guerra, 2013; Pohan, 1996; Pohan \& Aguilar, 2001; Silverman, 2010; Van Hook, 2002). Bennett (2001) cited Pohan and Aguilar's (2001) study as an example of research in the prejudice reduction genre. The purpose of Pohan and Aguilar's study was to measure educators' beliefs about a range of diversity issues. The underlying assumption of their research is that an individual's personal beliefs about diversity might differ from her or his beliefs in a professional context. Through their research, they emphasized both personal and professional beliefs about diversity and developed a "rigorous and psychometrically sound" belief assessment tool (Pohan \& Aguilar, 2001, p. 163). 
Bennett (2001) suggested that studies like Pohan and Aguilar's (2001) can "contribute to prejudice reduction research in teacher education" (p. 196). In the same way, my research was designed to examine Korean teachers' beliefs about diversity for the purpose of supporting Korean teachers' multicultural competence which may ultimately affect their teaching practice. In this context, my research was categorized within prejudice reduction research genre in the multicultural competence cluster within Bennett's (2001) framework. In the context of teachers' prejudice reduction and multicultural competence research, I review the research that focused on teachers' beliefs about diversity in the next section.

\section{Teachers' Beliefs about Diversity}

According to Bennett (2001), research examining teachers' efficacy and beliefs is an illustration of multicultural competence research. Research has revealed that teachers' personal beliefs have a strong impact on their professional practice of teaching (Brown, 2004; Eisenhart et al., 1988; Kyles \& Olafson, 2008; Mills, 2008; Nespor, 1987; Ogletree, 2013; Pajares, 1992; Pohan, 1996; Pohan \& Aguilar, 2001). Nelson and Guerra (2014) argued that "personal beliefs are powerful filters that shape how an individual sees the world, sees other people, and sees oneself" (p. 70) and personal beliefs are a greater predictor of personal behaviors than professional knowledge.

Grounded on the importance of teachers' personal beliefs in relation to their professional practice of teaching, a number of researchers have examined preservice teacher's beliefs, perspectives, and attitudes about diversity (Gentry, Lamb, Becker, \& Hall, 2012; Harmon \& Wilson, 2011; Kumar \& Hamer, 2012; Kyles \& Olafson, 2008; 
Lee \& Herner-Patnode, 2010; Milner, Flowers, Moore, Moore, \& Flowers, 2003; Nadelson et al., 2012; Pohan \& Aguilar, 2001; Silverman, 2010). The research varied in terms of participants and the study settings. However, the overarching key idea across these studies is the examination of examine teachers' underlying beliefs about diversity in relation with multicultural education.

Among these researchers, Harmon and Wilson (2011) studied 123 public school educators' beliefs about diversity using two survey instruments: "Personal and Professional Beliefs about Diversity Scale" (Pohan \& Aguilar, 2001) and "Diversity Awareness Survey" (University of Washington School of Public Health). Their study revealed that educators held a range of beliefs and that there was little agreement on cultural diversity issues. Harmon and Wilson also indicated that, for the most part, educators showed a lack of positive beliefs on most culturally diverse issues.

Silverman's (2010) study focused on examining what diversity and multiculturalism meant for preservice teachers. She surveyed 88 preservice teachers in education-related undergraduate and graduate programs to identify what constitutes diversity and multiculturalism. Silverman investigated identities related to diversity and multiculturalism "within the context of classroom, including efficacy for multicultural instruction, sense of responsibility for teaching about diverse people, and sense of advocacy for oppressed groups" (p. 292). Her study revealed that preservice teachers' limited view of diversity may affect their sense of efficacy and responsibility as individuals and as teachers. 
From a different perspective in beliefs research, some researchers assumed that an individual's personal and professional beliefs about diversity may not be consistent, so they attempted to examine teachers' diversity beliefs in both personal and professional contexts (Cardona, 2005; Gentry et al., 2012; Harmon \& Wilson, 2011; Leavy, 2005; Middleton, 2002; Pohan \& Aguilar, 1994, 2001; Pohan et al., 2009). The main survey instrument used in these studies was "Personal and Professional Beliefs about Diversity Scale" (Pohan \& Aguilar, 2001). As a result, a number of researchers reported a significant difference existed between the personal and professional beliefs. For example, Gentry, Lamb, Becker, and Hall (2012) found that regardless of diversity experience or lack of experience, the preservice teachers studied had different attitudes about diversity at personal and professional levels. On a professional level, preservice teachers knew they must be open-minded to all aspects of diversity. However, in their personal lives, teachers' beliefs remained closer to the values, in which, they were raised. Another example that brings in an international perspective is Cardona (2005)'s study. Cardona researched the beliefs and perceptions about diversity with 75 inservice teachers in Spain. Results showed that Spanish teachers' beliefs about diversity differed in personal and professional contexts, and that the differences were larger in the answers of inexperienced teachers.

As the research suggested, each individual teacher has different beliefs about diversity and that these beliefs can change over time. Then, what cause the differences in each teacher's beliefs on issues of diversity? Some researchers have attempted to identify 
the factors that influence teachers' beliefs about diversity (Dedeoglu \& Lamme, 2011; Kyles \& Olafson, 2008; Milner et al., 2003: Nadelson et al., 2012).

Kyles and Olafson (2008) looked at how teachers' experience of multicultural schooling and diversity influenced their multicultural teaching. They examined 15 preservice teachers' beliefs and attitudes about diversity and diverse learners using a mixed-method approach. The quantitative data was collected using three measures as pre and post-tests of a semester of course work: (a) the Hope Scale (Snyder, 1995), (b) the Motivation for Teaching Scale (Schraw \& Olafson, 2002), and (c) the Teacher Efficacy Scale (Hoy \& Woolfolk, 1993): Short Form. The Personal and Professional Beliefs about Diversity Scales were also completed at the end of semester. Additionally, they collected qualitative data through participants' reflective response writings to the prompts for instructional goals in teaching diverse students and prompts for autobiographies about experiences with diversity. Findings from the quantitative data suggested there was not any meaningful change in participants during the course of semester. However, the qualitative data analysis indicated that preservice teachers who had multicultural schooling and diverse life experience showed a stronger connection to multiculturalism and positive beliefs about diverse learners and multicultural practices than the preservice teachers with monocultural schooling and life experiences.

In another study, Dedeoglu and Lamme (2011) investigated how preservice teachers' demographic variables such as race, inner city program experiences, religious affiliation, and cross-cultural friendship influence their beliefs on issues of diversity. They administered The Personal and Professional Scales about Diversity (Pohan 
\&Aguilar, 1994) to 274 preservice teachers enrolled in Children's Literature classes, as pre and post-surveys. The results indicated that religious affiliation and cross-cultural friendship were significant predictors of preservice teachers' responses on the surveys. Specifically, preservice teachers who had many cross cultural friendships and who belonged to liberal religious groups had higher scores on all scales.

Middleton (2002) and Milner, Flowers, Moore, Moore, and Flowers (2003) examined the factor of teacher education programs that affect teachers' diversity beliefs. Middleton studied the diversity beliefs and commitment of preservice teachers who enrolled in a diversity course. They collected quantitative data using the Beliefs about Diversity Scale (Pohan \& Aguilar, 1995) as a pre and post-test, and they gathered qualitative data from a self-reflective journal and discussion. The quantitative data revealed a significant difference from pre to post-test, though the change was not always positive. The qualitative data showed specific changes over the course of study. Middleton concluded that given time and appropriate interventions, the preservice teachers are likely more accepting of the beliefs of diversity. Milner et al. investigated 99 preservice teachers' general awareness of cultural differences using the Cultural Diversity Awareness Inventory (Larke, 1990). The participating preservice teachers were enrolled in a teacher education program in a large Midwestern university. Milner found that the preservice teachers were more likely to agree on cultural inclusion and respect for diversity in the classroom, which indicated an improvement of preservice teachers' attitude about cultural diversity. 
The important question is why do teachers' beliefs matter in multicultural education? Beyond just the investigation of teachers' beliefs, researchers have studied the relationship between teachers' beliefs about diversity and their practice of teaching with diverse students. The researchers in this context studied how beliefs affected teachers' classroom teaching, particularly toward students from racial and cultural minority groups (Kumar \& Hamer, 2012; Love \& Kruger, 2005; Ogletree, 2012). Kumar and Hamer (2012) examined the relationship between preservice teachers' beliefs regarding culturally diverse students and those teachers' instructional practice that they were likely to implement. Their study used both cross-sectional and longitudinal data collected from 868 white preservice teachers enrolled in licensure coursework in a Midwestern university in the U.S. Kumar and Hamer developed measures based on an extensive literature review. The longitudinal data showed positive changes in preservice teachers' beliefs and attitude toward diversity: the preservice teachers were less biased and prejudiced and more likely to practice adaptive instruction by the time they graduated. However, the analysis of cross-sectional data revealed that approximately $25 \%$ of the preservice teachers explicitly showed stereotypic beliefs about poor and minority students and discomfort with student diversity in their classroom. Kumar and Hamer (2012) concluded that preservice teachers who believed that all students from diverse backgrounds can succeed and who stated an interest and willingness to work with diverse students, were more likely to "endorse mastery-focused achievement goals" in which students' critical thinking is emphasized (p. 173). On the other hand, they also reported that preservice teachers who held biased beliefs toward poor and minority students had an 
uncomfortable feeling toward interacting with culturally diverse students, and were more likely to adopt "performance-focused instructional goals" in which students' superior achievement over other students is important (p. 173).

Scholars like Ogletree (2012) contended that teachers' diversity beliefs influence their selection of instructional materials. She furthermore insisted that teachers' instructional decisions strongly reflected their own cultural background and teachers who had a positive attitude about diversity tend to have more multicultural literature in the classroom.

To summarize, the research literature asserted the importance of teachers' personal beliefs in relation to their professional practice of teaching and suggested that factors like multicultural teacher education programs and teachers' prior experiences influence diversity beliefs. Research findings also indicated that preservice teachers with supporting beliefs about cultural diversity found stronger connections to multicultural education. Additionally, preservice teachers' beliefs about diversity affected their multicultural teaching practice including their selection of teaching materials.

\section{Korean Teachers' Perspectives about Multicultural Education}

While a body of research has been conducted to examine teachers' beliefs on issues of diversity in the U.S., little research is found on Korean teachers' beliefs about diversity. Instead, some researchers have investigated Korean teachers' perspectives or attitudes about multicultural education. Watson, Park, and Lee (2011) studied South Korean preservice teachers' attitudes toward the issues of diversity and multicultural education in K-12 Korean schools. They surveyed 82 preservice teachers in a Korean 
teacher education university during the 2010 academic year to examine the preservice teachers' awareness of an emerging multicultural society in Korea and their perspectives about multicultural education. The survey instrument in the study was developed by Watson et al. based on a review of literature, member-checking, and peer-debriefing; and is comprised of 14 multiple-choice questions and six open-ended questions. Watson et al. (2011) identified multiple themes from their analysis. Both quantitative and qualitative data indicated that most of the preservice teachers were aware of the emerging diversity in South Korean society and they were interested in using multicultural approaches in their future classroom. However, the preservice teachers held conflicting views about the demographic and social changes in South Korea and they were not sure about the concept of multicultural education. In addition, results indicated that the preservice teachers: (a) have a mixed feeling regarding the demographic shift in South Korea; and (b) felt highly unprepared and under-resourced as multicultural educators (Watson, Park, \& Lee, 2011, p. 13). In conclusion, Watson et al. (2011) suggested that multicultural education for South Korean preservice teachers must critique the Korean homogeneity myth and challenge them to define multicultural education in the context of privileges and disadvantages and examine their positionality towards class distinction.

While the number of research articles regarding Korean teachers' beliefs about diversity is limited, in recent years, a few doctoral students have examined South Korean teachers' and administrators' perceptions and attitudes toward multicultural education. For example, J. Lee (2008) studied South Korean elementary teachers' experiences and perspectives about multicultural education along with Korean school curriculum. 
Specifically, she explored how multicultural education is contextualized at the level of classroom teachers in South Korean schools. J. Lee conducted interviews with 10 elementary school teachers and one policy maker to investigate each teacher's perceptions and stories regarding multicultural education. She also analyzed documents such as policy documents, curricula, reports on multicultural education developed by Korean Ministry of Education and the local offices of education, administrative documents, news clippings and articles. As a result, J. Lee found that most South Korean teachers participating in her research perceived multicultural education as an approach to address social justice and inequality, and to ensure educational equity for multicultural students. The teachers also viewed increasing cultural awareness and developing positive attitudes toward different racial and ethnic groups would be important goals in multicultural education.

In another doctoral dissertation, J. Y. Lee (2013) reported how Korean elementary school teachers recognize multicultural contents in textbooks and how they analyze and communicate them to elementary students in class. She analyzed fifth grade Korean Language and sixth grade Korean Language and Social Studies textbooks through "Conceptual Model of a Comprehensive Multicultural Curriculum (Bennett, 2006)", and also interviewed fifth and sixth grade teachers to investigate how they recognize and communicate multicultural content in class. J. Y. Lee (2013) found that most interviewed teachers perceived the term "multiculturalism" and "multicultural education" as referring to multicultural families, that is, foreign workers and marriage immigrant families. She also reported that Korean teachers had difficulties in teaching multicultural materials to 
their students because they did not have enough experience with multicultural teaching or experience in communicating with multicultural families. J. Y. Lee (2013) concluded teachers' perception about multicultural contents was the result of the government initiated multicultural education policies in South Korea. She also indicated a gap between the Korean government's initial intentions for multicultural education and teachers' actual perceptions of multicultural materials and their practical use in instruction.

Along with research studied and published in English, there is some research by Korean scholars, written in Korean, regarding Korean teachers' views which are referred to as perception, perspectives, attitudes, and recognition on the issues of multicultural education. These researchers reported that Korean teachers were aware of the need for multicultural education and the importance of teachers' role in multicultural teaching (Bae, 2012; Jang \& Jeon, 2013; Kim \& Kim, 2008). The Korean teachers who were studied emphasized the importance of maintaining positive attitude toward students' diversity, while, simultaneously, they were concerned about their own lack of knowledge and experiences with multicultural education. Viewing this from a different angle, scholars like H. Lee (2014) indicated that the Korean elementary and middle school teachers that she studied did not have a critical perception of multicultural education. She argued that these Korean teachers had a conservative view about multiculturalism, such as the melting pot model, and they viewed cultural assimilation as a goal in multicultural education.

In summary, research indicates that Korean teachers are aware of the importance of multicultural education and the critical role of teachers in multicultural practices. 
However, most Korean teachers feel that they are unprepared and under-resourced as multicultural educators. Additionally, Korean teachers' implementation of multicultural education is not consistent with the government's intention per policies.

\section{Critique of the Research Literature}

Understanding South Korean teachers' perspectives and attitudes about multicultural education provides useful information that can guide Korean multicultural education policy and curricula as well as multicultural teacher education programs. However, there is a missing link of understanding about Korean teachers' beliefs about diversity. In the literature reviewed, I found a gap in the research related to Korean teachers' beliefs about diversity. Without a clear understanding of Korean teachers' beliefs about diversity that underlies their perceptions about multicultural education, it is hard to comprehend the full picture of Korean multicultural education and to support teachers to improve their multicultural competence.

Another a big gap found in the literature review is that most research about teachers' diversity beliefs focused on preservice teachers enrolled in teacher preparation programs. I understand that these types of studies are meaningful in the sense that preparing culturally competent preservice teachers will benefit their future class teaching. Also, it may be more feasible and convenient to conduct research on a group of preservice teachers in a one-place setting and at multiple times as necessary. On the contrary, the research on inservice teachers' beliefs about diversity is largely missing. The problem is teachers' beliefs are changing over time from their personal life experiences, teaching experiences, and professional training opportunities. Thus, there is 
a need to study what inservice teachers, who are in charge of actual multicultural teaching, believe about diversity issues.

Many studies discussed the factor of teacher education programs on fostering positive diversity beliefs (Middleton, 2002; Milner et al., 2003; Watson et al., 2011). In contrast, little research has examined the personal experience factors such as intercultural friendship and multicultural teaching experiences. Castro (2010) suggested that investigating the relationship between preservice teachers' attitudes toward diversity, and prior experiences and social interaction with culturally diverse others is significant. Therefore, more attention needs to be placed on research that explores the relationship between teachers' intercultural experiences and their development of beliefs about diversity.

\section{Review of Methodological Literature}

To answer my research questions, I employed a mixed methods approach: using both quantitative data collection (i.e., surveys) and qualitative data collection (i.e., individual interviews). In this section, I review methodological literature that attempts to measure teachers' beliefs related to diversity issues. My goal is to justify my selection of research methods using evidence gathered in this review.

\section{Measuring Teachers' Beliefs about Diversity}

Research shows that the assessment of teachers' beliefs about diversity can be achieved in a number of ways, including through the use of surveys with open-ended questions, interviews, and selected response instruments (Nadelson et al., 2012). To review the instrument which measures beliefs and the relevance to my research, I categorize the instruments into two categories: quantitative and qualitative instruments 
Quantitative instruments. Brown (2004) reviewed and critiqued quantitative measures, instruments, and inventories that assess teachers' beliefs, attitudes, and perceptions. She introduced 10 studies that examine preservice and inservice teachers' beliefs related to diversity issues and discussed the development and use of several of the instruments used in the studies. According to Brown (2004), one of the most frequently cited measures in the literature is the Cultural Diversity Awareness Inventory (CDAI; Henry, 1986). Henry (1986) created a questionnaire to examine educators' awareness of their attitudes, beliefs, and behaviors toward young elementary school children of culturally diverse backgrounds. The CDAI uses a 5-point Likert-type scale and consists of 28 agree/disagree opinion statements that address general cultural awareness.

Although Henry (1986) did not provide information for scoring, interpretation, reliability, and validity of the CDAI check list, several studies have used the instrument to study preservice teachers' awareness of diversity (Collins, 2009; Larke, 1990; Milner et al., 2003).

As a result of reviewing existing empirical measures, Brown (2004) suggested two measures as more effective tools because they broadly define diversity, report validity and reliability data, and are relatively easy to administer and score. The two instruments are the Cultural and Educational Issues Survey (Pettus \& Allain, 1999) and the Personal and Professional beliefs about Diversity Scales (Pohan \& Aguilar, 2001). Pettus and Allain (1999) developed version B of the Cultural and Educational Issues Survey to measure educators' attitudes concerning cultural and educational issues that affect educators' educational decision making. The term "cultural" used in this 
instrument involves "the ideas, customs, learnings, interests, desires, skills, arts, and behaviors of given group of people" (Brown, 2004, p. 337). The instrument contains four demographic items and 59 opinion statements, and uses a 5-point Likert-type format ranging from 1 (strongly agree) to 5 (strongly disagree).

Pohan and Aguilar (2001) designed the Personal and Professional Beliefs about Diversity Scales to assess educators' beliefs about diversity. Their two-dimensional approach to assessing beliefs was based on the idea that individual's personal beliefs about issues of diversity might differ from his or her beliefs in a professional context. More detail of Personal and Professional Beliefs about Diversity Scales is discussed further in Chapter 3.

Another scale used by a number of investigators in more recent years is the Multicultural Efficacy Scale (MES). Guyton and Wesche (2005) developed the MES to measure teachers' multicultural efficacy, which is, teachers' confidence that they can effectively teach children in multicultural settings. It also measures multicultural teacher education dimensions such as intercultural experiences, minority group knowledge, attitude about diversity, and knowledge of multicultural teaching skills (Guyton \& Wesche, 2005). The MES, a 35-item Likert-type scale includes three subscales that are designed to assess individual experiences, attitudes toward teaching, and efficacy for teaching in multicultural environments. Guyton and Wesche (2005) provided a guide for scaling items and synthesizing scores that instructs researchers on how to interpret outcomes and frame result in context (Nadelson et al., 2012). Guyton and Wesche (2005) reported Cronbach's alpha of .89 for the full instrument, with a sub-scale alpha of .78 for 
experience, .72 for attitude, and .93 for efficacy. Their data supports the internal reliability of total MES and sub-scales.

Qualitative instruments. Pajares (1992) argued that quantitative instruments such as belief inventories provide limited information because by the instruments one cannot understand the contexts that influence the formation of beliefs. Nevertheless, qualitative measurements are less common in the research that examines teachers' beliefs.

One example of research that employed a qualitative measuring instrument is Nelson and Guerra (2014) study of practicing educators' beliefs about diverse students and families. The participants were 111 educators in two school districts in Midwestern states. Data were collected through a qualitative instrument in which participants responded in a written form to scenarios depicting cultural conflicts that commonly occur in schools. The instrument consisted of scenarios which dealt with components of schooling such as instruction, curriculum, building relationships with students and families. All scenarios were based on actual experiences of educators. Nelson and Guerra's example scenarios are shown in Table 1. The instrument was administered for a 45-minute time period and the participants were asked to read each scenario and answer two questions: (a) What is happening in the scenarios; (b) If you were the educator in the scenario, how would you have responded and why? Once the completed instruments were collected, the Nelson and Guerra (2014) analyzed the data using constructivist grounded theory and comparative analysis. All data were first coded to identify categories of educator belief, knowledge of culture, and application of cultural knowledge in practice, then, each category was assessed in the context specific scale. 
Table 1

Quantitative Instrument Example: Brief Scenario Description

\begin{tabular}{|c|c|}
\hline Topic & Description \\
\hline $\begin{array}{l}\text { Your Answer or } \\
\text { Mine? }\end{array}$ & $\begin{array}{l}\text { A teacher asks his class to diagram the relationships of } \\
\text { characters in a book. Most of the CLED students create one type } \\
\text { of diagram while the majority of White students depict another } \\
\text { form. The teacher indicates the one drawn by the CLED students } \\
\text { are incorrect. }\end{array}$ \\
\hline $\begin{array}{l}\text { Where are all the } \\
\text { black Cowboys? }\end{array}$ & $\begin{array}{l}\text { A museum curator reports to a teacher that a group of African } \\
\text { American students are running through the museum and informs } \\
\text { her they must leave. }\end{array}$ \\
\hline Writing a story & $\begin{array}{l}\text { A teacher gives instructions for completing assignment. Two } \\
\text { CLED students approach her several times for clarification about } \\
\text { the assignment. }\end{array}$ \\
\hline First days of School & $\begin{array}{l}\text { During a meeting with principal, a group of elementary teachers } \\
\text { discuss the situation of Hispanic parents walking their children } \\
\text { to classrooms in the morning. }\end{array}$ \\
\hline Faculty Meeting & $\begin{array}{l}\text { During the faculty meeting, the principal asks his teacher how to } \\
\text { get "minority" parents involved in their children's education. }\end{array}$ \\
\hline Huckleberry Finn & $\begin{array}{l}\text { In thinking about novels for students to read, a group of English } \\
\text { teachers debate adding Huckleberry Finn to the list of required } \\
\text { readings. }\end{array}$ \\
\hline Eating Well & $\begin{array}{l}\text { Asian Indian parents do not follow the recommended nutrition } \\
\text { plan for their special needs child that was developed by the } \\
\text { school's intervention team. }\end{array}$ \\
\hline Health Lesson & $\begin{array}{l}\text { In a classroom discussion on how to keep from getting sick, a } \\
\text { teacher acknowledges a student who responds with the answer } \\
\text { "shots" but does not accept the response from a student who } \\
\text { states "my mother makes a special tea." }\end{array}$ \\
\hline Leading School & $\begin{array}{l}\text { Data from a needs assessment administered to teachers in a low- } \\
\text { performing school identifies students and parents are the greatest }\end{array}$ \\
\hline Reform & $\begin{array}{l}\text { challenges to improving achievement and staff and programs as } \\
\text { assets. }\end{array}$ \\
\hline
\end{tabular}


Note. Reproduced from "Brief scenario description" by Nelson \& Guerra, 2014, Educational Administration Quarterly, 50, p. 75. CLED student = culturally, linguistically, and economically diverse student.

In recent years, many scholars adapt combined quantitative and qualitative instruments to examine teachers' beliefs. Pajares (1992) suggested that for "richer and more accurate" assessment, additional instruments such as open-end interviews, responses to scenarios, observation should be included along with quantitative instruments.

Kyles and Olafson (2008) examined preservice teachers' beliefs about diversity using both quantitative and qualitative instruments. In their research, 15 preservice teachers completed reflective response letters along with four kinds of previously published quantitative instruments. For the reflective letters, researchers provided prompts that related to goals as multicultural educators and cultural autobiographies regarding personal diversity experiences. Findings from quantitative measurements did not reveal a significant relationship between the participants' engagements in the enrolled course for a semester and their development of efficacy. However, Kyles and Olafson argued that the qualitative instrument yielded some meaningful findings: preservice teachers who had multicultural schooling and life experiences were more likely to have supporting beliefs and attitudes toward cultural diversity.

To summarize, there is a growing body of research to investigate preservice and practicing teachers' beliefs and attitudes about diversity. From my review, I discovered that the majority of measures which have been implemented in the literature were quantitative instruments. Yet, literature indicates that combing qualitative instruments 
such as reflective writings to quantitative instruments provide a greater depth of examination and a better understanding about the teachers' beliefs.

\section{Summary of the Research Literature and Application to the Study}

In the previous sections, I reviewed multicultural education research in South Korea critically and indicated that the research on this topic in South Korea has been studied in a limited way. Then, I attempted to suggest alternative multicultural education research genres in the South Korean context through Bennett's (2001) frame of multicultural education research genres. As a result, I suggested prejudice reduction education in multicultural competence research genre is meaningful in the Korean context. Furthermore, I argued that, among the studies that has a root in the prejudice reduction research, a study on teachers' beliefs research would be one of significant values in the South Korean context.

Research indicates that teachers' beliefs on issues of diversity are a critical predictor of their multicultural teaching practice. Therefore, the examination of teachers' diversity beliefs is a starting point, from which, to reframe teachers' beliefs and eventually improve their cultural competence that will lead to a better practice of multicultural education. In my review of the literature, however, I identified a gap in the research concerning Korean teachers' beliefs about diversity. I argue that a clear understanding about what beliefs Korean teachers have about diversity, particularly in both personal and professional contexts would provide meaningful insight on how to support teachers to practice more effective multicultural teaching. 
Finally, in my review of the methodology literature, I suggested that using combined instruments to examine teachers' beliefs would be more beneficial than using quantitative or qualitative alone. The research that has used combined measurements provides a deeper and clearer understanding about teachers' beliefs.

In essence, the reviewed literature supports and justifies the need for my research that examines South Korean teachers' beliefs in personal and professional contexts in relation to multicultural education. To investigate South Korean teachers' beliefs about diversity, I use a mixed-methods approach which includes quantitative data collection (i.e., surveys) and qualitative data collection (i.e., individual interviews). I explain the methods in detail in Chapter 3. 


\section{Chapter 3: Methods}

The purpose of this study was to investigate South Korean teachers' beliefs about diversity in personal and professional contexts and to examine the impact of those beliefs on their practice of multicultural teaching. In the previous chapter, I argued that teachers' affirming beliefs about diversity are more critical than their multicultural knowledge in developing their multicultural competence in the classroom (Pohan \& Aguilar, 2001). Thus, the beliefs about diversity held by teachers must be identified, challenged, and reframed for improved multicultural education teaching practice. To support South Korean teachers' practice of multicultural teaching, Korean teachers' beliefs about diversity first need to be examined and identified. Ultimately, South Korean teachers' acceptance of diversity would be the starting point, from which, to develop better multicultural education in South Korean schools. Given the importance of teachers' beliefs about diversity in multicultural education, I sought to examine the beliefs on the issues of diversity held by Korean teachers, particularly in both personal and professional contexts.

In the process of exploring South Korean teachers' beliefs about diversity, the following five research questions guided my research.

1. What are South Korean teachers' beliefs about diversity in personal contexts?

2. What are South Korean teachers' beliefs about diversity in professional contexts?

3. How do South Korean teachers' beliefs about diversity differ between personal and professional contexts? 
4. How do South Korean teachers' beliefs about diversity in personal and professional contexts differ based on their demographics, and teaching and intercultural experiences?

5. What impact do South Korean teachers' beliefs about diversity have on their practice of multicultural education?

\section{Research Methods}

In this section, I explain the guiding research paradigm including the key characteristics of the pragmatic approach and the reasons to employ it for my research. I also provide the justification for selecting the mixed methods approach.

\section{Research Paradigm}

My research design was framed by a pragmatic approach (Morgan, 2007). Among the scholars who studied research paradigms, Morgan compared and critiqued the paradigms previously used in the social science field in a most explicit way (Teddlie \& Tashakkori, 2010). As result, Morgan (2007) suggested four alternative interpretations about paradigm: paradigm as worldviews, paradigm as epistemological stances, paradigm as model examples, and paradigm as "shared beliefs among a community of researchers" (p. 51). Morgan (2014) theorized that pragmatism disrupts the assumptions of older approaches based on the philosophy of knowledge, while providing new directions for understanding the nature of research in the social science field.

Morgan (2007) advocated the version of paradigm as shared beliefs among a community of researchers. His view of paradigm placed an emphasis on the "shared beliefs within a community of researchers who share a consensus about which questions 
are most meaningful and which procedures are most appropriate for answering those questions" (p. 53). Morgan (2007) called this alternative to previous paradigms the “pragmatic approach" (p. 60). He advocated a pragmatic approach:

as a guiding paradigm in social science research, both as a basis for supporting work that combines qualitative and quantitative methods and as a way to redirect our attention to methodological rather than metaphysical concerns. (p. 48)

The key issues in pragmatism were how much mutual understandings are shared"shared meaning" and what behaviors are possible from the understanding__ "joint action" (Morgan, 2007, p. 67). Consequently, pragmatism placed methodology at the center of research, as the link between epistemology and methods. In line with this position, Creswell (2010) viewed the mixed methods in research mainly as a methods approach rather than an approach that mixes philosophical foundations.

I found that the Morgan's pragmatic approach corresponded with my approach to research and therefore was appropriate to guide my research. First, the pragmatic world view encourages others to share understandings and the possible subsequent behaviors as a result of research. My research goal was to investigate South Korean teachers' beliefs about diversity and to seek a common understanding of the importance of the teachers' beliefs to create a better practice of multicultural education in South Korea. Based on a shared understanding, Korean teacher educators and administrators may be able to support teachers and improve e multicultural teaching practice. Second, the pragmatic approach can combine the strengths of qualitative and quantitative methods. Korean teachers' beliefs about diversity is a multi-dimensional and complex topic, thus I found combining the strength of two methods would be beneficial to investigate the beliefs. 


\section{Mixed Methods Approach}

To understand the complex and multi-dimensional teachers' beliefs system, applying combined quantitative and qualitative methods together would be more beneficial than employing a single method. However, instead of just combining two different methods, the goal of mixed method is to connect and integrate the methods effectively to get the best result (Creswell, 2010; Morgan, 2013).

Regarding the sequence of data collection, Morgan (2013) categorized the sequential contributions model into four designs: (a) qual $\rightarrow$ QUANT, (b) quant $\rightarrow$ QUAL, (c) QUANT $\rightarrow$ qual, and (d) QUAL $\rightarrow$ quant. The capital letters in each model displays the emphasis in that specific model. For example, the "QUANT $\rightarrow$ qual" design uses the qualitative method to follow up on the largely quantitative research. In this design, the general emphasis of the data collection process is on the quantitative method and the qualitative data play a supporting role (Morgan, 2013). Other scholars like Creswell (2003) use a different descriptive terminology. Creswell described "QUANT

$\rightarrow$ qual" research design as "Sequential Explanatory Design" and "QUAL $\rightarrow$ quant" design as "Sequential Exploratory Design."

I employed the "QUANT $\rightarrow$ qual" research design, in Creswell's terminology, "Sequential Explanatory Design.” This model is beneficial when addressing new questions that cannot be wholly answered by quantitative data alone, and need further clarification using another method (Morgan, 2013). It is also appropriate when qualitative results are used to assist in explaining and interpreting the findings of a primarily quantitative study (Creswell, 2003; Creswell \& Plano Clark, 2011). 
Vogt et al. (2012) identified six reasons to choose a mixed methods research design. Among their reasons for combining research designs, I found three reasons relevant to my research topic and questions. These are shown in Table 2, along with examples for each reason.

Table 2

Reasons for Mixed Methods Research

\begin{tabular}{ccc}
\hline Reason & \multicolumn{1}{c}{ Examples of mixed methods design in my research } \\
\hline $\begin{array}{l}\text { 1. When you want to } \\
\text { one method to } \\
\text { inform another } \\
\text { method }\end{array}$ & - & $\begin{array}{l}\text { Use survey data to revise interview questions that } \\
\text { can probe in greater depth the primary area of } \\
\text { inquiry raised in the survey }\end{array}$ \\
& - $\begin{array}{l}\text { Use survey data to construct general information } \\
\text { about interviewees concerning research topic, } \\
\text { before interviews }\end{array}$ \\
\hline $\begin{array}{l}\text { 2. When you want to } \\
\text { elaborate, clarify, } \\
\text { or build on findings } \\
\text { from other methods }\end{array}$ & - & $\begin{array}{l}\text { Conduct follow up interviews to elaborate and } \\
\text { clarify the responses from survey data } \\
\text { Seeking answers to questions like "why do they } \\
\text { answer this way?" which are not easily answered } \\
\text { with surveys alone }\end{array}$ \\
\hline $\begin{array}{l}\text { When you want to } \\
\text { "tell the full story" } \\
\text { in an area of } \\
\text { inquiry }\end{array}$ & $-\begin{array}{l}\text { Use survey and interview combined methods to } \\
\text { collect both general and specific information on } \\
\text { the topic } \\
\text { To draw a big picture of the research topic instead } \\
\text { of limited information of the topic } \\
\text { Use interview data to examine the deeper } \\
\text { meaning of the responses to draw richer results }\end{array}$ \\
\hline
\end{tabular}

Note. Adapted from When to Use What Research Design (p. 107), by Vogt, Gardner, \& Haeffele, 2012, New York, NY: Guilford Press. Copyright 2012 by the Guilford Press.

In the first phase of my study, I used a survey collected quantitative data at one point in time. The first part of the survey (i.e., Demographic and Experience Survey) was to examine participants' demographic information and teaching and intercultural experiences such as gender, age, the number of years that they have taught, experience of teaching multicultural education and taking multicultural training courses, experiences of 
travelling or living in foreign countries, and friendship with culturally diverse others. The second part of survey, Personal and Professional Beliefs about Diversity Scales (Pohan \& Aguilar, 2001), was to investigate South Korean teachers' general beliefs about diversity in personal and professional contexts.

After the survey data were collected, I analyzed the quantitative data to revise and reorganize the interview questions. The survey results confirmed the scope of the interview questions and provided an opportunity to add questions to achieve a deeper understanding of Korean teachers' beliefs about diversity in relation to their practice of multicultural education. I selected the interview participants by a convenient sampling (Creswell, 2013). The data from interview helped clarify and elaborate on responses from the survey.

In essence, by adopting a mixed methods approach, I collected both general and specific information, at a deeper level on the topic. While the data from the survey provided me more general and broad information about Korean teachers' beliefs on diversity, through the interview I gathered more specific, personal, and anecdotal stories of Korean teachers' experience. Combining and integrating multiple methods enabled me to collect richer and more in-depth data to answer my research questions.

\section{Participants}

The participants in my study were 110 elementary teachers in a South Korean school district. I selected the participants from 10 different schools from four different districts in a Metropolitan city in south eastern Korea. The Metropolitan city is one of the largest cities in South Korea with a population of roughly 2.5 million people. The 
city has four school districts and a total of 8,869 teachers teaching in 221 elementary schools (Korean Education Statistics Office, 2015). In terms of the teachers' socioeconomic status, they belong to the middle class considering their average salary level and job security in Korean society. Additionally, this Metropolitan city in south eastern Korean is well known nationally for its conservative culture, particularly compared to the south western region of Korea. So, it is most likely as in Korean tradition, the teachers are natives from this city and would tend to have more conservative perspectives and attitudes about general social and cultural issues. I used cluster sampling to select participants which is a two-level random sampling process. I selected two to three schools from each of the four school districts in the city; then, I contacted those schools to choose participants. According to Vogt et al. (2012), cluster sampling is efficient and a great time saver to find representative participants from a large population.

Because the purpose of my research was to uncover South Korean elementary teachers' beliefs on issues of diversity, the participants were inservice teachers in South Korean elementary schools, specially, in a Metropolitan city in south eastern Korea. My motivation to choose elementary school teachers came from my belief that the elementary school age is the critical time for students to form attitudes and perceptions toward social values which will last throughout ones' life. My personal experience as a school teacher supports this belief. Another motivation is the fact that the majority of multicultural students are attending elementary schools. According to the Korean Ministry of Education (2016), in 2015, $73 \%$ of multicultural students attended elementary schools. 
This number suggests the critical importance of multicultural education in elementary schools in South Korea.

In phase 2 of the study, I conducted interviews with six South Korean elementary school teachers from the survey group. The interviewees were selected by a convenient sampling. They were introduced by my friend teachers and volunteered to participate in an individual interview. All interviewed teachers were female and their teaching and intercultural experiences were varied.

\section{Procedures}

My research followed “QUANT $\rightarrow$ qual” procedures (Morgan, 2013), in another terminology, a sequential explanatory design (Creswell, 2003), in which quantitative data were collected in the first phase and the assisting qualitative data were collected in the second phase.

In the first phase, I collected quantitative data using Personal and Professional Beliefs about Diversity Scales (Pohan \& Aguilar, 2001). The purpose of collecting quantitative data was to have an overall explanation of Korean teachers' beliefs about diversity, while the qualitative data collected in the second phase refined and elaborated the quantitative data by exploring a few cases. In other words, the survey data provided a normative and general perspective of Korean teachers' beliefs about diversity; however, the qualitative data from an in-depth interview presented more detailed, specific, and more contextual information. Thus, the second phase of study served to enhance and clarify my interpretation of the quantitative results. My research procedure is summarized in Table 3. 
Table 3

Research Procedure

\begin{tabular}{|c|c|c|}
\hline Phase & Procedure & Product \\
\hline $\begin{array}{l}\text { Quantitative Data } \\
\text { Collection }\end{array}$ & $\begin{array}{l}\text { - Demographic and } \\
\text { experience Survey }(n=110) \\
\text { - Personal and Professional } \\
\text { Beliefs about Diversity } \\
\text { Scales }(n=110)\end{array}$ & $\begin{array}{l}\text { - survey responses } \\
\text { - numeric data }\end{array}$ \\
\hline $\begin{array}{l}\text { Initial Quantitative Data } \\
\text { analysis }\end{array}$ & - frequency analysis & $\begin{array}{l}\text { - descriptive statistics } \\
\text { - response tendency }\end{array}$ \\
\hline $\begin{array}{l}\text { Interview questions } \\
\text { Development }\end{array}$ & $\begin{array}{l}\text { - developing interview } \\
\text { questions }\end{array}$ & - interview questions \\
\hline $\begin{array}{l}\text { Qualitative Data } \\
\text { Collection }\end{array}$ & $\begin{array}{l}\text { - individual in-depth } \\
\text { interviews }(n=6)\end{array}$ & $\begin{array}{l}\text { - cases }(n=6) \\
\text { - interview recording files } \\
\text { - text data } \\
\text { - interview transcripts }\end{array}$ \\
\hline Quantitative Data analysis & $\begin{array}{l}\text { - frequency analysis } \\
\text { - paired samples } t \text {-test } \\
\text { - multiple linear regression } \\
\text { tests } \\
\text { - quantitative results } \\
\text { analysis \& interpretation }\end{array}$ & $\begin{array}{l}\text { - descriptive statistics } \\
\text { - percentage of agreement } \\
\text { per item in both scales } \\
\text { - correlation coefficients } \\
\text { - regression coefficients } \\
\text { - analysis \& interpretation }\end{array}$ \\
\hline Qualitative Data analysis & $\begin{array}{l}\text { - coding and thematic } \\
\text { analysis } \\
\text { - within-case and across } \\
\text { case theme development } \\
\text { - cross thematic analysis } \\
\text { - qualitative results analysis } \\
\& \text { interpretation }\end{array}$ & $\begin{array}{l}\text { - codes and themes } \\
\text { - themes and categories }\end{array}$ \\
\hline $\begin{array}{l}\text { Integration of the } \\
\text { Quantitative and } \\
\text { Qualitative results }\end{array}$ & $\begin{array}{l}\text { - interpretation and } \\
\text { explanation of the } \\
\text { quantitative and qualitative } \\
\text { results }\end{array}$ & $\begin{array}{l}\text { - synthesis of results } \\
\text { - quantitative \& qualitative } \\
\text { - situated in larger context } \\
\text { - implications } \\
\text { - future research }\end{array}$ \\
\hline
\end{tabular}

Note. Adapted from "Using mixed methods sequential explanatory design: From theory to practice" by Ivankova, Creswell, \& Stick, 2006, Field Methods, 18(1), p. 16., Copyright 2006 by Sage Publications. 
Regarding the actual administration of measures, the surveys were conducted using a paper copy of the measure. The reason I provided a paper copy instead of electronic copy is that Pohan and Aguilar's scales were originally administered using paper copy. Being consistent with the original research method was important to help ensure the validity of the survey. During July to August 2015, the participants were asked to self-administer the survey; one volunteer teacher in each school gathered and returned the survey copies to me. Because it was an international study and the surveys were self-administered, it was impossible to share personally with all the participants the purpose of my study. To describe the study and assure confidentiality of the data, I included the following text at the beginning section of the survey:

You are invited to participate in a research study in which the researcher expects to learn about participants' beliefs about diversity in personal and professional contexts. Your participation will increase understanding about Korean teachers' diversity beliefs and ways to support the practice of multicultural education. The data collected through this survey will be used for research purpose only and will be kept confidential by the researcher.

In second phase of the study, I conducted semi-structured personal interviews with six teachers. The main goals of interviews were to examine how Korean teachers' intercultural experience influences their beliefs about diversity, and if teachers' beliefs about diversity served as a support or a barrier for their multicultural teaching. Each Individual interview was conducted for 30-50 minutes using Internet calls and was recorded through a recording application.

\section{Instruments}

As I employed a mixed method approach, I used two different types of instruments to collect data: quantitative survey scales and qualitative interview questions. 


\section{Instrument for the Quantitative Data Collection}

I used a two-part survey instrument that included the Demographic and Experience Survey and the Personal and Professional Beliefs about Diversity Scales. The Demographic and Experience Survey was used to solicit data on participants' age, gender, the number of years taught, multicultural teaching experiences, multicultural teacher training experiences, traveling and living abroad experiences, and friendship with culturally diverse others (see Appendix A).

To investigate teachers' beliefs about diversity, I adopted and adapted the scales from Pohan and Aguilar's (2001) study. Their study was based on the idea that individual's personal beliefs about issues of diversity might differ from his or her beliefs in a professional context. Pohan and Aguilar documented and validated a survey instrument that measures personal and professional beliefs in eight areas of cultural diversity that educators address in Pre-K-12 public schools. Different from previous instruments, Pohan and Aguilar's scales measure a wider range of diversity, not just limited to race and ethnicity. They covered a variety of culturally diverse topics teachers face in today's school systems, such as the sociocultural disparities related to social class, gender, religion, languages, and sexual orientation.

To develop an attitude assessment tool that was rigorous and psychometrically sound, Pohan and Aguilar (2001) conducted extensive pilot and field testing. The reliability coefficients stated by the authors ranged from 0.71 to 0.81 on the personal beliefs and 0.78 to 0.90 on the professional beliefs (Pohan \& Aguilar, 2001). Construct validity of the instrument was shown to be strong and positive between the personal and 
professional beliefs surveys (Pohan \& Aguilar, 2001). Pohan and Aguilar (2001) concluded that the developmental process of the measures led to "psychometrically promising measures" (Pohan \& Aguilar, 2001, p. 175). However, Pohan and Aguilar noted the limitations of the study in that the participants were white and most of them enrolled in diversity and multicultural related courses.

The Personal and Professional Beliefs about Diversity Scales consist of 25 professional beliefs about diversity items and the 15 personal beliefs items which measure participants' beliefs about issues concerning race, ethnicity, gender, sexual orientation, physical disabilities, socioeconomic class and language as they relate to classroom and personal contexts. Each scale uses a 5-point Likert type format ranging from $1=$ strongly disagree to $5=$ strongly agree. Some items are reverse coded to avoid response bias. Possible scores on the professional scale range from 25 to 125 . The possible range for the personal scale is 15 to 75 .

I found that Personal and Professional Beliefs about Diversity Scales (Pohan \& Aguilar, 2001) were appropriate to measures Korean teachers' beliefs on issues of diversity for the following reasons. First, my research was framed by a social constructivism assumption that an individual develops knowledge and beliefs within sociocultural contexts from interactions with others. The Personal and Professional Beliefs about Diversity Scales was designed to investigate teachers' beliefs, particularly, within individual and social contexts and in association with their experiences as they are related to issues of diversity. Thus, the purpose of the instrument was in accordance with the assumptions of social constructivism. 
Second, the scales were based on the idea that there might be a situation in which one's personal and professional beliefs are conflicting. In my experience, this assumption has been true for many Korean teachers. For example, a Korean teacher might believe that having friendship with foreign friends is valuable experience in a personal context; however, the same teacher possibly is against the plan of the city educational budget being spent on programs for multicultural students. Therefore, it is important to assess Korean teachers' beliefs about diversity in both personal and professional contexts and how the two different beliefs are related and affect each other.

Third, I found a significant body of research that examined teachers' diversity beliefs through Personal and Professional Beliefs about Diversity Scales (Cardona, 2005; Dedeoglu \& Lamme, 2011; Gentry et al., 2012; Harmon \& Wilson, 2011; Leavy, 2005; Lee \& Herner-Patnode, 2010; Middleton, 2002; Pohan, Ward, Kouzekanani, \& Boatright, 2009; Torok \& Aguilar, 2000). These studies employed the Personal and Professional Beliefs about Diversity Scale as a single instrument or combined with other surveys for the purpose of investigating preservice and inservice teachers' beliefs and perspectives about diversity. The number of studies provided evidence that Personal and Professional Beliefs about Diversity Scales were appropriate instruments to investigate South Korean teachers' beliefs about diversity.

To use Personal and Professional Beliefs about Diversity Scales for this research (Pohan \& Aguilar, 2001), I asked permission from the authors and received permission from Dr. Pohan (see the permission email in Appendix B) 
Instrument modification. For the purpose of this study, I modified the Personal and Professional Beliefs about Diversity Scale for two reasons. First, some items reflected types of diversity which are not present in the Korean context. For example, in Personal Beliefs about Diversity Scale, it was asked "In general, White people place a higher value on education than do people of color" (Pohan \& Aguilar, 2001, p. 178). I modified this item to "In general, the Korean family places a higher value on education than does a multicultural family." In another example, I modified the question in Professional Beliefs about Diversity Scale: "Students living in racially isolated neighborhoods can benefit socially from participating in racially integrated classrooms." The modified question is "Students from multicultural background can benefit socially from participating in multicultural classrooms."

Second, I modified items which include some terminologies that are not frequently used among Korean teachers. In other words, as an experienced teacher myself, I found some terminologies used in the scales were probably unacceptable, because they could be considered too progressive for Korean teachers in a local city in South Korea. For example, a question in Professional Beliefs about Diversity Scale asked "Tests, particularly standardized tests, have frequently been used as a basis for segregating students." I modified this item to "Tests, particularly standardized tests, have been used to sort students (e.g., high or low grades)" (see Appendix C and D for the modified version of the scales).

In addition, because the participants of my study were Korean teachers, the translation of tests into Korean language is another modification. To reduce the issues of 
translation, I had two reviewers who were Korean educational doctoral student in a North West U.S. college. They reviewed the Korean translations of questions in both scales and provided feedback on the translations, as well as content validity of the modified questions.

Before I administered the tests to participants, I conducted a pilot test with a small group of Korean teachers during May 2015. This pilot testing was important to establish the content validity and improve questions (Creswell, 2003). The participants for the pilot testing were five female inservice elementary teachers in a Metropolitan city in south eastern Korea. All of them taught more than 10 years, however their intercultural experiences were varied. They provided me with feedback on the contents of the questions and the survey format, particularly, they checked that the questions in the scales were accurate and made sense. I incorporated their feedback into the final version of scales.

\section{Instruments for the Qualitative Data Collection}

For the follow-up interview, I selected six Korean teachers from the participants of the first phase survey. The participants were selected by a convenient sampling. They were introduced by my friend teachers and volunteered to participate in the interview. During January 2016, I interviewed each participant individually through Internet phone calls and the interviews were recorded using a phone-based recording application. Each interview session lasted 30-50 minutes. Through the interviews, I elaborated on the results of the quantitative survey and explored the results in more detail and within an individual specific context. 
My interview questions were designed to answer following research questions: How do Korean teachers' intercultural experiences influence their beliefs about diversity in personal and professional contexts? What impact do Korean teachers' personal and professional beliefs about diversity have on their multicultural teaching? What supports and barriers do Korean teachers have in their multicultural teaching? (see Appendix E, for interview questions.) However, the interview questions were slightly different according to the situation and responses of each individual interviewee. I also asked them additional questions regarding their multicultural education experiences and their ideas about improvement of the multicultural teacher education program. Those questions helped me to understand better about Korean multicultural contexts and to elaborate how to support teachers for a better practice of teaching.

\section{Role of Researcher}

The influence of the researcher on the setting or participants is known as "reactivity (Maxwell, 2013)." This research was an international study in that the quantitative and qualitative data were collected from South Korean teachers in a Metropolitan city in south eastern Korea. As a former teacher and a current researcher, I had influences over my research process. One positive influence was that as a former teacher, I had access to Korean elementary school teachers. On the other hand, although I was introduced as a researcher and I made sure that teachers' participation was voluntary. The teachers might have felt required to participate in my study and felt compelled to provide positive and supposedly good answers rather than their honest 
perspectives. Possibly this is because they viewed me as a privileged teacher who is conducting research as part of a doctoral program in an American university.

In addition, even though I am a supporter of diversity in a society, I tried not to influence participants with my own beliefs and would not suggest or impose my beliefs about diversity and multicultural education to participants. However, it is possible that participants were influenced by me and my beliefs, particularly, in the process of interview data collection and analysis.

To minimize my influence as the researcher, I explicitly explained the purpose of my study and that my survey and interview data would not be used for questioning their thoughts or evaluating their teaching practice. During the interview, I avoided questions that intentionally led participants to desirable outcomes from participants, and included both supporting and discrepant data for my research.

To reduce the validity threats and increase credibility in my research, I applied multiple strategies. By Maxwell (2013), triangulation is a strategy used to collect data from a diverse range of individuals and setting, using a variety of methods. In my research, I collected data through multiple methods such as surveys and interviews. I used the SPSS program to analyze my survey data and applied coding and a thematic analysis process to the interview data. The participants were selected from four school districts and 10 elementary schools. Multiple research methods and participants from all four school district reduced the risk of chance of association biases and increased the generality of the research. 
To make sure of the clarity of survey questions, I conducted a pilot test with a small group of five Korean teachers. Additionally, I had peer reviews on the process of data collection. To avoid translation error from Korean to English, I used two bilingual peer reviewers to check the translation for the survey measures. The reviewers were a professional in the field of education as well as knowledgeable of the South Korean context.

\section{Data Collection and Analysis}

Mixed methods studies include two types of data sets - one quantitative and one qualitative, and two types of analyses - statistical and thematic (Creswell \& Plano Clark, 2010). My study employed mixed methods to answer research questions and address the research goal. Accordingly, two types of data, quantitative and qualitative, were collected and analyzed.

\section{Quantitative Data: Survey}

The first part of the survey, Demographic and Experience Survey, provided background information about participants such as age, gender, the number of years taught, experience of teaching multicultural students and taking multicultural education programs, experience of traveling and living abroad, and friendship with people from different cultures. The second part of the survey, Personal and Professional Beliefs about Diversity Scales, examined teachers' beliefs about diversity in personal and professional context.

The data collected through quantitative surveys were analyzed statistically using the SPSS program. Before any statistical analyses were run, negatively worded items 
were inversely coded. To answer Research Question 1 and 2, what are Korean teachers' beliefs about diversity in personal and professional contexts, I calculated descriptive statistics. The descriptive analysis indicates the means, the standard deviation, and the range of scores of these variables (Creswell, 2013). Particularly, I calculated the percentage of agreement per item for both Personal and Professional beliefs about Diversity Scales. In addition, I identified the three items that showed the highest level of acceptance and the three items that revealed the lowest level of acceptance.

To answer Research Question 3, how do South Korean teachers' beliefs about diversity differ between personal and professional contexts, I ran a paired samples $t$ - test. The $t$-tests are commonly used to compare the means from two different groups of data. They can help you find out if means are significantly different from one another or if they are relatively the same (Field, 2013). In my research, the dependent samples $t$ - test examined if a difference exists between teachers personal and professional beliefs about diversity and if the difference is significant.

Last, to answer Research Question 4, how do South Korean teachers' beliefs about diversity in personal and professional contexts differ based on their demographics, and teaching and intercultural experiences, I conducted multiple linear regression tests. In regression with multiple independent variables (demographics and experiences), the coefficients calculated how much the dependent variables (teachers' personal and professional beliefs about diversity scores) are expected to increase by independent variables. 


\section{Qualitative Data: Interviews}

In second phase of study, qualitative data were collected through interviews with six Korean elementary school teachers. The qualitative data mainly expanded upon Research Question 4, how do South Korean teachers' beliefs about diversity in personal and professional contexts differ based on their demographics, and teaching and intercultural experiences, and Research Question 5, What impact do South Korean teachers' beliefs about diversity have on their practice of multicultural education?

For analysis, I recorded and transcribed each individual interview. Then, the text data were analyzed using coding and thematic analyses. To develop a theme from the data, I labeled similar and different concepts across cases, defined categories, and developed themes. The overview of data collection measures and analysis methods that correspond to each research question are found in Table 4.

Table 4

Overview of Data Collection Measures and Analysis Methods

\begin{tabular}{|c|c|c|c|}
\hline & Research Questions & Data collection measures & Data analysis methods \\
\hline & $\begin{array}{l}\text { What are South Korean } \\
\text { teachers' beliefs about } \\
\text { diversity in personal } \\
\text { contexts? }\end{array}$ & $\begin{array}{ll}- & \text { Personal and } \\
\text { Professional Beliefs } \\
\text { about Diversity Scale }\end{array}$ & $\begin{array}{ll}\text { - } & \text { Statistical analysis } \\
\text { using SPSS program } \\
\text { - } & \text { Descriptive statistics } \\
\text { - } & \text { Frequency analysis: }\end{array}$ \\
\hline 2. & $\begin{array}{l}\text { What are South Korean } \\
\text { teachers' beliefs about } \\
\text { diversity in professional } \\
\text { contexts? }\end{array}$ & $\begin{array}{l}\text { Personal and } \\
\text { Professional Beliefs } \\
\text { about Diversity Scale }\end{array}$ & $\begin{array}{l}\text { percentage of } \\
\text { agreement and more } \\
\text { strongly agreed and } \\
\text { disagreed items }\end{array}$ \\
\hline 3 & $\begin{array}{l}\text { How do South Korean } \\
\text { teachers' beliefs about } \\
\text { diversity differ between } \\
\text { personal and professional } \\
\text { contexts? }\end{array}$ & $\begin{array}{l}\text { Personal and } \\
\text { Professional Beliefs } \\
\text { about Diversity Scale } \\
\text { - } \quad \text { Individual Interviews }\end{array}$ & 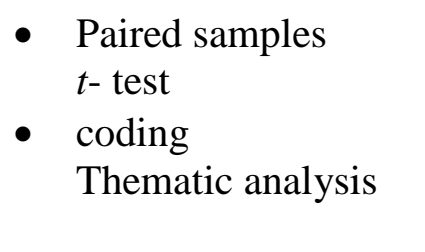 \\
\hline
\end{tabular}


4. How do South Korean teachers' beliefs about diversity in personal and professional contexts differ based on their demographics and teaching and intercultural experiences?

5. What impact do South Korean teachers' beliefs about diversity have on their practice of multicultural education?
- Demographic and experience survey

- Personal and Professional Beliefs about Diversity Scale

- Individual Interviews

- Demographic and experience survey

- Personal and Professional Beliefs about Diversity Scale Individual Interviews
- Multiple linear regressions tests

- coding

- Thematic analysis

- coding

- Thematic analysis

To summarize, I described the data collection and analysis procedures in relation to each research question. To analyze two types of data sets, one quantitative and one qualitative, I applied two types of analyses: statistical and thematic (Creswell \& Plano Clark, 2010). I analyzed the quantitative survey data statistically using SPSS program and qualitative data through coding and thematic analysis. 


\section{Chapter 4: Analysis and Results}

South Korean schools began to pay attention to the importance of multicultural education as Korea transforms into a multicultural society from a historically monoculture society. Because of Koreans' pride of their homogeneity in race, language, and culture, multiculturalism is an idea that is hard to accept. Studies have also indicated that Korean teachers feel that they are not prepared well for multicultural education because they lack of knowledge and materials to teach multicultural education. In the previous chapters, I argued that to support Korean teachers to improve multicultural education practice, Korean teachers' beliefs about diversity should be examined first because teachers' belief is a powerful predictor of their teaching practice.

The purpose of this study was to investigate South Korean teachers' beliefs about diversity in personal and professional contexts. My study also aimed to examine what influence the formation of Korean teachers' beliefs about diversity. Ultimately, my study sought to answers on how teachers' beliefs about diversity affect their actual multicultural teaching in their classroom. As previously described, in Korea, multicultural family refers to the family where one or both parents are a different ethnicity than Korean. Multicultural family in Korea mainly includes the family formed by international marriages and the family consists of foreigners living in Korea. Generally, multicultural students are those from multicultural families and attending elementary and secondary schools.

The following five questions guided my study to achieve the purpose of study:

1. What are South Korean teachers' beliefs about diversity in personal contexts? 
2. What are South Korean teachers' beliefs about diversity in professional contexts?

3. How do South Korean teachers' beliefs about diversity differ between personal and professional contexts?

4. How do South Korean teachers' beliefs about diversity in personal and professional contexts differ based on their demographics, and teaching and intercultural experiences?

5. What impact do South Korean teachers' beliefs about diversity have on their practice of multicultural education?

In Chapter 3, I described participants of study, my selection of mixed methods, and I provided the justification of the selection related to research problem and questions. I also explained the detailed procedure of data collection and described the data collection instruments, such as survey tools and interview questions. I employed the "QUANT $\rightarrow$ qual" research design (Morgan, 2013) in which general quantitative data were collected in the first phase and supporting qualitative data were collected in the second phase.

In Chapter 4, I describe the demographics of participants. I explain the data analysis of the quantitative and qualitative measures and the interpretation of the findings to address and connect my research purpose and questions. Because I employed a mixed methods study, I use the following sequence to present results. First, I share the quantitative survey data; then, I present qualitative interview data. Specifically, I answer Research Question 1, 2, 3 using quantitative data, Research Question 4 by quantitative 
and qualitative data, and Research Question 5 by qualitative data. Finally, I explain the limitation of my study and analysis of data. Figure 2 displays the data collection instruments and the data analysis methods that employed in this study.

\begin{tabular}{|c|c|c|c|c|}
\hline $\begin{array}{l}\text { Instruments } \\
\text { /Analysis }\end{array}$ & $\begin{array}{c}\text { Q.1\&2 } \\
\text { Korean } \\
\text { teachers' Beliefs } \\
\text { about Diversity }\end{array}$ & $\begin{array}{c}\text { Q.3 } \\
\text { Differences } \\
\text { between Personal } \\
\text { and Professional } \\
\text { Beliefs }\end{array}$ & $\begin{array}{c}\text { Q.4 } \\
\text { Factors that } \\
\text { influence } \\
\text { Teachers' } \\
\text { Beliefs }\end{array}$ & $\begin{array}{c}\text { Q.5 } \\
\text { Impacts of } \\
\text { Beliefs on } \\
\text { Practice }\end{array}$ \\
\hline \multirow{2}{*}{\multicolumn{5}{|c|}{$\begin{array}{l}\text { Personal } \\
\& \text { Professional } \\
\text { beliefs about } \\
\text { diversity Scales } \\
\text { Individual }\end{array}$}} \\
\hline & & & & \\
\hline $\begin{array}{l}\text { Statistical } \\
\text { analysis }\end{array}$ & $\begin{array}{l}\text { Frequency } \\
\text { analysis }\end{array}$ & $\begin{array}{l}\text { Paired samples } \\
t \text {-tests }\end{array}$ & $\begin{array}{l}\text { Multiple linear } \\
\text { regression tests }\end{array}$ & \\
\hline $\begin{array}{l}\text { Thematic } \\
\text { analysis } \\
\text { - Coding }\end{array}$ & & & & \\
\hline
\end{tabular}

Figure 2. Data collection instruments and analysis methods

\section{Quantitative Results}

For the first step of data analysis, I analyzed the Demographics and Experience Survey using descriptive statistics in an effort to explain the detail characteristics of the participants. Then, I analyzed quantitative data from the Personal and Professional Beliefs about Diversity Survey using SPSS statistics program. I calculated descriptive statistics such as percentages of agreement per item for both Personal and Professional beliefs about diversity scales to look at South Korean teachers' beliefs about diversity. Next, I ran paired samples $t$-test to identify if a difference exists between teachers' personal and professional beliefs about diversity. Last, to examine the association of 
teachers' demographics, teaching and intercultural experiences, and their diversity beliefs, I conducted multiple linear regression tests.

\section{Demographic Description of Participants}

To identify the general characteristics of participants, I examined descriptive statistics from the Demographics and Experience Survey, which included public elementary school teachers from four different school districts in a Metropolitan city in south eastern Korea. There were 121 surveys returned; however, I excluded the 11 incomplete surveys, which left a sample of 110 surveys. I provided hard copies of the survey instrument to each participating teachers and they self- administered the survey during July to August 2015. In my study, all of participants were teachers.

In my study of 110 teachers, $83.6 \%(n=92)$ were female and $16.4 \%(n=18)$ were male. Their age ranges varied with $36.4 \%(n=40)$ between age 24 to 30 years old, $34.5 \%(n=38)$ between 31 to 40 years old, $16.4 \%(n=18)$ between 41 to 50 years old, and $12.7 \%(n=14)$ above 50 years old. In the Metropolitan city, among total 8,869 elementary school teachers, $82.0 \%(n=7,271)$ were female and $18.0 \%(n=1,598)$ were male. Teachers' age range was $15.7 \%(\mathrm{n}=1,390)$ below 30 years old, $42.9 \%(\mathrm{n}=3,808)$ between 30 to 39 years old, $15.0 \%(n=1,332)$, and between 40 to 44 years old (Korean Educational Statistics Service, 2015). So, the gender and age range of participating teachers were roughly equivalent to those in the city as a whole.

As for teaching experiences, $32.7 \%(n=36)$ taught less than 5 years, $25.5 \%(n=$ 28 ) taught 5 to 10 years, $16.4 \%(n=18)$ taught 11 to 15 years, $6.4 \%(n=7)$ taught 16 to 20 years, and $19.1 \%(n=21)$ taught above 20 years. Concerning their multicultural 
education teaching experiences, $45.5 \%(n=50)$ of the teachers had experiences of working with multicultural students and $35.5 \%(n=39)$ of the teachers participated to one or more multicultural education training courses.

Regarding teachers' intercultural experiences, $36.4 \%(n=40)$ traveled abroad six and more times, 33.6\% $(n=37)$ traveled three to five times, $26.4 \%(n=29)$ traveled one to two times, and 3.6\% $(n=4)$ had not traveled overseas. As few as $11.8 \%(n=13)$ had experiences of living in foreign countries more than six months, and $31.8 \%(n=35)$ answered that they had intercultural experiences such as friendship with people from different countries. Descriptions about participants' demographic and educational and intercultural experiences are presented in Table 5.

In summary, the teachers were predominantly female (82.0\%) with a range of age and teaching years. Their experiences of working with multicultural students and multicultural training and intercultural friendships were also varied.

Table 5

Demographic Description of Participants

\begin{tabular}{ll}
\hline Descriptions & $\%$ of Teachers $(n=110)$ \\
\hline Gender & Female $=83.6 \%(n=92)$ \\
& Male $=16.4 \%(n=18)$ \\
Age & $24-30 \mathrm{yrs}=36.4 \%(n=40)$ \\
& $31-40 \mathrm{yrs}=34.5 \%(n=38)$ \\
& $41-50 \mathrm{yrs}=16.4 \%(n=18)$ \\
& $51+\mathrm{yrs}=12.7 \%(n=14)$ \\
Years taught & $1-4 \mathrm{yrs}=32.7 \%(n=36)$ \\
& $5-10 \mathrm{yrs}=25.5 \%(n=28)$ \\
& $11-15 \mathrm{yrs}=16.4 \%(n=18)$ \\
& $16-20 \mathrm{yrs}=6.4 \%(n=7)$ \\
& $21+\mathrm{yrs}=19.1 \%(n=21)$
\end{tabular}




$\begin{array}{ll}\text { Experience of teaching multicultural students } & \begin{array}{l}\text { Yes }=45.5 \%(n=50) \\ \text { No }=54.5 \%(n=60)\end{array} \\ \text { Experience of multicultural teaching training } & \text { Yes }=35.5 \%(n=39) \\ & \text { No }=64.5 \%(n=71) \\ \text { Times traveled abroad } & 0 \text { times }=3.6 \%(n=4) \\ & 1-2 \text { times }=26.4 \%(n=29) \\ & 3-5 \text { times }=33.6 \%(n=37) \\ & 6+\text { times }=36.4 \%(n=40) \\ & \\ \text { Experience of living in foreign countries } & \text { Yes }=11.8 \%(n=13) \\ & \text { No }=88.2 \%(n=97) \\ \text { Intercultural experiences (e.g., intercultural } & \\ \text { friendship, study abroad.) } & \text { Yes }=31.8 \%(n=35) \\ \end{array}$

\section{Analysis of Data}

In this section, I describe the analysis of data from quantitative survey in four categories. I explain the different statistic tests in each category according to the purpose of analysis and the results using various tables and figures to help understanding.

Korean teachers' beliefs about diversity in personal contexts. The survey data showed that South Koreans teachers' beliefs about diversity in personal contexts varied. Teachers showed stronger agreement on particular diversity items and also revealed stronger disagreement on certain items. Table 6 displays the percentage of agreement for each item in Personal Beliefs about Diversity Scale. The test measures the level of agreement on specific diversity items by 5- point Likert scales: "Strongly Disagree," "Disagree," "Undecided," "Agree," "Strongly Agree."

The two items that had the highest level of agreement (Strongly Agree) were:

- Item 7: People should develop meaningful friendships with others from different racial/ethnic groups $(83.6 \%)$; and 
- Item 4: Accepting many different ways of life in Korea will strengthen us as a nation $(57.3 \%)$.

In contrast, the items that had the highest level of disagreement (Strongly Disagree) were:

- Item 8: People with physical limitations are less effective as leaders than people without physical limitations (69.1\%); and

- Item 11: Since men are frequently the heads of households, they deserve higher wages than females (60.9\%).

Table 6

Percentage of Agreement in the Personal Diversity Beliefs Scale

\begin{tabular}{|c|c|c|c|c|c|}
\hline \multirow{2}{*}{ Item } & \multicolumn{5}{|c|}{$\%(\mathrm{n})$} \\
\hline & SD & $\mathrm{D}$ & $\mathrm{U}$ & $\mathrm{A}$ & SA \\
\hline $\begin{array}{l}\text { 1. There is nothing wrong with people } \\
\text { from different racial backgrounds } \\
\text { having/raising children. }\end{array}$ & $1.8(2)$ & $11.8(13)$ & $17.3(19)$ & $31.8(35)$ & $37.3(41)$ \\
\hline $\begin{array}{l}\text { 2.* Korean immigrant and refugee policy } \\
\text { has led to the deterioration of Korea. }\end{array}$ & $20.9(23)$ & $23.6(26)$ & $32.7(36)$ & $18.2(20)$ & $4.5(5)$ \\
\hline $\begin{array}{l}\text { 3.* Making all public facilities accessible } \\
\text { to the disabled is simply too costly. }\end{array}$ & 49.1(54) & $27.3(30)$ & $11.8(13)$ & $9.1(10)$ & $2.7(3)$ \\
\hline $\begin{array}{l}\text { 4. Accepting many different ways of life } \\
\text { in Korea will strengthen us as a nation. }\end{array}$ & $2.7(3)$ & $3.6(4)$ & $6.4(7)$ & $30.0(33)$ & $57.3(63)$ \\
\hline $\begin{array}{l}\text { 5. } \text { It is not a good idea for same-sex } \\
\text { couples to raise children. }\end{array}$ & $18.2(20)$ & $10.0(11)$ & $21.8(24)$ & $22.7(25)$ & $27.3(30)$ \\
\hline $\begin{array}{l}\text { 6. }{ }^{*} \text { The reason people live in poverty is } \\
\text { that they lack motivation to get } \\
\text { themselves out of poverty. }\end{array}$ & $39.1(43)$ & $31.8(35)$ & $13.6(15)$ & $12.7(14)$ & 2.7(3) \\
\hline $\begin{array}{l}\text { 7. People should develop meaningful } \\
\text { friendships with others from different } \\
\text { racial/ethnic groups. }\end{array}$ & $0(0)$ & $0(0)$ & $2.7(3)$ & $13.6(15)$ & $83.6(92)$ \\
\hline $\begin{array}{l}\text { 8. People with physical limitations are } \\
\text { less effective as leaders than people } \\
\text { without physical limitations. }\end{array}$ & $69.1(76)$ & $22.7(25)$ & $5.5(6)$ & $2.7(3)$ & $0(0)$ \\
\hline $\begin{array}{l}\text { 9. }{ }^{*} \text { In general, Korean family places a } \\
\text { higher value on education than does } \\
\text { multicultural family. }\end{array}$ & $16.4(18)$ & $10.9(12)$ & $15.5(6)$ & $40.9(45)$ & $16.4(18)$ \\
\hline
\end{tabular}


10. Many women in our society continue to live in poverty because males still dominate most of the major social systems in Korea.

$\begin{array}{rrrrr}17.3(19) & 27.3(30) & 19.1(21) & 28.2(31) & 8.2(9) \\ 60.9(67) & 21.8(24) & 6.4(7) & 10.9(12) & 0(0) \\ & & & & \\ 2.7(3) & 6.4(7) & 14.5(16) & 36.4(40) & 40.0(44) \\ & & & & \\ 21.8(24) & 21.8(24) & 19.1(21) & 20.0(22) & 17.3(19) \\ & & & & \\ 8.2(9) & 20.9(23) & 22.7(25) & 28.2(31) & 20.0(22) \\ & & & & \\ 51.8(57) & 23.6(26) & 9.1(10) & 12.7(14) & 2.7(3)\end{array}$

11.* Since men are frequently the heads of households, they deserve higher wages than females.

12. It is a good idea for people to develop meaningful friendships with others having a different sexual orientation.

13.* Society should not become more accepting of gay/lesbian lifestyles.

14.* It is more important for immigrants to learn Korean than to maintain their first language.

15.* In general, men make better leaders

D" = "Strongly Disagree," "D"= "Disagree," "U"= Note. * Indicates negatively worded items. "SD" = "Strong
"Undecided," "A"= "Agree," "SA" = "Strongly Agree."

When combining "Strongly Agree" and "Agree" categories the majority of participating Korean teachers (97.2\%) agree with Item 7: It is meaningful to develop friendships with people from different racial/ethnic groups. It is also noticeable there was no disagreement with the importance of friendships with people from different racial backgrounds. The majority of teachers (87.3\%) also agree with Item 4: Accepting many different ways of life will strengthen Korea as a nation.

On the other hand, when combining "Strongly Disagree" and "Disagree," the majority of teachers disagreed with (a) Item 8: People with physical limitations are less effective as leaders than people without limitation (91.8\%), and (b) Item 11: Since men are frequently the heads of households, they deserve higher wages than females(82.7\%). Additionally, the most undecided response was for Item 2: Korean immigrant and refugee policy has led to the deterioration of Korea (32.7\%). 
Korean teachers' beliefs about diversity in professional contexts. Survey data indicated that South Koreans teachers' beliefs about diversity in professional contexts also varied. Table 7 displays the level of agreement in each diversity item in professional contexts.

The items that showed the highest level of agreement (Strongly Agree) were:

- Item 8: The attention girls receive in school is comparable to the attention boys receive $(70.9 \%)$;

- Item 4: Students and teachers would benefit from having a basic understanding of different religions $(61.8 \%)$;

- Item 14: Students from multicultural family can benefit socially from participating in integrated classrooms with Korean students (48.2\%); and

- Item 9: Tests particularly standardized tests have been used to sort students (e.g., high or low grades) $(47.3 \%)$.

Conversely, the items that revealed the highest level of disagreement (Strongly Disagree) were:

- Item 23: Students should not be allowed to speak a language other than Korean while in school $(68.2 \%)$;

- Item 5: Money spent to educate the severely disabled would be better spent on programs for gifted students $(64.5 \%)$; and

- Item 1: Teachers should not be expected to adjust their preferred mode of instruction to accommodate the needs of all students (41.8\%). 
Table 7

Percentage of Agreement in the Professional Diversity Beliefs Scale

\begin{tabular}{|c|c|c|c|c|c|}
\hline \multirow{2}{*}{ Item } & \multicolumn{5}{|c|}{$\%(\mathrm{n})$} \\
\hline & SD & $\mathrm{D}$ & $\mathrm{U}$ & A & SA \\
\hline $\begin{array}{l}\text { 1.* Teachers should not be expected to } \\
\text { adjust their preferred mode of } \\
\text { instruction to accommodate the needs } \\
\text { of all students. }\end{array}$ & $41.8(46)$ & $35.5(39)$ & $12.7(14)$ & $9.1(10)$ & $0.9(1)$ \\
\hline $\begin{array}{l}\text { 2. The traditional classroom has been set up } \\
\text { to support the middle-class lifestyle. }\end{array}$ & $6.4(7)$ & $15.5(17)$ & $25.5(28)$ & $40.0(44)$ & $12.7(14)$ \\
\hline $\begin{array}{l}\text { 3.* Gays and lesbians should not be allowed } \\
\text { to teach in public schools. }\end{array}$ & $34.5(38)$ & $22.7(25)$ & $12.7(14)$ & $14.5(16)$ & $15.5(17)$ \\
\hline $\begin{array}{l}\text { 4. Students and teachers would benefit from } \\
\text { having a basic understanding of } \\
\text { different (diverse) religions. }\end{array}$ & $0.9(1)$ & $0.9(1)$ & $10.9(12)$ & $25.5(28)$ & $61.8(68)$ \\
\hline $\begin{array}{l}\text { 5.* Money spent to educate the severely } \\
\text { disabled would be better spent on } \\
\text { programs for gifted students. }\end{array}$ & $64.5(71)$ & $21.8(24)$ & $7.3(8)$ & $2.7(3)$ & $3.6(4)$ \\
\hline $\begin{array}{l}\text { 6. All students should be encouraged to } \\
\text { become fluent in one foreign language. }\end{array}$ & $14.5(16)$ & $23.6(26)$ & $18.2(20)$ & $27.3(30)$ & $16.4(18)$ \\
\hline $\begin{array}{l}\text { 7. Schools serving multicultural students } \\
\text { need a racially, ethnically, and } \\
\text { culturally diverse staff and faculty. }\end{array}$ & $7.3(8)$ & $15.5(17)$ & $18.2(20)$ & $34.5(38)$ & $24.5(27)$ \\
\hline $\begin{array}{l}\text { 8. The attention girls receive in school is } \\
\text { comparable to the attentions boys receive. }\end{array}$ & $1.8(2)$ & $1.8(2)$ & $6.4(7)$ & 19.1(21) & $70.9(78)$ \\
\hline $\begin{array}{l}\text { 9. Tests, particularly standardized tests have } \\
\text { been used to sort students (e.g., high or } \\
\text { low grades). }\end{array}$ & $3.6(4)$ & $4.5(5)$ & $7.3(8)$ & $37.3(41)$ & $47.3(52)$ \\
\hline $\begin{array}{l}\text { 10.* People from diverse culture and races } \\
\text { are adequately represented in most } \\
\text { textbooks today. }\end{array}$ & $10.9(12)$ & $31.8(35)$ & $23.6(26)$ & $28.2(31)$ & $5.5(6)$ \\
\hline $\begin{array}{l}\text { 11. Students with physical limitations } \\
\text { should be placed in the regular } \\
\text { classroom whenever possible. }\end{array}$ & $3.6(4)$ & $10.9(12)$ & $28.2(31)$ & $44.5(49)$ & $12.7(14)$ \\
\hline $\begin{array}{l}\text { 12. Males are given more opportunities in } \\
\text { math and science than females. }\end{array}$ & 19.1(21) & $30.0(33)$ & $20.0(22)$ & $19.1(21)$ & $11.8(13)$ \\
\hline $\begin{array}{l}\text { 13.* Generally, teachers should group } \\
\text { students by ability levels. }\end{array}$ & $22.7(25)$ & $33.6(37)$ & $24.5(27)$ & $18.2(20)$ & $0.9(1)$ \\
\hline $\begin{array}{l}\text { 14. Students from multicultural family can } \\
\text { benefit socially from participating in } \\
\text { integrated classrooms with Korean }\end{array}$ & $0(0)$ & $1.8(2)$ & $10.0(11)$ & $40.0(44)$ & $48.2(53)$ \\
\hline
\end{tabular}


15. Historically, education has been monocultural, reflecting only one reality and has been biased toward the dominant (Korean) group.

$$
0.9(1) \quad 5.5(6) \quad 10.0(11) \quad 54.5(60) \quad 29.1(32)
$$

16. Whenever possible, students from multicultural family should receive instruction in their first language until they are proficient enough to learn via Korean instruction.

17. Teachers often expect less from students from the lower socioeconomic class.

$\begin{array}{rrrrr}5.5(6) & 13.6(15) & 33.6(37) & 32.7(36) & 14.5(16) \\ & & & & \\ 21.8(24) & 20.0(22) & 16.4(18) & 34.5(38) & 7.3(8) \\ & & & & \\ 10.9(12) & 16.4(18) & 24.5(27) & 33.6(37) & 14.5(16) \\ & & & & \\ 7.3(8) & 28.2(31) & 43.6(48) & 12.7(14) & 8.2(9) \\ & & & & \\ 14.5(16) & 34.5(38) & 29.1(32) & 15.5(17) & 6.4(7) \\ & & & & \\ 0.9(1) & 3.6(4) & 17.3(19) & 41.8(46) & 36.4(40)\end{array}$
experience working with students from diverse racial and ethnic backgrounds.

22. Students from lower socioeconomic backgrounds typically have fewer educational opportunities than their middle-class peers.

23.* Students should not be allowed to speak a language other than Korean while in school.

$\begin{array}{rrrrr}4.5(5) & 10.9(12) & 11.8(13) & 32.7(36) & 40.0(44) \\ 68.2(75) & 24.5(27) & 4.5(5) & 2.7(3) & 0(0) \\ 0.9(1) & 2.7(3) & 11.8(13) & 30.0(33) & 54.5(60)\end{array}$

24. It is important to consider religious diversity in setting public school policy.

25.* Multicultural education is less important than reading, writing, arithmetic, and computer literacy. $24.5(27) \quad 35.5(39) \quad 26.4(29) \quad 11.8(13) \quad 1.8(2)$

Note. * Indicates negatively worded items. "SD" = "Strongly Disagree," "D"= "Disagree," "U"= "Undecided," "A"= "Agree," "SA" = "Strongly Agree."

When combining "Strongly Agree" and "Agree" categories, the majority of teachers agreed that (a) Item 8: Girls receive comparable attention to boys in school (90\%); (b) Item 14: It is socially beneficial for multicultural students to participate in 
integrated classrooms (88.2\%); and (c) Item 4: the understandings about diverse religions would benefit students and teachers $(87.3 \%)$.

Then, when combining "Strongly Disagree" and "Disagree," the majority of teachers disagreed that (a) Item 23: students should not speak a language other than Korean in school (92.7\%); (b) Item 5: money for education for the severely disabled would be better spent for gifted students (86.3\%); and (c) Item 1: teachers should not adjust their preferred mode of instruction to fulfill the needs of all students (77.3\%).

Additionally, the most undecided responses were for Item 19: More women are needed in administrative positions in schools (43.6\%). Another item with high percentage of undecided responses was Item 16: Students from multicultural family should receive instruction in their first language until they are proficient enough to learn via Korean instruction (33.6\%).

\section{The difference between teachers' beliefs in personal and professional}

contexts. To discover the difference between Korean teachers' personal and professional beliefs about diversity, I conducted a paired samples $t$-test. Before I ran the $t$-test, negatively worded items were reverse-coded and a sum score was calculated for each individual on the personal and professional scales. Because the data from the scales are categorical, not continuous, I chose to compute the sum score on each personal scale and professional scale instead of a mean score.

As seen in the Table 8, the average sum scores for Personal and Professional Diversity Scales were 0.74 and 0.73 , respectively, which means the two mean scores were virtually equivalent and comparable each other. 
Table 8

Paired Samples Statistics of Individual Personal and Professional Scales Sum

\begin{tabular}{llcccr}
\hline & Mean & N & Std. Deviation & Std. Error Mean \\
\hline Pair 1 & individual personal sum & .7406 & 110 & .11051 & .01054 \\
& individual professional sum & .7335 & 110 & .07686 & .00733 \\
\hline
\end{tabular}

Table 9 shows the correlation for individual teacher's sum scores on the two tests was 0.563 , which indicates a positive and moderately strong correlation.

Table 9

Paired Samples Correlations of Individual Personal and Professional Scales Sum

\begin{tabular}{llccr}
\hline & & $\mathrm{N}$ & Correlation & Sig. \\
\hline Pair 1 & $\begin{array}{l}\text { individual personal sum \& individual } \\
\text { professional sum }\end{array}$ & 110 & .563 & .000 \\
\hline
\end{tabular}

The correlation of personal and professional scales was also confirmed visually in Figure 3. The association was relatively strong upward linear, which was consistent with the output that we see from Table 9. It indicates that two diversity beliefs scales' sum scores were positively/ moderately correlated. In other words, a teacher who has a lower sum score on the personal scale also showed a lower score on the professional scale. Conversely, a teacher who scored a higher score on personal scale also showed a higher score on the professional scale. 


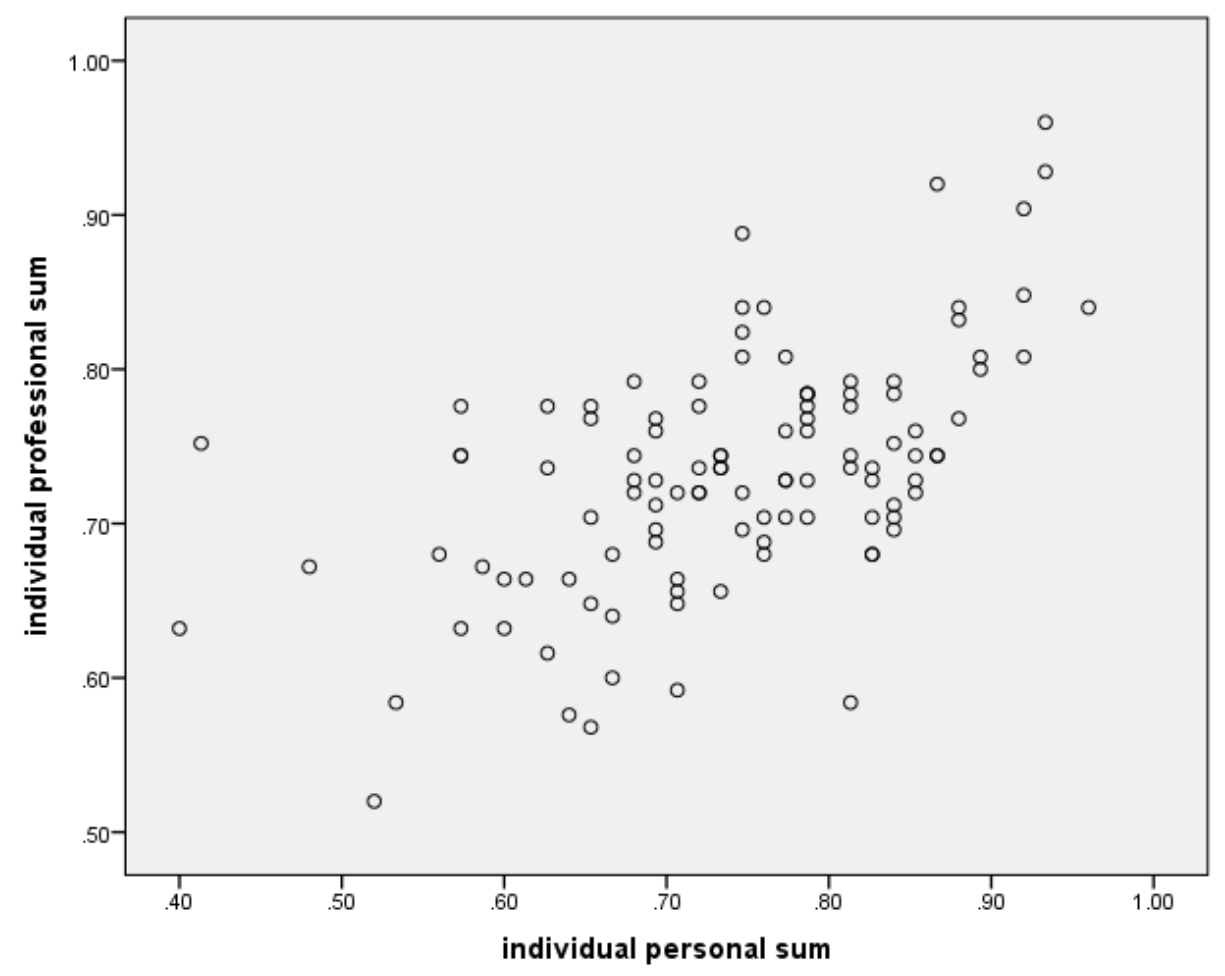

Figure 3. A visual display of correlation between personal and professional sum scores

Although there was a moderately strong correlation between the sum scores on the personal and professional scales, in terms of statistical significance, the paired samples $t$ test indicated that the sum score differences were not statistically significant $[t(109), p=$ 0.419] because the $p$-value was greater than $\alpha$-level of 0.05 (see Table 10). In my study, the $t$-test used an alpha level of 0.05 which is generally accepted in the social science field. 
Table 10

Paired Samples t-Test of Individual Personal and Professional Scales Sum

\begin{tabular}{|c|c|c|c|c|c|c|c|c|c|}
\hline & & \multicolumn{5}{|c|}{ Paired Differences } & \multirow{3}{*}{$\mathrm{t}$} & \multirow{3}{*}{ df } & \multirow{3}{*}{$\begin{array}{l}\text { Sig. } \\
(2- \\
\text { tailed })\end{array}$} \\
\hline & & \multirow[t]{2}{*}{ Mean } & \multirow{2}{*}{$\begin{array}{c}\text { Std. } \\
\text { Deviation }\end{array}$} & \multirow{2}{*}{$\begin{array}{l}\text { Std. } \\
\text { Error } \\
\text { Mean }\end{array}$} & \multicolumn{2}{|c|}{$\begin{array}{l}95 \% \text { Confidence } \\
\text { Interval of the } \\
\text { Difference }\end{array}$} & & & \\
\hline & & & & & Lower & Upper & & & \\
\hline Pair 1 & $\begin{array}{l}\text { individual } \\
\text { personal sum - } \\
\text { individual } \\
\text { professional } \\
\text { sum }\end{array}$ & .00715 & .09253 & .00882 & -.01033 & .02464 & .811 & 109 & .419 \\
\hline
\end{tabular}

The influence of demographics and experiences on teachers' beliefs. To

examine the association between the teachers' demographics, teaching and intercultural experiences and their personal and professional beliefs about diversity, I conducted a multiple linear regression test. In the test, demographics and experiences variables included age, gender, the number of years taught, multicultural education experience, multicultural education training experience, friendship with foreigners, traveling abroad experience, and living abroad experience. In regression with multiple independent variables (demographics and experiences), the coefficient indicates how much the dependent variables are (teachers' diversity beliefs sum score) expected to increase when the independent variable increases by one, in the condition when all the other independent variables are controlled.

After calculating the coefficient scores for teachers' personal beliefs about diversity, I displayed the results in Table 11. As seen in the table, the two most 
significant predictors for teachers' personal diversity beliefs were "gender" and "frequency of traveling abroad."

The coefficient for gender is 0.77 which was statistically significant $(p=0.016)$. Table 11 shows female teachers had a positive coefficient number, which means that female teachers had higher scores on the personal diversity test than their comparison group of male teachers.

Another factor that was revealed as statistically significant was "frequency of traveling abroad." The reference group in this analysis was the group of teachers who travelled abroad six times and more. All groups that traveled less than the reference group had negative coefficient scores: the coefficient scores for the group had no travel abroad experience, traveled 1-2 times, and traveled 3-5 times were $-1.45,-0.37$, and -0.35 , respectively. However, the coefficient scores for groups traveled 1-2 times and 3-5 times are comparable with the reference group. It indicates that generally, the teachers who travelled less tend to have lower scores on the personal diversity test. Particularly, the coefficient for the group of teachers with no experience of traveling abroad was -1.45 and it was statistically significant $(p=0.026)$. The negative coefficient number suggests the teachers with no experience of travelling abroad were expected to have lower scores on the personal scale than the teachers in the reference group and it was statistically significant. Additionally, it was revealed that the frequency of traveling abroad did not make a significant difference but presence or absence of the experience mattered more. 
In summary, the multiple linear regression analysis showed that teachers' gender and traveling abroad experience were important factors that affect their personal beliefs about diversity.

Table 11

Regression Coefficient for Personal Beliefs Sum Score

\begin{tabular}{lrrr}
\hline Variables & Coefficient & (Standard Error) & $p$-value \\
\hline Age & & & \\
$\quad$ age 31-40 & .013 & $.037)$ & .724 \\
$\quad$ age 41-50 & -.067 & $(.059)$ & .265 \\
$\quad$ age 50+ & -.082 & $(.067)$ & .226 \\
Gender & & & \\
$\quad$ female=1 & .077 & $(.031)$ & .016 \\
Years taught & & & \\
$\quad$ tchyr 5-10 & .008 & $(.035)$ & .814 \\
$\quad$ tchyr 11-15 & .006 & $(.047)$ & .902 \\
$\quad$ tchyr 16-20 & .061 & $(.065)$ & .354 \\
$\quad$ tchyr 20+ & .043 & $(.021)$ & .521 \\
Multicultural Ed Experience=1 & .002 & $(.023)$ & .923 \\
Multicultural Ed Training=1 & .002 & $(.027)$ & .914 \\
Friendship with foreigners=1, & -.049 & & .078 \\
Frequency of traveling abroad & & $(.064)$ & .026 \\
$\quad$ trvltimes 0 & -.145 & $(.032)$ & .261 \\
trvltimes 1-2 & -.037 & $(.029)$ & .222 \\
trvltimes 3-5 & -.035 & $(.036)$ & .319 \\
Experience of living abroad=1 & .036 & & \\
\hline
\end{tabular}

I ran another multiple linear regression test to examine the association between teachers' professional beliefs about diversity and their demographics and experiences. I calculated the coefficient scores for teachers' professional beliefs about diversity, which are seen in Table 12. Table 12 shows the correlation coefficient for gender and professional belief about diversity was 0.51 , which was one statistically significant 
predictor for teachers' professional diversity beliefs $(p=0.022)$. In other words, female teachers scored higher on the professional scale as well as on the personal scale than their counterpart male teachers.

While it was not statistically significant because the $p$-value $(p=0.052)$ is slightly above the threshold level of 0.05 , "number of years taught" appeared to capture the relationship between teachers' professional beliefs about diversity and years taught.

Particularly, the teachers who taught for 15-20 years showed highest coefficient score of 0.090 when compared to the reference group of teachers who taught less than five years. Interestingly, those teachers who taught more than 20 years showed a lower coefficient score than teachers who taught $15-20$ years. The multiple linear regression test revealed that generally, teachers who had more teaching experiences tended to have higher scores on the professional scales.

Table 12

Regression Coefficientfor Professional Beliefs Sum Score

\begin{tabular}{lrrr}
\hline Variables & Coefficient & (Standard Error) & $p$-value \\
\hline Age & $-2.353 \mathrm{E}-5$ & $(.026)$ & .999 \\
$\quad$ age 31-40 & -.052 & $(.042)$ & .220 \\
$\quad$ age 41-50 & -.060 & $(.047)$ & .206 \\
$\quad$ age 50+ & & & .022 \\
Gender & .051 & $(.022)$ & \\
$\quad$ female=1 & & & .257 \\
Years taught & .038 & $(.033)$ & .755 \\
tchyr 5-10 & .008 & $(.025)$ & .052 \\
tchyr 11-15 & .090 & $(.046)$ & .194 \\
tchyr 16-20 & .061 & $(.047)$ & .487 \\
tchyr 20+ & -.010 & $(.015)$ & .310 \\
Multicultural Ed Experience=1 & .017 & $(.016)$ &
\end{tabular}


Friendship with foreigner=1

Frequency of traveling abroad trvltimes 0

trvltimes $1-2$

trvltimes 3-5

Experience of living abroad $=1$
.001

$(.019)$

$-.036$

$-.013$

.015

.027
.960

.429

.574

.454

.283

To compare the overall strength of the association of teachers' experience variables and personal and professional beliefs, I calculated $\mathrm{R}^{\mathbf{2}}$ for both scales. $\mathrm{R}^{\mathbf{2}}$ is the proportion of variance in the dependent variable (Personal and Professional Diversity Beliefs sum scores) that can be explained by the independent variables (demographics and experience variables). The corresponding $\mathrm{R}^{2}$ for independent variables (demographics and experience variables) and personal beliefs was 0.231 . The $\mathrm{R}^{2}$ value of 0.231 indicates $23.1 \%$ of the variance in the teachers' personal diversity beliefs score can be explained by the demographics and experience variables taken into account in this analysis. Additionally, from regression analysis corresponding $\mathrm{R}^{2}$ for professional beliefs sum score was calculated to 0.210 , which indicating $21.0 \%$ variance in the teachers' professional diversity beliefs scale score can be explained by the demographics and experience variables considered in this test.

Thus, the variables used in the study such as age, gender, teaching years, multicultural education experiences, multicultural education raining experiences, frequency of travelling abroad, and friendship with foreigners accounted for slightly more of teachers' personal diversity beliefs (23\%) than their professional beliefs $(21 \%)$. Nevertheless, those demographics and experiences variables were accountable for only $21 \%$ to $23 \%$ of teachers' beliefs about diversity. 
In summary, through multiple linear regression tests, I found "gender," "traveling abroad experience," and "teaching years" were important predictors for teachers' beliefs about diversity in personal and professional contexts. Particularly, female teachers who taught for 15-20 years and traveled abroad 6 and more times scored higher on the personal and professional scales than teachers in other comparing group. Additionally, the $\mathrm{R}^{2}$ score of roughly $20 \%$ indicated that $20 \%$ of variance in teachers' beliefs about diversity can be explained by the variable that considered in this analysis.

\section{Interpretation of Findings}

In the previous analysis section, first, I reported my analyses of data using frequency counts to examine teachers' beliefs about diversity in personal and professional contexts. Next, using paired samples $t$-test, I analyzed data to investigate if there exists a difference in teachers' personal and professional diversity beliefs. Then, I ran multiple linear regression tests to look at the influences of teachers' demographics and experiences on diversity beliefs. In this section, I interpret the findings by evidence and address and connect them to my research questions.

Korean teachers' beliefs about diversity. Personal and Professional Diversity Scales were designed to examine the level of acceptance or openness to diversity issues in personal and professional, in other words, educational contexts (Pohan \& Aguilar, 2001). According to Pohan and Aguilar (2001), low scores on the scales indicated general intolerance of diversity, while higher scores reflected acceptance or openness of diversity issues. Employing Pohan and Aguilar's interpretation of scores, I interpreted the findings from quantitative data analysis. Particularly, because some items in both 
scales are negatively worded, for the interpretation, I marked and interpreted those items inversely. The negatively worded items are marked with an asterisk in the following explanation. Thus, a negatively worded item that shows high score indicates low acceptance or intolerance about a diversity issue.

Teachers' beliefs about diversity in personal and professional contexts varied. On some diversity issues, teachers were more accepting, while on other issues they were less accepting. In the following, an asterisk indicates the negatively worded items, so those items were inversely interpreted. I defined "higher levels of acceptance" using the combined scores of "Strongly Agree" and "Agree" for each item and using the combined scores of "Strongly Disagree" and "Disagree" in the negatively worded items. For the interpretation of the lower levels of acceptance, I used the combined scores of "Strongly Disagree" and "Disagree" and the combined scores of "Strongly Agree" and "Agree" in the negatively described items.

On Personal Diversity Scale, the three items that showed the higher levels of acceptance were: (a) Item 7: People should develop meaningful friendships with others from different racial/ethnic groups (97.2\%); (b) Item $8^{*}$ : People with physical limitations are less effective as leaders than people without physical limitation (91.8\%); and (c) Item 4: Accepting many different ways of life in Korea will strengthen us as a nation (87.3\%). (The * refers to negatively stated items).

On the other hand, the three items that scored lower levels of acceptance were: (a) Item $9^{*}$ : In general, a Korean family places a higher value on education than does a multicultural family $(57.3 \%)$; Item $5^{*}$ : It is a good idea for same-sex couples to raise 
children (50.0\%); and Item 14*: It is more important for immigrants to learn Korean than to maintain their first language $(48.2 \%)$.

Thus, I interpret the results to mean that teachers were more accepting of the diversity issues regarding (a) friendships with people from different racial/ethnic backgrounds, (b) physical limitations as not limiting leaders' effectiveness, and diverse ways of life in Korea strengthen us as a nation. I also conclude that teachers were less accepting of diversity issues that (a) multicultural family values education as much as Korean family does; (b) it is ok for same-sex couples to raise children; and (c) it is important to maintain first language in addition to learn Korean.

Concerning the professional scale, teachers' acceptance of diversity items was also varied. The items on which teachers showed higher level of acceptance were (a) Item $23^{*}$ : Students should not be allowed to speak a language other than Korean while in school (92.7\%); (b) Item 8: The attention girls receive in schools is comparable to attentions boys receive (90.0\%); and (c) Item 14: Students from multicultural family can benefit socially from participating in integrated classrooms with Korean students (88.2\%).

On the other hand, the items that scored lower level of acceptance were (a) Item 12: Males are given more opportunities in math and science than females (49.1\%); (b) Item 20: Large number of multicultural students is improperly placed in special education class by school personnel (49.0\%); and (c) Item $18^{*}$ : Multicultural education is most beneficial for students from multicultural family (48.1\%).

Thus, from these results, I conclude that teachers were more accepting of diversity issues when (a) using a language other than Korean in school; (b) giving attention that 
girls receive in schools; (c) integrating classrooms with Korean and multicultural students. In addition, I interpret the results to mean that that teachers were less accepting of diversity issues regarding (a) more opportunity given to males in math and science; (b) improper placement of multicultural students; (c) multicultural education that benefit all students.

Additionally, teachers showed the most undecided responses concerning Korean refugee policy (32.7\%) in personal contexts and regarding women in administration positions in school (43.6\%) in professional contexts. I interpret the results to mean that Korean teachers were unable or unwilling to express an opinion about issues related to government and school administration. The inability or unwillingness of these teachers may have been influenced by Korean hierarchical culture in school and in nation overall. Now, I connect the findings to my research questions

Diversity in personal contexts. With respect to Research Question 1, what are South Korean teachers' beliefs about diversity in personal contexts, teachers' beliefs about diversity were varied. Teachers were more accepting of issues regarding friendships across racial/ethnic backgrounds, physical limitations in effective leaders, and accepting diverse ways of life in Korea. On the other hand, teachers were less accepting of issues concerning multicultural family's equally valuing education, same-sex couples as parents, and multicultural students' maintenance of first language.

Diversity in professional contexts. Regarding to Research Question 2, what are South Korean teachers' beliefs about diversity in professional contexts, teachers' beliefs about diversity were as varied as they were in personal contexts. Teachers were more 
accepting of diversity issues regarding using other languages than Korean in school, attention that girls receive in schools and integrated classrooms with Korean and multicultural students. On the contrary, teachers were less accepting of issues concerning more opportunity given to males in math and science, improper placement of multicultural students, and multicultural education that benefit all students.

\section{Differences between teachers' beliefs in personal and professional contexts.}

For Research Question 3, how do South Korean teachers' beliefs about diversity differ between personal and professional context, I conducted a paired samples $t$-test to examine if difference exists between teachers' beliefs in personal and professional contexts. The $t$-test calculated the mean scores for the sum of personal and professional scales as 0.74 and 0.73 , respectively. The correlation for individual teacher's sum score on the two scales was 0.563 and it was statistically significant $(p<0.001)$. The results indicated that the average sum scores for personal beliefs and professional belief scales were equivalent and comparable each other and the two mean scores had positive and moderately strong correlation. That is to say, the results suggest that teachers scored higher on the personal scale also scored higher on the professional scale. Conversely, teachers scored lower on the personal scale also scored lower on the professional scale. Thus, I interpret the results to mean that teachers more accepting of diversity issues in the personal context are more accepting of diversity in the professional context as well. In other words, teachers who are more culturally responsive in their personal sphere also are more culturally responsive within the setting of schooling. 
Influence of demographics and experiences on teachers' beliefs. For Research

Question 4, how do South Korean teachers' beliefs about diversity differ based on their demographics, and teaching and intercultural experiences, I ran multiple linear regression tests. The results indicated that certain demographics and experiences more positively influence teachers' beliefs about diversity on both personal and professional scales. Gender was a significant factor that predicts teachers' beliefs about diversity on both personal $(p=0.016)$ and professional $(p=0.022)$ scales. Female teachers were more positively accepting of diversity issues than male teachers.

Traveling abroad experience was a significant factor that influences teachers' beliefs about diversity in personal context, not in professional context. When comparing each group who traveled at least one time and more with the reference group who traveled more than six times, the coefficient for each group were comparable. However, I found the group who had no travel experience showed significantly lower coefficient score than the reference group, which was statistically significant. In other words, when compared to teachers who traveled more than six times, while holding all other variables constant, those who have never traveled abroad were expected to have a significantly lower personal beliefs sum score $(p=0.026)$. I interpret the results that teachers who had no travel abroad experience were less positive about diversity issues comparing teachers who had travel experiences. Also, I take the results to mean that what makes a difference in teachers' personal diversity beliefs is not the frequency of traveling abroad, but whether existence or absence of traveling abroad. Put differently, one time traveling abroad experience possibly makes a change in their beliefs. 
Last, the number of years taught also was an important predictor that influences teachers' beliefs in professional context. Even though it was not statistically significant $(p=0.052)$, teachers who taught for $15-20$ years scored the highest coefficient score among comparison groups. So, I concluded that teachers who taught for more years tended to be more accepting of diversity issues in professional context than teachers who taught for fewer years. Teachers who taught for more than 20 years also showed a higher coefficient score than teachers who taught for fewer years. However, interestingly, they showed a lower coefficient score than teachers those who taught for 15-20 years. One possible explanation for this might be 15-20 years in a teaching career is the time for teachers to be most enthusiastic and professional about teaching including multicultural education however, after 20 years teachers tend to be less enthusiastic and open-minded. Another explanation can be the teachers with 20 years and more teaching experiences are the generation of more conservative culture. Their conservative attitude might be reflected on their beliefs about diversity.

Additionally, I calculated $\mathrm{R}^{2}$ for both scales to compare the overall strength of the association of teachers' experience variables and personal and professional beliefs. $\mathrm{R}^{2}$ for demographics and experiences and personal and professional beliefs were 0.231 and 0.210 , respectively. The result indicated that $23.1 \%$ and $21.0 \%$ of the variance in the teachers' personal and professional beliefs score can be explained by the demographics and experience variables used in this analysis. Thus, $\mathrm{R}^{2}$ score of roughly $20 \%$ suggests that more variables that influence teachers' beliefs exist and more variables need to be taken into account to understand teachers' beliefs about diversity. 
In sum, with regard to Research Question 4, how do South Korean teachers' beliefs about diversity differ based on their demographics, and teaching and intercultural experiences, teachers' beliefs about diversity differ by certain demographics and teaching and intercultural experiences. Gender was a significant factor on both personal and professional scales: female teachers were more positively accepting of diversity issues than male teachers. Traveling abroad experience was a significant factor on personal scale: generally, teachers who traveled abroad more were more accepting of diversity. The number of years taught also was an important predictor on the professional scale: generally, teachers who taught for more years were more accepting of diversity issues than teachers who taught for fewer years.

\section{Qualitative Results}

In the second phase of my study, I collected qualitative data through interviews. I interviewed six Korean teachers who were teaching in public elementary schools. I used convenient sampling to select the interviewees from the pool of total survey participants. The interviewees were all female teachers and their teaching years varied from 5 years to 30 years. I conducted the interviews in an effort to: (a) investigate if and how Korean teachers' experiences might influence their beliefs about diversity; (b) examine if and how teachers' beliefs impact their practice of multicultural education; (c) explore challenges and supports for multicultural education. I also asked teachers additional questions regarding their multicultural education experiences and multicultural teacher education program. Those additional questions helped me to understand specific situations in Korean multicultural education contexts and to elaborate ideas to support teachers in multicultural teacher education programs. Regarding the teacher education 
programs, I focused on inservice teacher education programs more than preservice teacher education programs; because the ultimate purpose of this study was provide inservice teachers with support to improve their multicultural education practice.

The interviews were conducted through internet calls during January 2016 and were recorded in my phone using a recording application. I conducted an interview with each teacher that created six files of the recording. In the next section, I explain how I developed codes and formed categories through coding process to analyze my interview data. I also explain each step of analysis process and present the codes and categories that I developed. Then, I describe the themes from the analysis process in detail and include verbatim quotes from interview data. In each theme, I eventually connect the findings to my research questions. Particularly, Research Question 4 and 5 are answered by the qualitative results. Finally, I present a bigger picture of what I learn from the themes.

\section{Analysis of Data}

When all interviews were complete, I transcribed the entire interview into Korean because all interviews were conducted in Korean. As Seidman (2013) noted, because teachers' thoughts are embodied in their words, I transcribed their words as fully as possible. I kept the Korean transcriptions for the initial analysis steps, such as marking and creation of initial codes. I chose to use Korean for my initial analysis because I wanted to keep the original sense of Korean words and sentences that interviewees spoke. Once initial codes were formed, I translated them into English and all the subsequent processes were conducted in English. 
Concerning the process of analysis, I followed a qualitative data analysis process suggested by Seidman (2013). The general process of qualitative data analysis is summarized in Figure 4.

For the first step, I read through the interviews multiple times to marked the passages which were interesting and meaningful to me. Then, I labeled passages tentatively with in vivo terms, or words suggest category or subject, or words summarizing the passages, which became my initial codes. I read through the marked passages and initial codes again, revised the codes, and regrouped them as needed. Then, I put the excerpt from transcripts into categories. Under each category, I filed excerpts with codes that matched. Seidman (2013) referred to this process of analysis as classifying or coding. The list of categories and codes from my interview data are found in Appendix F. 


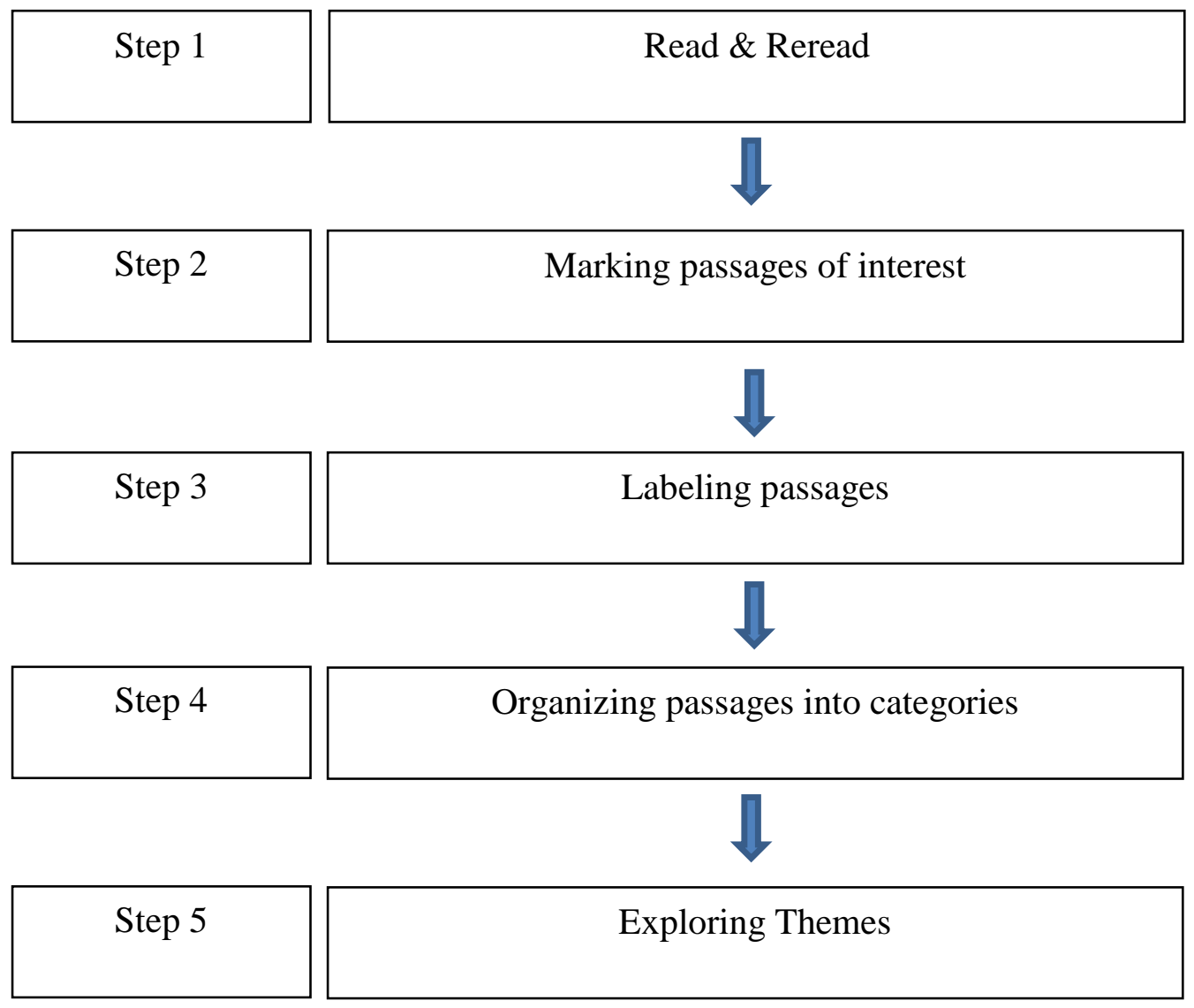

Figure 4. Qualitative data analysis suggested by Seidman (2013)

Finally, I identified five themes through examining the recurring patterns in the categories and excerpts and looking at the relationships and sequences between categories. The identified themes are displayed in Figure 5. 


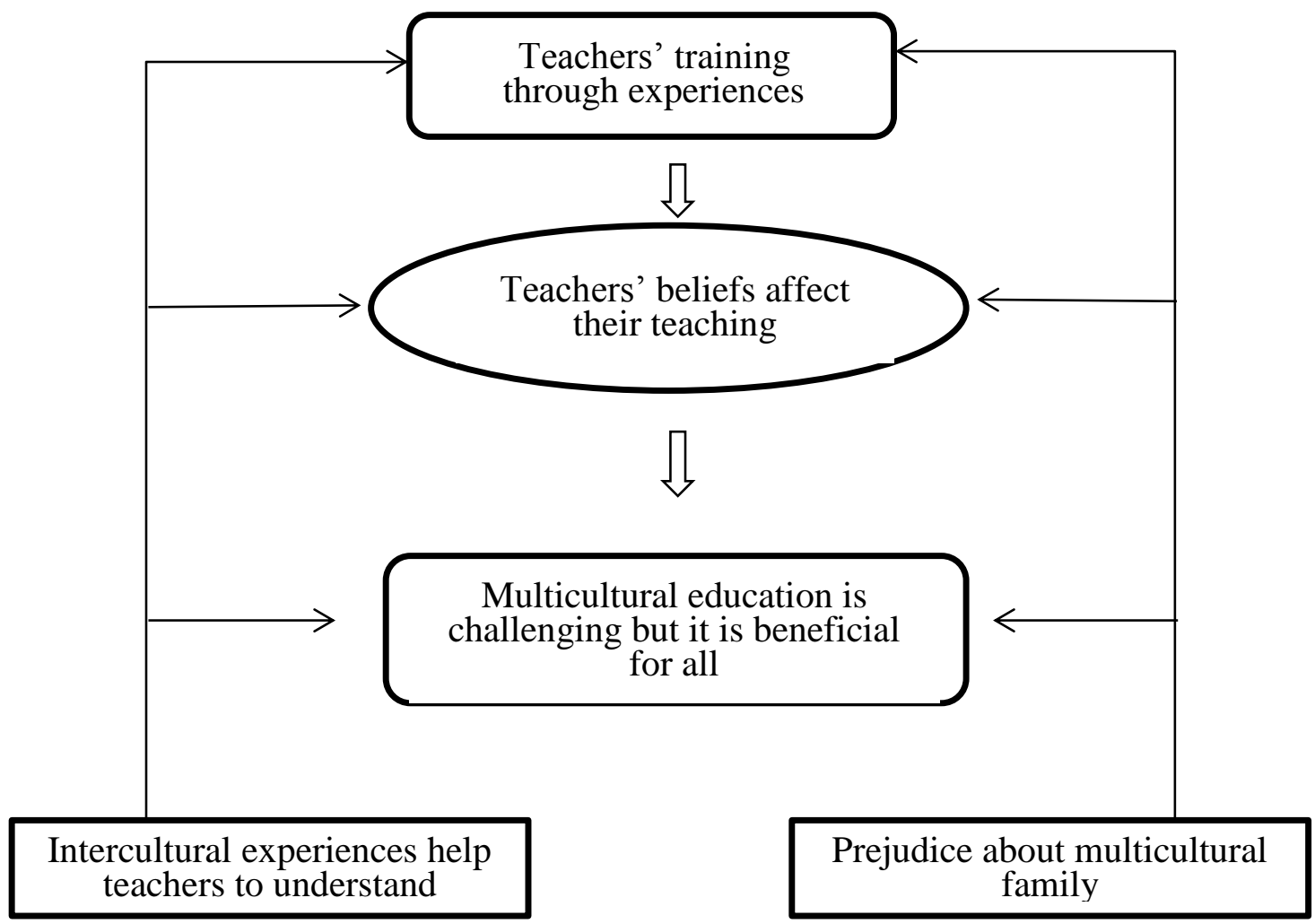

Figure 5. Themes identified from qualitative data analysis

Categories developed from qualitative analysis. In this section, I describe the six categories developed from my analysis of the quantitative data: (a) teachers' experiences with multicultural family, (b) effects of intercultural experiences, (c) the impact of teachers' beliefs on multicultural education, (d) challenges in multicultural education, (e) how to support multicultural education, and (f) teacher education program. Then, I explain and support each of these categories with verbatim quotes from the interviewees.

To assure interviewee confidentiality, I assigned each a pseudonym: (a) interviewee one-Ms. Choi, (b) interviewee two-Ms. Joo, (c) interviewee three-Ms. Lee, 
(d) interviewee four-Ms. Park, (e) interviewee five-Ms. Kim, (f) interviewee six-Ms.

Cho.

Teachers' experiences with multicultural family. To begin, I describe teachers' experience with multicultural family and students. What the teachers saw, heard, and experienced with multicultural families varied but were relatively negative. Two teachers explained that Koreans generally have a spectrum of racial preference. For example, Koreans treat white Westerners with favor but discriminate against South East Asian immigrants. To explain, four teachers stated that multicultural families whose parents are mainly South East Asian immigrants were trying to hide their identity as multicultural people. Ms. Joo commented about a multicultural family who changed their family name and did not want to be registered as multicultural family in school even though there are benefits given to a multicultural student. Ms. Joo added, "In Gyeonggi province where multicultural families are common, I didn't meet anyone who hid their identity. ... Maybe because this is a conservative city?" Ms. Choi also shared one story related to the identity issue:

(In our school) there were twin girls who graduated last year. They looked different and spoke (Korean) a bit differently because their mom was from South East Asia. You know, there are lots of benefits for multicultural students in school. However, they insisted that they are not multicultural family until they graduated. I think they thought that there would be some discrimination if they appeared like a South East Asian. I think there exists discrimination against them, even though we (teachers) treated them equally (as we do to Korean students).

Although the parents are not South East Asians, some students still tried to hide their identity as a multicultural student. Ms. Park shared the interesting and rather surprising story of Alice with me. Alice was a third grader whose father was a white American and 
mother was Japanese. Even though Alice's English was much better than her classmates, she would not show it. Ms. Park said:

(In English class) Although Alice knows a certain vocabulary, she avoids letting people know that she knows. What my native teacher said about her was that "Alice pretends that she is a Korean." So, I think Alice found it was embarrassing that she alone knows English when all other (Korean) kids do not.

These teachers' stories indicate that multicultural students and their families do not want to reveal their identity as foreigners but want to be treated equally as Koreans.

Related to the identity issue, four interviewees reported that multicultural students were experiencing prejudice and discrimination from their peer students and other. As for the main reason for multicultural students' exclusion in their class, five teachers spoke of the language issue, that is, their lack of fluency in Korean. Teachers connected the language issue to multicultural students' low academic performance and to the exclusion from their peer group. Ms. Park spoke of multicultural students in her school:

These kids do not have a good understanding about Korean language. Because they don't understand Korean well, their test scores for all subjects are below average and they are labeled as "a low grade student." Consequently, that labeling excluded them from their peer group.

Teachers also mentioned that the language barriers created communication problems between the parents and school. Because the immigrant parents could not communicate properly with teachers, they could not support their children for school work well that added to multicultural students' low academic performance in school. Thus, from the teachers' statement I learned that the issues of prejudice about immigrants in Korea, multicultural families' language barrier, multicultural families' poor communication with 
school, and multicultural students' low academic performance seemed to be related and affected each other as cause and effect.

Effects of intercultural experiences. All the teachers that I interviewed had intercultural experiences other than traveling abroad for short period of time, such as participating in a youth exchange program or a teacher education program abroad, working with native teachers, or living in a foreign country for six years. Their experiences with people from different cultures were varied but all the teachers described their experiences as positive and encouraging. Teachers reported that cultural experiences with others improved their understanding of others and increased their interests in other cultures and people. For example, Ms. Choi stated her intercultural experience encouraged her to see others on an equal footing. She added:

For me, I was very ignorant about South East Asian culture. Through the program (a youth exchange program) and friends there, I became more interested in their culture.

I found that what form South East Asian culture are Islam and Hinduism.

Further, four teachers stated that intercultural experiences helped them to become more culturally sensitive. They described that after their intercultural experiences they developed more inclusive and empathetic perspectives toward people from different cultures. Because teachers developed respect toward different cultures, they were able to advise students to be more culturally responsive when they faced multicultural issues in school. Also, four teachers explained that their intercultural experiences were one of their best teaching materials because a teacher's experience became an indirect experience for students. Particularly, in social studies or English class, using pictures 
taken and stories experienced by teachers were more effective than standardized teaching aids.

Impact of teachers' beliefs on multicultural education. Regarding Research Question 5, what impact do South Korean teachers' beliefs about diversity have on their practice of multicultural education, the teachers in this study shared how their beliefs affected multicultural education. For example, Ms. Lee was assertive about the influence of teachers' beliefs on their practice. She explained that teachers' beliefs in general are more influential in Korean school because many classes are still taught in a teacherdirected way. She articulated:

It (teachers' belief) has a huge influence. I think what a teacher thinks is directly transmitted to the students. Even more so in a teacher-directed class which is quite common in Korean schools. Teachers' thought and consciousness about certain issues are all embedded in their class. No matter what guidelines exist to tell teachers to teach this way or that way, teachers' beliefs always are involved. Because my thoughts are involved in the process (teaching), if my thoughts change, it (teaching) immediately changes too. ... For example, when teaching multicultural education, if a teacher is aware of the need of the improvement for multicultural education class, she would emphasize the class and look for better materials, things like that.

Ms. Cho lived in a foreign country for six years. She stated that her experience of living abroad encouraged her to change her beliefs about diversity and eventually her perspective about education. She shared that she was able to understand the uniqueness of each individual student and tried to be more flexible and open-mined about education. Ms. Cho stated:

(Because of her experience of living abroad) I can understand better diverse students. I think about education a lot differently (than before). Out of the fixed idea that I used to have, now I have more flexible idea about education .... It was important for me to teach students to respect rules and accomplish tasks, but now I think it is more important to understand each of my students and love them. 
Particularly, Ms. Cho found that she became more accommodating and cooperative in the communication with parents so that she could develop better relationships with parents.

Challenges in multicultural education. While teachers shared their intercultural experiences were a positive impact on multicultural education, the teachers faced difficulties to teach multicultural education in their classroom. The challenges existed at many levels. First, three teachers chose Koreans' stereotyping or prejudice about multicultural family as a barrier for multicultural education. Teachers acknowledged that there are Koreans--even teachers-- who hold stereotypical views of multicultural family including that they are of low socioeconomic status or the family is not functioning well. Consequently, the stereotyping created a negative image of multicultural family and that influenced teachers' teaching practice. Ms. Cho elaborated:

(Because we have negative images of them) we think that oh, it's weird because they're different from us. We don't think it's ok even though they are different.... The biggest problem is the difficulties that multicultural families have created in us a prejudice against them. (for example,) We might assume because his mom is from South East Asia, so, his family might have an economic hardship and he might not doing well in school either... There are some Koreans who complain that our tax money is wasted to help foreigners.... I think the conflict is getting worse because we limit our thinking to believe that multicultural people are the only ones who need our supports unconditionally.

In addition to the negative image of a multicultural family, two teachers reported that multicultural students developed a low self-esteem about themselves. Teachers indicated the students' lower academic performance is one main reason for their low selfesteem. Because one of multicultural students' parents, usually their mother is a foreigner, their Korean language ability was not good enough to keep up with the school work, so that they had poorer academic performance compared to Korean students. 
Particularly, in Korea where the academic excellence is the top priority in any school setting, multicultural students ended up being excluded by their classmates and that contributed a negative image about themselves.

Another barrier to multicultural education that I found in my interviews was the Korean teachers' mindset that multicultural education is not their priority. Teachers stated that as an elementary school teacher there were so many tasks that needed to be accomplished, that they felt sorry that they did not have time to carefully plan multicultural education in their classroom. Ms. Choi stated that teachers considered multicultural education as their extra work and not an essential task. Because teachers accepted multicultural education as "have-to-do" work, two teachers said it has been practiced in superficial ways. Five teachers that I interviewed considered multicultural education was mainly for multicultural students, not all students including Koreans. Teachers followed the curriculum guidelines for multicultural education, however it remained at a superficial level to fulfill the requirement. Ms. Choi pointed out:

Because the class (multicultural education) is very superficial, sometimes I wondered myself that if this is making any sense to my students. And teachers wonder themselves if they should do this (multicultural education).

How to support multicultural education. Teachers experienced and recognized the issues and hindrances to teaching multicultural education in their classrooms. At the same time, teachers were able to suggest thoughts and ideas that supported their practice of multicultural education. Their suggestions were valuable in the sense that these were ideas from teachers who play a significant role in the practice of teaching. Four of six teachers stated that to support multicultural education, an integrated class with multicultural students, in which, students learn and live a daily class life together would 
be the best. Teachers explained that, through a multicultural student in their class, Korean students became more interested in another culture and learned a lot about cultural diversity. Ms. Lee related her experience with a special education student to multicultural education:

In my class, I had a kid who was on Autism spectrum last year. The kid couldn't get along with other kids. He was not able to share his feelings with others, but only bothered other students in class. However, while we spent a whole school year together, I found that he (with Autism) did not learn something from other kids, instead, other kids learned from him something important as they tried to understand and help him. I think students learn better and more while they become tolerant and understandable in the integrated class. Like that, I think students learn better multicultural education if there is a multicultural student in their class.

Teachers also referred to practical aspects, diverse human resources like native English teachers and multicultural students facilitated effective teachings. Teachers noted that through the human resources, students had indirect experience about new cultures and teachers found a way to teach cultural contexts more practically and easily. Teachers also expressed their hope that they want a specialist on multicultural education in their schools. Because multicultural education is a relatively new concept for them, they found a need to have a specialist in school for asking questions to and practical help when they had issues of multicultural education in their class.

Multicultural teacher education program. Concerning their teacher education programs, teachers stated a lecture type of training program was not as helpful as they had expected. Particularly, Ms. Choi indicated that the training hours were spent on introducing and displaying cultural items, such as diverse foods and costumes in other countries were not meaningful. Instead of the theoretical or superficial level teacher's 
multicultural education programs, three teachers wanted to learn though experiences. For example, teachers suggested visiting model schools in multicultural education, participating in exchange programs at school level and cultural experience programs with people from diverse cultures. While teachers' suggestions about the training program were varied, overall, I found teachers preferred to learn by doing, not listening. Ms. Park Stated:

I went to a teacher education program, where instructors from different cultures shared their culture using realia and we had a chance to experience them....I enjoyed the program a lot and still remember it. If teachers can learn about diverse cultures like that, teachers will understand better and approach easily to different cultures.

Additionally, two teachers suggested teacher education programs that support actual classroom teaching on multicultural education. In Korean curriculum, multicultural education is embedded in multiple subjects, such as ethics, social studies, English, and so on. Teachers wanted to learn about practical strategies or materials to teach the multicultural aspects of the subjects. They said just learning about different cultural items is less meaningful, but they wanted to learn how to deal with multicultural aspects of a certain subject.

\section{Interpretation of Findings}

From the categories and codes, I developed five themes (see Figure 5). According to Creswell (2013), interpretation in qualitative research is a process of making sense out of data. Interpretation includes the process of abstracting out and organizing themes to larger units. In the following section, I explain each of five themes, 
then reorganize and interpret them to create a bigger picture, and finally, connect the themes to my research questions.

Themes identified from qualitative data analysis. As displayed in Figure 4, I identified five themes from the analysis of categories and codes. Each theme is not isolated, but it is connected to the other themes. In the next sections, I explain and interpret each theme and lessons learned from the themes.

Prejudice about multicultural family. Through teachers' experiences with multicultural families, I found that prejudice and bias exists about multicultural people in Korea. Teachers' prejudice was expressed in forms of stereotyping and discrimination of multicultural families by people around them. Consequently, with negative images of themselves, multicultural families in Korean were not proud of who they are so that they tried to hide their identity as immigrants. Particularly in school, difficulties with the Korean language created multicultural students' low academic performance and eventually an isolation or exclusion from their peer groups. I connect the not-so-bright picture of multicultural families to Koreans' pride on their racial and cultural homogeneity. As discussed in previous chapters, Korea is a unique country in the sense that it has a long history of pride on being a homogeneous country with one race and one language. Thus, for Koreans it is difficult to accept immigrants who look different and speak different languages into the boundary of Korean.

Intercultural experiences help teachers to understand diversity. The interviewed teachers had various intercultural experiences in which they were involved lasting from a month to years. From my interviews, I recognized that the experiences 
affected them positively as a person and as an educator. Most of all, I found that teachers' intercultural experiences encouraged them to open their eyes to cultural diversity. Subsequently, the teachers themselves grew to be more culturally sensitive in both personal and professional contexts as they became more knowledgeable about different cultures. For example, teachers became more inclusive toward immigrants and sympathetic toward people with different cultural backgrounds. Teachers also became more responsive and thoughtful when they encountered multicultural issues in class. Overall, these results are significant because teachers' responses in interviews correspond with the quantitative results that some intercultural experience was associated with teachers' beliefs about diversity and some intercultural experience positively influenced teachers' beliefs. These results address with Research Question 4 that teachers' intercultural experiences are important predictors for their beliefs about diversity.

Teachers'beliefs affect their teaching. It was impressive to find that teachers themselves recognized that teachers' beliefs have an impact on their classroom teaching. As one teacher pointed out it is more likely in a Korean context because a teacherdirected type of instruction is frequently practiced in Korean schools. Particularly, teachers' beliefs about diversity influenced their emphasis on multicultural education and selection of multicultural teaching materials as well. In terms of the relationships in school settings, teachers' beliefs about diversity encouraged them to be more responsive and accommodating in their relationship with students and parents. Even though not all teachers mentioned directly regarding the impact of teachers' beliefs, I can interpret that teachers' beliefs have a significant impact on their teaching, accordingly teachers' beliefs 
about diversity affect their practice of multicultural education remarkably. With respect to impact of teachers' beliefs on their practice, the results suggest that positive teachers' beliefs about diversity positively impact their practice of multicultural teaching.

Multicultural education is challenging but there is a way to support it. A number of barriers are identified in multicultural education in South Korea. Koreans' stereotypes or prejudice about the multicultural family and multicultural students' low self-esteem were seen as the most difficult challenges by teachers. I recognize that on the top of the prejudice about the multicultural family, multicultural students' Korean language difficulties are one underlying reason for their isolation in school. Another important issue that I uncovered was Korean teachers' mindset that does not consider multicultural education as their priority task. For many teachers multicultural education was a "have-to-do" work instead of a "want-to-do" task. I interpret this as a significant issue because if teachers do not truly believe in the need or value of multicultural education, it will be practiced only at a superficial level. On this point, I find the additional importance of teachers' beliefs on their practice of teaching.

Although there are barriers to practice multicultural education in the Korean context, I found teachers knew ways to support it. Teachers suggested an integrated class with multicultural student would be the best way for Korean students to learn cultural diversity and tolerance and respect about different people. By getting along together with people with different backgrounds, teachers expected for their students to learn better and more easily. 
I conclude teachers' recognition of both the challenges and the solutions are promising for multicultural education in Korea. It is meaningful that teachers argued they can teach multicultural values better if they have a multicultural student in the class. In other words, teachers viewed learning by experiencing diversity was one of the most effective ways to teach multicultural education.

Multicultural teachers'education through experiences. Concerning a education opportunities for multicultural education, teachers preferred a education program in which they can learn through doing and experiencing. At the same time, teachers wanted an education that would be practically helpful to practice multicultural education. Teachers might develop the views for training from their previous learning opportunities and from a need for a practical help in multicultural teaching. Teachers' views about education programs are significant in the following reasons. First, because teachers' views correspond with the quantitative results that showed teachers' specific experiences influenced their diversity beliefs. Second, if the experience matters, the selection of more effective and influential experiences should be the point for the improvement of teachers' education program.

The bigger picture: Lessons learned. The picture of multicultural education in Korean schools appears to be rather negative. Through teachers' voices, I recognized again that multicultural students in Korea were facing difficulties as they were adjusting themselves to Korean schools. Because their parents, usually their mother is from a foreign country, their Korean ability is not fluent so that the language barrier became one 
main reason to make their adjustment difficult. I interpret that this situation basically originates from Koreans' pride on the nation's homogeneity.

Through the process of coding and thematic analysis, I was able to make connections to my research questions. With respect to Research Question 4, I interpret that teachers' intercultural experiences were influential on their beliefs about diversity in personal and professional contexts. Concerning Research Question 5, I conclude that teachers' beliefs about diversity influenced their practice of multicultural education.

Teachers were more knowledgeable about multicultural education than I expected. They indicated several challenges to practice multicultural education in Korean school. They also had suggestions to support multicultural education and to improve multicultural teacher education programs. In essence, teachers' suggestions could be described in one word: experience. Experience was a recurrent theme in many interviews. Teachers suggested with a multicultural student in their class, Korean student would learn better through interactions and experiences with culturally different others. Teachers also recommended that teachers' multicultural training program would work better if teachers can learn through experiences of different cultures and visiting model classes.

Interestingly, findings from interviews corresponded with quantitative results that showed certain intercultural experiences influenced teachers' diversity beliefs positively. Overall and together with these results provide insights into how to support teachers to practice better multicultural education in South Korea. 


\section{Limitation of Study}

Although my research addressed all the research questions, it has limitations that need to be taken into account. I explain the limitations are explained in four categories: sample, data collection methods, translation issue, and researcher bias.

\section{Limited Sample of Teachers}

The main limitation of this study concerns the limited sample of teachers. The research was conducted with a particular group of teachers from one targeted city, a Metropolitan city in south eastern Korean. Therefore, the findings may be limited to this specific group of teachers from one city. If I conducted this study with teachers from a south western Korean city, the results about teachers' beliefs might have been different. To expand the findings to general population of Korean teachers, a study would need to include a representative sample of teachers teaching in the other regions in South Korea.

\section{Data Collection Methods}

The data collection method to answer a certain research question was limited. For example, one of the research questions of this study was to examine how teachers' beliefs about diversity influence their practice of multicultural education. For this purpose, I focused only on teachers' discourse. I did not collect classroom observation or other data to investigate how teachers actually practiced multicultural education. While not a focus of this study, it is important to examine teachers' actual practice of multicultural education. Thus, the data source for this question was limited to interviews with teachers.

I also used survey instruments to collect quantitative data. Because this was an international study in which participating teachers reside in South Korea, I relied on teachers' self-administration of the survey. Accordingly, volunteers distributed the 
survey to teachers at their convenience. To minimize the issues associated with selfadministered instrument, I made sure that all questions were simple and short to ease understanding of the questions. Plus, all the questions in the survey in my study were categorical in style. I also collected qualitative data (interviews) to corroborate the findings from the quantitative data (self-administered surveys). I conducted follow-up interviews with selected teachers to gain a deeper understanding about teachers' experiences, beliefs, and practice of teaching multicultural education.

\section{Translation Issues}

Two main translation processes were included in my study. The first one was the translation of the survey instruments from English to Korean. Pohan and Aguilar (1998) designed and tested the original instruments in English. For the purpose of my study, the instrument was translated and modified into Korean to test Korean teachers' beliefs about diversity. To minimize possible translation errors, I had two Korean colleague researchers who both are native Korean speakers and knowledgeable about education in South Korea to review the translated survey instruments. I also conducted a pilot test with five Korean teachers during May 2015 before I administered the surveys. Through the pilot test, I was able to review and double-check if the translation was appropriate and each survey question was making accurate and acceptable sense in Korean.

I used a second translation during the interview data analysis process. Initially, I transcribed and analyzed all interview data in Korean. Then, I translated the essential part of data (i.e., themes, categories and codes, verbatim phrases) into English. However, due to the complexity of translation and distance, I did not employ member checking. 


\section{Researcher Bias and Reactivity}

Researcher bias and reactivity, the influence of the researcher on the setting or individuals studied (Maxwell, 2013), is another limitation of qualitative research. Yet, according to Maxwell (2013), minimizing the researcher influence is not a goal for qualitative study. What is more meaningful is to understand how and what influence the researcher has and to use this influence productively.

As a researcher in this study, I was responsible for all the phases of the research. Particularly, because it was an international study using both quantitative and qualitative data, it required me to have a full commitment as a researcher. The roots of my commitment for this research came from my life experience of being situated in two different cultures. In my life, I moved back and forth between the United States and Korea. I was born, grew up, and worked as a school teacher in one city in South Korea. I moved to the United States twice for my graduate studies afterwards. Until I moved to the United States, my world was limited to the city in which I was born and taught. However, my experience of living in two totally different cultures changed my understandings about diversity, particularly my perspectives toward people who are different from me. In addition, my experience as a mainstream citizen in Korea and as a minority foreign student in the United States improved my understandings about minority groups in a society and eventually helped me to recognize the value of multicultural education.

My life experiences and perspective may have influenced my interviews with teachers, interview data analysis, and interpretation, and possibly the whole research 
process. However, my experience as a school teacher in Korea enabled me to understand South Korean educational system and multicultural contexts in Korea, to find a need for this research, and made it possible to connect to Korean teachers for my research. Additionally, my life experience in the United States provided me of multicultural perspectives and my learning about multicultural education theories that developed in the United States became the fundamental elements for this research. 


\section{Chapter 5: Conclusion}

Researchers have asserted that teachers' positive beliefs about diversity play a significant role to develop their multicultural competence and eventually to practice better multicultural education (Pohan \& Aguilar, 2001). However, little has been found in the literature about Korean teachers' beliefs about diversity: what are their beliefs, what are the factors that influence the development of those beliefs, and how teachers' beliefs affect their practice of multicultural teaching. Based on the assumption that Korean teachers' beliefs about diversity need be identified to support teachers to improve

their multicultural teaching, I have examined Korean teachers' beliefs about diversity and the influence of those beliefs on their teaching practice. Therefore, the purpose of this study was to examine South Korean teachers' beliefs about diversity and the factors that influence those beliefs, and finally, to investigate the impact of their beliefs on their practice of multicultural education teaching.

In the process of examining South Korean teachers' beliefs about diversity, the following five research questions guided my research.

1. What are South Korean teachers' beliefs about diversity in personal contexts?

2. What are South Korean teachers' beliefs about diversity in professional contexts?

3. How do South Korean teachers' beliefs about diversity differ between personal and professional contexts?

4. How do South Korean teachers' beliefs about diversity in personal and professional contexts differ based on their demographics, and teaching and intercultural experiences? 
5. What impact do South Korean teachers' beliefs about diversity have on their practice of multicultural education?

In Chapter 4, I presented demographic descriptions of participants in this study, particularly, those related to their teaching and intercultural experiences. Then, I described the analysis and interpretation of data from the quantitative surveys and qualitative interviews. For quantitative data analysis, I applied three different statistical tests including frequency analysis, paired samples $t$ - test, and multiple linear regression tests. Concerning the qualitative data analysis, I employed a thematic analysis. I analyzed and created codes and categories and finally developed themes out of the interview data. The findings from both quantitative and qualitative data analysis were applied to answer research questions and address the purpose of study.

In Chapter 5, I synthesize the findings from quantitative and qualitative analysis. In particularly, I organize the major findings by research questions that guided my research. The findings are also situated and explained within a larger educational context. In addition, I interpret the findings through the lens of past research: whether the results support or contradict the prior research. Then, I draw conclusions through the predictions of the theoretical framework that was set up in the literature review. Last, I suggest implications for the policy and practice of multicultural education in South Korea and provide recommendations for future research directions.

\section{Synthesis of Findings and the larger context}

In this section, I synthesize the findings from quantitative and qualitative analyses and describe how the results are situated within a broader context. I explain the findings 
in relation to the theoretical framework that underlies my research. To clearly connect the findings to the goals of the research, I organize the section by the five research questions

\section{Korean Teacher's Beliefs about Diversity in Personal Contexts}

According to Pohan and Aguilar (2001), low scores on Personal and Professional Diversity Scales indicated general intolerance of diversity issues, while higher scores reflected acceptance or openness toward diversity issues. I interpreted the quantitative findings by employing Pohan and Aguilar's interpretation of scores, in effort to answer research questions.

Research Question 1 asked: what are South Korean teachers' beliefs about diversity in personal contexts? The results from quantitative data analysis showed that teachers' beliefs about diversity in personal contexts varied according to particular issues. In other words, on some diversity issues, teachers were more accepting, while on other issues they were less accepting.

Teachers were more accepting of issues including friendships across racial or ethnic backgrounds, the physical limitations of effective leaders, and acceptance of diverse ways of life in Korea. On the other hand, teachers were less accepting of issues regarding a multicultural family's valuation of education, same-sex couples as parents, and multicultural students' maintenance of their first language.

Scholars in social constructivism emphasized the importance of cultural context in understanding the construction of knowledge (McMahon, 1997; Richardson, 1997). Social constructivists asserted that a belief system is developed from social and cultural 
influences (Lee \& Dallman, 2008) and the interaction of the people in the society. Through the lens of social constructivism, I suggest that the teachers' acceptance in multicultural issues is learned and influenced from social and cultural contexts in South Korea. For example, teachers showed a lower acceptance on the issue that a multicultural family values education as much as a Korean family does. I find the teachers' beliefs about education are rooted in Korean historical and cultural backgrounds. Historically, Koreans have had extraordinary educational enthusiasm that has been described as “education fever" (Anderson \& Kohler, 2013; Kim, Lee \& Lee, 2005; C. J. Lee, 2005; Park, 2009). Generally, for Koreans, educational success or excellence is one of the highest values in life, and accordingly the educational goal in any school setting is set to academic excellence. In this context, it is hard for South Korean's to accept that a multicultural family values education as much as a Korean family does.

Teachers also showed a lower acceptance of multicultural students' maintenance of their first language. A possible explanation for the lower tolerance would be the teachers' belief that the students should learn Korean language first to be competitive and academically excellent in school. Teachers believed that acquiring a fluent Korean ability is the most important condition to be successful in school. The explanation was supported by the qualitative results. Multiple teachers that interviewed stated that understanding and speaking fluent Korean is a starting point for a multicultural student to perform well in a Korean school and to be included in their peer groups. 


\section{Korean Teacher's Beliefs about Diversity in Professional Contexts}

Research Question 2 queried: what are South Korean teachers' beliefs about diversity in professional contexts? The results of quantitative analysis showed that teachers' beliefs about diversity in professional contexts varied as well as they had in personal contexts. Teachers were more accepting of diversity issues regarding using other languages than Korean in school, the attention that girls receive in schools, and integrated classrooms with Korean and multicultural students. On the contrary, teachers were less accepting of other diversity issues including more opportunity given to males in math and science, improper placement of multicultural students, and multicultural education benefits all students.

One consistent finding was that teachers showed a higher acceptance of girls receiving equal attention in school and a lower acceptance of males being given more opportunity in math and science. The results showed that teachers believed that female and male students need to be given equal opportunities in school education. It seems like Korean teachers have a progressive perspective about an equal education opportunity regardless of gender; there is no apparent gender discrimination in Korean schools. However, also there is a possibility that teachers were not able to or willing to recognize gender discrimination in education.

Teachers were positively accepting of integrated classrooms with Korean and multicultural students. This finding was consistent with the results from the interview data. Many teachers interviewed agreed that an integrated class would be the best way to teach cultural diversity to Korean students. Teachers stated that they had experienced the 
benefits of integrated classrooms in their teaching practice. I found that the social constructivist perspective supports the teachers' realizations of the importance of learning by including diverse students. According to social constructivism perspectives, values and beliefs are not taught by teachers, instead students are asked to be the active owner of their learning through social interaction. Teachers were finding that integrated classrooms with multicultural students provided Korean students with a better chance to learn respect and tolerance toward diversity, through which, learning through interaction among students was emphasized.

In line with the social constructivist learning principle, a number of studies explored the importance of experiences with culturally diverse others in teacher education (Brown, 2004; Garmon, 2005; Kyles \& Olafson, 2008; Mills, 2008; Pohan, 1996; Pohan \& Aguilar, 2001). Garmon $(2004,2005)$ asserted that preservice teachers' prior experience is one of the critical factors that change their beliefs and attitudes about diversity. Mills (2008) suggested that in teacher education, engagement with diverse student populations would be an effective way to challenge and change preservice teachers' values and attitudes about diversity.

Interestingly, I found an inconsistency in teachers' personal and professional beliefs about diversity issues. Teachers showed a higher acceptance of using a language other than Korean in school, while they showed a lower acceptance of multicultural students' maintenance of first language in personal contexts. I interpret this to mean that teachers believed that learning Korean is more important than maintenance of first language in personal settings; however, teachers found a need to use another language in 
school until multicultural students become fluent at Korean. The results are not consistent with the quantitative finding that showed teachers' personal and professional beliefs were positively correlated. However, on the issue of use of another language, teachers seem to have more tolerant beliefs in professional settings.

Last, one significant finding in teachers' professional beliefs about diversity was that teachers had a lower acceptance for the belief that multicultural education benefits all students not only multicultural students. The results indicated that teachers perceive multicultural education as an education that mainly supports multicultural students' adjustment to Korean schools, and the benefit does not extend to Korean students. Previous researchers who studied multicultural education in Korean schools concurred with this finding (Lee, J. Y., 2013; Park, 2007). Teachers' limited understanding about multicultural education could significantly hinder their motivation to expand multicultural education for all students to learn about cultural diversity and eventually gain respect for it. I also found that teachers' mindset about multicultural education as their priority was another barrier for advancing multicultural education in Korea. If teachers do not find a need and motivation for multicultural education, so that, multicultural education remains merely a "have-to-do" work, their practice will be no more than a superficial level of teaching.

\section{Differences between Korean Teacher's Beliefs about Diversity in Personal and Professional Contexts}

Research Question 3 looked at discrepancies across beliefs: how do South Korean teachers' beliefs about diversity differ between personal and professional contexts? 
Quantitative results showed that teachers' beliefs about diversity in personal and professional context were statistically comparable and equivalent as reported as the average sum score for Personal and Professional scores were 0.74 and 0.73 , respectively. In addition, the two beliefs had a moderately positive correlation $(r=0.563)$, which indicates that one belief is a good predictor for the other belief. Thus, teachers who are more accepting of diversity in personal settings are also more accepting of diversity issues in the contexts of schooling.

Overall, qualitative results strengthened the positive correlation between two teachers' personal and professional beliefs. The South Korean teachers that I interviewed had personally positive beliefs about diversity. Through various intercultural experiences, teachers became more interested in other cultures and learned a respect toward the different cultures. I found teachers' personal positive beliefs about diversity influenced their professional beliefs as well. One teacher noted that when she personally became culturally sensitive, as a school teacher, she was able to advise her students to be more respectable and inclusive toward different cultures.

Consequently, teachers' positive personal beliefs about diversity led them to their professional realization that diversity in school would benefit both Korean students and multicultural students. Teachers were also realizing that it becomes more important to teach students to develop cultural competence as Korean society is rapidly becoming multicultural.

Although overall the quantitative tests showed that teachers' beliefs about diversity in personal and professional contexts were statistically comparable, I found 
some discrepancy in the two beliefs specifically, such as, teachers' inconsistent beliefs about multicultural students' use and maintenance of their first language. The cause of this discrepancy of teachers' personal and professional beliefs about diversity was not the focus in this study. For these discrepancies, a further investigation would be required to examine possible explanations.

\section{Factors that Influence Teachers' Beliefs}

Research Question 4 probed: how do South Korean teachers' beliefs about diversity in personal and professional contexts differ based on their demographics and teaching and intercultural experiences? To answer this question, I identified important findings from both quantitative and qualitative results.

From quantitative results, I found that gender was a statistically significant factor to predict both personal $(p=0.016)$ and professional beliefs about diversity $(p=0.022)$ : females were expected to have significantly higher diversity beliefs sum scores than males. I also found that a traveling abroad experience was a significant factor for personal diversity beliefs: the teachers who had no traveling abroad experience were expected to have significantly lower personal diversity beliefs sum scores comparing the teachers who traveled more than six times $(b=-0.145, p=0.026)$. Additionally, I determined that the number of years taught was an important predictor for professional diversity beliefs even though it was not statistically significant: the teachers who taught for 16-20 years were expected to have higher professional beliefs sum scores comparing the teachers who taught less than five years. $(b=0.090, p=0.052)$. 
Regarding gender, female teachers were more accepting of diversity issues than male teachers in both personal and professional settings. This supports earlier literature that reported that females are more accepting of diversity. Throughout the development phases of Personal and Professional Beliefs about Diversity Scales, Pohan and Aguilar (2001) found that women were more accepting of diversity than were men on both beliefs measures. Ogletree (2013) also reported in her study with elementary teachers in Texas that teachers' gender was the only demographic variable that influenced teachers' personal and professional beliefs about diversity.

Generally, teachers who had traveled abroad more were more accepting of diversity issues in personal contexts. The teachers who had no experience traveling abroad were least positive about diversity compared to teachers who had travel experience. However, teachers who had traveled only once and those who had traveled more than six times did not show a statistically significant difference. That is to say, what made a difference in teachers' personal diversity beliefs was not the frequency of traveling abroad, but if teachers had any travel abroad experience or not. Thus, it is possible to say that traveling abroad at least once can make a change in teachers' beliefs about diversity in personal contexts. Even though the society has transformed into a multicultural society, still the majority of Korean teachers are not teaching multicultural students in their classrooms. In this context, I find that traveling abroad has been one significant way through which teachers have experienced cultural diversity.

Teachers who taught for more years tend to be more accepting of diversity in professional contexts than teachers who taught for fewer years. Even though this was not 
statistically significant, teachers who taught for 15 and more years appeared to be more accepting of diversity than teachers those who taught for fewer years. Thus, I found that generally teaching experiences influence positively teachers' beliefs about diversity in professional setting.

In this study, teachers' demographics and experiences likely affected their diversity beliefs. The teachers might have had rather conservative attitudes regarding general social issues, particularly compared to the teachers in a south western Korean city. So, I interpret the participating teachers' conservative perspectives and attitudes might have affected their beliefs about diversity in this study.

Qualitative results supported the quantitative results that teachers' intercultural experiences are important predictors for their beliefs about diversity in personal and professional contexts. Teachers stated that intercultural experiences affected them positively as a person and an educator. Most importantly, teachers agreed that the experiences provided them with opportunities to learn about diversity so that they became more culturally responsive and inclusive teachers. Thus, from the findings of both quantitative and qualitative results, I conclude that meaningful intercultural experiences can positively influence teachers' beliefs about diversity. Additionally, I find that the synthesized findings are in line with social constructivist perspectives which emphasize the social interactions in learning.

In relation to the findings in this study, a number of studies explored the importance of experience in teacher education (Brown, 2004; Garmon, 2004, 2005; Kyles \& Olafson, 2008; Mills, 2008; Pohan, 1996; Pohan \& Aguilar, 2001). Kyles and Olafson 
(2008) reported that teacher candidates with multicultural schoolings and life experiences are more likely have more favorable beliefs and attitude regarding cultural diversity than are candidates with monocultural schooling and life experiences. Garmon $(2004,2005)$ suggested six factors to change preservice teachers' attitude and beliefs about diversity. He explained the factors are associated with two categories: dispositions which include openness, self-awareness/self-reflectiveness, and commitment to social justice, and experiences which includes intercultural, educational, and support group experiences. $\mathrm{He}$ argued that in teacher education programs, more attention need to be given to students' entering disposition and prior experiences.

Interestingly, from both quantitative and qualitative results, I found teachers' multicultural teacher training experience did not significantly influence teachers' beliefs about diversity. This lack of influence raised a question about the effectiveness of multicultural teacher education programs in which the teachers had participated. I conclude that teacher education programs need to rethink and reform their programs to give teachers' the opportunity to challenge and transform their beliefs about diversity.

\section{Impact of Beliefs on Practice}

Research Question 5 inquired: what impact do South Korean teachers' beliefs about diversity have on their practice of multicultural education? I identified the answer from the interview data. Teachers stated that positive beliefs about diversity positively impact their practice of multicultural education. Ms. Lee stated that "what a teacher thinks is directly transmitted to students. Even more so in the teacher-directed class which is common in Korean school." Another teacher noted that her experiences and 
beliefs about diversity made a positive change in her relationships with students and parents, which contributed to a better classroom management.

The teachers that I interviewed may not be typical South Korean teachers in terms of their perceptions about diversity and multicultural education. Some research reported that Korean teachers had a mixed feeling regarding the shift to a multicultural society and the practice of multicultural education (Lee, H., 2014; Lee, J. Y, 2013; Watson et al., 2011). However, my findings are consistent with several previous studies that have argued that teachers' beliefs are powerful indicators for their practice of teaching (Brown, 2004; Eisenhart et al., 1988; Kyles \& Olafson, 2008; Mills, 2008; Nespor, 1987; Ogletree, 2013; Pajares, 1992; Pohan, 1996; Pohan \& Aguilar, 2001).

\section{Implications}

My findings provide additional evidence in support of previous studies that argued the importance of teachers' beliefs in their practice of teaching, and that meaningful intercultural experience has a critical impact on the development of teachers' beliefs about diversity. I join the call for multicultural teacher education reform grounded in fostering teachers with positive and affirming beliefs about diversity. In light of my findings, I suggest the following recommendations that may be worthy of consideration and further investigation.

\section{Recommendations for Practice}

First, for the better practice of multicultural education in Korea, I suggest that Korean teachers' beliefs need to be examined first. A clear understanding about teachers' beliefs about diversity should be the starting point for the reform of multicultural teacher 
education and eventually for the improved practice of multicultural education. In this study, I found teachers' traveling abroad experience was one significant factor that influences teachers' personal beliefs about diversity. I also found that teachers' personal beliefs and professional beliefs had a moderately strong correlation. If personal beliefs can be positively influenced by a direct intercultural experience, teacher education program planners need to expose teachers to various intercultural experiences inside and outside of the program courses. If professional beliefs are directly influenced by personal beliefs, teacher education program should include deeper issues related to diversity and multiculturalism (Brown, 2004; Pohan \& Aguilar, 2001).

Thus, I suggest that starting from examining teachers' beliefs is important, because by doing so we can find effective ways to support teachers to improve their beliefs about diversity.

Consequently, I recommend that through close examination of teachers' beliefs about diversity, multicultural teacher education programs need to be reformed to affect beliefs and monitor changes in their beliefs. Without addressing the underlying beliefs that influence teachers' practice, providing professional development does little to change practice when teachers return to classrooms (Guerra \& Nelson, 2009; Pohan, 1996). Staging superficial cultural events is not the type of multicultural education we want to create. Teachers only citing politically correct principles of multicultural education without having personal beliefs and commitments to teach for all students inclusively and equally are not the educators we want to foster (Kyles \& Olafson, 2008). 
Next, I suggest that teachers need to be involved in meaningful intercultural experiences in multicultural education programs. My study confirmed previous findings and contributes additional evidence with respect to the importance of intercultural experiences in teacher education. These results indicated that an intercultural experience positively influenced teachers' personal beliefs about diversity and the personal beliefs directly influence teachers' professional beliefs about diversity. Indeed, as Kyles and Olafson (2008) noted, every opportunity of contacting cultural diversity would provide teachers with experiences of reaffirming cultural diversity or challenging existing prejudices.

From interviews, I found the lecture type of teacher education program had little impact on teachers' beliefs about diversity. Through the voices of teachers, I recognized a need to reform multicultural teacher education. For the reform of multicultural teacher education program, Garmon's (2005) suggestions for effective educational experiences have significant implications for multicultural teacher education program in Korea. He explained considerations for effectively promoting multicultural growth for preservice teachers: first, a single multicultural teacher education course or field experience is insufficient; second, engaging and pursuing self-reflection and self-awareness is strongly encouraged in multicultural teacher education classrooms; third, it is valuable to have preservice teachers involved in field experiences or immersion-type programs, but appropriate guidance and support are needed; fourth, teacher education programs need to offer preservice teacher many opportunities for positive intercultural experiences. For that, it is important to recruit students of color into teacher education programs. 
Based on Garmon's (2005) suggestions, I recommend that the deeper and meaningful engagement with diversity, particularly, when they are through intercultural experiences and over a sustained period, would contribute to developing Korean teachers' positive beliefs about diversity. In the Korean context, it is not feasible to recruit students from different cultures into teacher education programs. However, pursuing self-reflection of teachers' beliefs about diversity and the intercultural experiences with appropriate guidance and support have significant implications. When teachers engage in the intercultural experiences that enable them to access, challenge, and transform their beliefs about diversity, their practice of multicultural education will benefit more students.

Finally, I suggest that the findings of this research may be used to develop targeted interventions aimed at developing multicultural teacher education programs. By looking at the intercultural experiences that work positively to promote beliefs of diversity, we can find the types of experiences that we might want to provide to teachers for their development of beliefs about diversity. I also recommend that this study may be used before and after a teacher education program to examine the long-term effects of a teachers' training program.

\section{Recommendations for Research}

My research has identified questions in need of further investigation. First, I suggest that a future study including a sample of teachers across the nation may provide more general ideas about Korean teachers' beliefs about diversity.

Second, I recommend that more variables to affect teachers' beliefs about diversity should be considered in the future studies. In this research, I examined 
multicultural teaching and training experiences, traveling and living abroad experiences, and friendship with people from different cultures, in relation to teachers' beliefs about diversity. However, the statistics showed that $\mathrm{R}^{2}$ scores for the above dependent variables and the personal and professional beliefs scores were 0.231 and 0.210 , respectively, which indicates that only roughly $20 \%$ of the variance in teachers' diversity beliefs is explained in this study. Future research including more variables would provide a clearer understanding about teachers' diversity beliefs.

Third, I recommend that a further study could assess how teachers' diversity beliefs affect their practical teaching. In this study, quantitative tests investigated the correlation between teachers' beliefs in personal and professional contexts. However, this study did not focus on teachers' actual practice of multicultural education. A future study can examine teachers' practice of multicultural education through multiple measures such as classroom observation and teachers' reflection on their classes. It can also investigate the correlation of teachers' beliefs and teaching practice.

Last, I suggest that there is a need to investigate the discrepancy in teachers' personal and professional beliefs. This study found some discrepancies exist, however it was not examined if more discrepancies of beliefs exist and their possible explanations.

During the process of my research, I was able to learn about Koreans teachers' concerns and expectations about multicultural education. I found that teachers seek practical supports to improve their teaching of multicultural education in their classrooms. The discussions about multicultural education in South Korea have started now and there need to be continuing conversations about it. As a researcher and an educator, I look 
forward to being part of the conversation through sharing this research with Korean administrators and teachers and engaging in reforming multicultural teacher education programs.

Teachers' beliefs about diversity are one of most the significant predictors for their practice of multicultural education. The research provides insight about how to support teachers to practice better multicultural education in South Korea by supporting them to change or improve beliefs about diversity. Through meaningful intercultural experiences, Korean teachers could develop more positive beliefs about diversity, could improve their cultural competence, and eventually become a better multicultural educator. 


\section{References}

Aguirre, J., \& Speer, N. M. (2000). Examining the relationship between beliefs and goals in teacher practice. Journal of Mathematical Behavior, 18(3), 327-356.

Akar, H., \& Yildirim, A. (2010). Effect of constructivist learning on student achievement in pre-service teacher education. New Educational Review, 21, 57-70.

Anderson, T., \& Kohler, H. P. (2013). Education fever and the East Asian fertility puzzle: A case study of low fertility in South Korea. Asian Population Studies, 9(2), 196215.

Bae, G. (2012). Secondary teachers' recognition of multicultural education. Kumi, South Korea: Kumho National Institute of Technology.

Bae, U. (2006). A study on the way to solve the problem in elementary school of foreign worker's children in South Korean. Korean Journal of Educational Anthropology, $9(2), 25-55$.

Banks, J. A. (2004). Multicultural education: Historical development, dimensions, and practice. In J. Banks \& C. Banks (Eds.), Handbook of research on multicultural education (2nd ed., pp. 3-24). San Francisco, CA: Jossey-Bass.

Banks, J. A. (2008). Diversity, group identity, and citizenship education in global age. Educational Researcher, 37(3), 100-110.

Banks, J., \& Banks, C. M. A. (2010). Multicultural education: Issues and perspectives ( $7^{\text {th }}$ ed.). New York, NY: Wiley.

Bennett, C. (2001). Genres of research in multicultural education. Review of Educational Research, 71(2), 171-217. 
Bennett, C. (2004). Research on racial issues in American higher education. In J. Banks \& C. Banks (Eds.), Handbook of research on multicultural education (2nd ed., pp. 663-682). San Francisco, CA: Jossey-Bass.

Bennett, C. I. (2006). Comprehensive multicultural education: Theory and practice. (6th ed.). Boston, MA: Allyn \& Bacon.

Brown, K. M. (2004). Assessing preservice leaders' beliefs, attitudes, and values regarding issues of diversity, social justice, and equity: A review of existing measures. Equity \& Excellence in Education, 37(4), 332-342. doi:10.1080/10665680490518948

Cardona, C. M. (2005, April). Assessing teachers' beliefs about diversity in personal and professional contexts. Paper presented at the annual meeting of the American Educational Research Association. Retrieved from http://eric.ed.gov/?id=ED490699

Castro, A. J. (2010). Themes in the research on preservice teachers' views of cultural diversity implications for researching millennial preservice teachers. Educational Researcher, 39(3), 198-210.

Chang, I. (2008). Exploring and developing model for teacher curriculum for multicultural education. The Journal of Elementary Education, 21(2), 281-305.

Choi, J. (2010). Educating citizens in a multicultural society: The case of South Korea. Social Studies, 101(4), 174-178.

Choi, Y., \& Yoon, H. (2008). Korea's initiatives in multicultural education. Retrieved from www.intlalliance.org/fileadmin/user_upload/...2010/NP-KO.pdf 
Choi, Y., Yoon, H., \& Park, S. (2006). A study on education in multicultural families. Seoul, Korea: Korean Ministry of Education and Human Resources.

Collins, S. E. (2009). Cultural diversity awareness of elementary teachers in Georgia classrooms. Electronic Theses \& Dissertations. Retrieved from http://digitalcommons.georgiasouthern.edu/etd/220/

Creswell, J. W. (2003). Research design: Qualitative, quantitative, and mixed methods approaches. Thousand Oaks, CA: Sage.

Creswell, J. W. (2010). Mapping the developing landscapes of mixed methods research. In Tashakkori \& C. Teddlie (Eds.), SAGE handbook of mixed methods in social and behavioral sciences (2nd ed., pp. 45-68). Thousand Oaks, CA: Sage.

Creswell, J. W. (2013). Qualitative inquiry and research design: Choosing among five approaches (3rd ed.). Thousand Oaks, CA: Sage.

Creswell, J. H., \& Plano-Clark, V. L. (2010). Designing and conducting mixed methods research. Thousand Oaks, CA: Sage

Dedeoglu, H., \& Lamme, L. L. (2011). Selected demographics, attitudes, and beliefs about diversity of preservice teachers. Education and Urban Society, 43(4), 468485. doi: $10.1177 / 0013124510380718$

Duarte, E. M., \& Smith, S. (2000). Multicultural education-What for? In E. M. Duarte, \& S. Smith (Eds.), Foundational perspectives in multicultural education (pp. 123). New York, NY: Longman. 
Eisenhart, M. A., Shrum, J. L., Harding, J. R., \& Cuthbert, A. M. (1988). Teacher beliefs definitions, findings, and directions. Educational Policy, 2(1), 51-70. doi: $10.1177 / 0895904888002001004$

Fang, Z. (1996). A review of research on teachers' beliefs and practice. Educational Research, 38(1), 47-65.

Field, A. (2013). Discovering statistics using SPSS (3rd ed.). London, England: Sage.

Fries, S. (2009). Cultural, multicultural, cross-cultural, intercultural: A moderator's proposal. Retrieved from http://www.tesol-france.org/uploaded_files/files/susanfries.pdfGarmon, M. A. (2005). Six key factors for changing preservice teachers' attitudes/beliefs about diversity. Educational Studies, 38(3), 275-286.

Gay, G. (1995). Mirror images on common issues: Parallels between multicultural education and critical pedagogy. In C. E. Sleeter \& P. McLaren (Eds.), Multicultural education, critical pedagogy, and the politics of difference (pp. 155189). Albany, NY: State University of New York Press.

Gentry, J., Lamb, H., Becker, M., \& Hall, R. (2012). Can pre-service teachers' perspectives on diversity change? The Journal of Multiculturalism in Education, 8, $1-18$.

Giroux, H. A. (2000). Insurgent multiculturalism and promise of pedagogy. In E. M. Duarte \& S. Smith (Eds.), Foundational perspectives in multicultural education (pp. 195-212). New York, NY: Longman.

Gollnick, D. M., \& Chinn, P. C. (1986). Multicultural education in a pluralistic society ( $6^{\text {th }}$ ed.). Upper Saddle River, NJ: Pearson. 
Grant, C. A., \& Sachs, J. M. (2000). Multicultural education and postmodernism: Movement toward a dialogue. In E. M. Duarte \& S. Smith (Eds.), Foundational perspectives in multicultural education (pp. 178-194). New York, NY: Longman.

Grant, C. A., \& Sleeter, C. E. (2010). Race, class, gender, and disability in the classroom. In J. A. Banks, \& C. A. M. Banks (Eds.), Multicultural education: Issues and perspectives ( $7^{\text {th }}$ ed., pp. 59-78). New York, NY: Wiley.

Guerra, P. L., \& Nelson, S. W. (2009). Changing professional practice requires changing beliefs. Phi Delta Kappan, 90(5), 354-359.

Guyton, E. M., \& Wesche, M. V. (2005). The multicultural efficacy scale: Development, item selection, and reliability. Multicultural Perspectives, 7(4), 21-29. Retrieved from http://stats.lib.pdx.edu/proxy.php?url=http://search.ebscohost.com/login.asp $\mathrm{x}$ ?direct $=$ true $\& \mathrm{db}=$ eric $\& \mathrm{AN}=\mathrm{EJ} 834783 \&$ site $=$ ehost-live

Han, K. (2007). Statistics and tasks of migrant foreigners' human rights in 2007. Human Right Report in 2007. 1-24. Seoul, Korea: Korean Association of Attorneys.

Harmon, C., \& Wilson, M. (2011). An investigation of the diversity beliefs of educators. The Journal of Multiculturalism in Education, 7, 1- 30.

Henry, G. B. (1986). Cultural Diversity Awareness Inventory = Inventario Sobre el Reconocimiento de Diversas Culturas. Retrieved from http://eric.ed.gov/?id=ED282657

Hong, W. (2010). Multicultural education in Korea: Its development, remaining issues, and global implications. Asia Pacific Education, 11(3), 387-395. 
Hoy, W. K., \& Woolfolk, A. E. (1993). Teachers' sense of efficacy and the organizational health of schools. Elementary School Journal, 93, 356-372.

Ivankova, N. V., \& Creswell, J. W. (2006). Using mixed methods sequential explanatory design: From theory to practice. Field Methods, 18(1), 3-20.

Jang, I., \& Jeon, K. (2013). A case study of elementary teachers' multicultural education perception and practices. Multicultural Education Studies, 6(1). 73-103.

Jeon, K. (2010). Case study of elementary teachers' multicultural education perception and practices. Incheon, South Korea: Gyeongin National University of Education.

Kagan, D. M. (1992). Implications of research on teacher belief. Educational Psychologist, 27, 129-169.

Kahn, M. (2008). Multicultural education in the United States: Reflections. Intercultural Education, 19(6), 527-536.

Kang, S. (2010). Multicultural education and the rights to education of migrant children in South Korea. Educational Review, 62(3), 287-300.

Kim, A. (2010). Korean multiculturalism: The genealogy of the concept, shifting meanings, issues and implications. Asea Yeongu [Asian Research], 53(2), 102202.

Kim, H., \& Kim, D. (2008). A study on elementary school teachers' perceptions about multicultural education. Journal of Educational Research [Kyoyuk Yeongu Nonchong], 29(2), 41-63. 
Kim, J., Lee, H., Bae, U., \& Hu, C. (2005). A study on the conditions of educational welfare for the foreign workers' children in South Korea. Seoul, South Korea: Korean Education Development Institute.

Kim, J., Lee, J. G., \& Lee, S. K. (2005). Understanding of education fever in Korea. KEDI Journal of Educational Policy, 2(1).

Kim, Y. (2007). Study on policy paradigm shift into multiethnic and multicultural society. Seoul, South Korea: Korean Institute of Women Development.

Korean Educational Statistics Service. (2015). Primary educational statistics. Retrieved from http://kess.kedi.re.kr/index

Korean National Key Indicators System. (2016). Statistics on foreign residents. Retrieved from http://www.index.go.kr/potal/enaraIdx/idxField/userPageCh.do?idx_cd=2915

Korean Ministry of Education. (2016). Plan for supporting multicultural students. Retrieved from http://www.joongboo.com/?mod=news\&act=articleView\&idxno=1054893

Kumar, R., \& Hamer, L. (2012). Preservice teachers' attitudes and beliefs toward student diversity and proposed instructional practices: A sequential design study. Journal of Teacher Education, 64(2), 162-177.

Kyles, C. R., \& Olafson, L. (2008). Uncovering preservice teachers' beliefs about diversity through reflective writing. Urban Education, 43(5), 500-518.

Kymlicka, W. (1995). Multicultural citizenship: A liberal theory of minority rights. Oxford, UK: Oxford University Press. 
Larke, P. J. (1990). Cultural diversity awareness inventory: Assessing the sensitivity of preservice teachers. Action in Teacher Education, 12(3), 23-30.

doi:10.1080/01626620.1990.10734396

Leavy, A. (2005). "When I meet them I talk to them": The challenges of diversity for preservice teacher education. Irish Educational Studies, 24(2-3), 159-177. doi:10.1080/03323310500435422

Lee, C. J. (2005). Korean education fever and private tutoring. KEDI Journal of Educational Policy, 2(1).

Lee, H. (2014). A narrative inquiry of in-service teachers' perceptions and experiences in multicultural education. Theory and Practice of Education [Kyoyukui Ilonkwa Silcheon], 19(2), 75-95.

Lee, J. (2008). Multicultural education in South Korean public elementary schools: An analysis of teachers' experiences and perspectives and school curriculum. ProQuest LLC. Retrieved from ERIC database. (ED527503)

Lee, J. Y. (2013). Multicultural education in the Republic of Korea: How elementary school teachers interpret multicultural education and its practical use in classrooms. Available from ProQuest Dissertations \& Theses Global. (1458440969). Retrieved from

Lee, M., \& Greene, G. J. (1999) A social constructivist framework for integrating crosscultural issues in teaching clinical social work, Journal of Social Work Education, $35(1), 21-37$ 
Lee, S., \& Dallman, M. (2008). Engaging in a reflective examination about diversity: Interviews with three preservice teachers. Multicultural Education, 15(4). 36-44.

Lee, Y. (2013). Critical discourse analysis of multicultural education policies and their local implementation in Korea (Ed.D.).. Available from ProQuest Dissertations \& Theses Global. (1430907037). Retrieved from http://search.proquest.com.proxy.lib.pdx.edu/docview/1430907037/abstract/DA2 FA59E8B594424PQ/4?accountid=13265

Lee, Y., \& Herner-Patnode, L. (2010). Developing teacher candidates' knowledge, skills, and dispositions to teach diverse students. Journal of Instructional Psychology, $37(2), 222-235$.

Love, A., \& Kruger, A. C. (2005). Teacher beliefs and student achievement in urban schools serving African American students. Journal of Educational Research, 99, 87-98.

Maxwell, J. A. (2013). Qualitative research design: An interactive approach $\left(3^{\text {rd }} \mathrm{ed}.\right)$. Thousand Oaks, CA: Sage.

McLaren, P. (2000). White terror and oppositional agency: Toward a critical multiculturalism. In E. M. Duarte. \& S. Smith (Eds.). Foundational perspectives in multicultural education (pp. 213-242). New York, NY: Longman.

McMahon, M. (1997, December). Social constructivism and the World Wide Web - A Paradigm for learning. Paper presented at the ASCILITE conference. Perth, Australia. 
Middleton, V. A. (2002). Increasing preservice teachers' diversity beliefs and commitment. Urban Review, 34(4), 343-361. Retrieved from http://stats.lib.pdx.edu/proxy.php?url=http://search.ebscohost.com/login.aspx?dire $\mathrm{ct}=$ true $\& \mathrm{db}=$ ehh $\& \mathrm{AN}=11308939 \&$ site $=$ ehost-live

Mills, C. (2008). Making a difference: Moving beyond the superficial treatment of diversity. Asia-Pacific Journal of Teacher Education, 36(4), 261-275.

Milner, H. R., Flowers, L. A., Moore, E., Moore, J. L., \& Flowers, T. A. (2003). Preservice teachers' awareness of multiculturalism and diversity. The High School Journal, 87(1), 63-70.

Moon, S. (2010). Multicultural and global citizenship in a transnational age: The case of South Korea. International Journal of Multicultural Education, 12(1), 1-15. Retrieved from http://ijme-journal.org/index.php/ijme/article/view/261

Morgan, D. L. (2007). Paradigms lost and pragmatism regained methodological implications of combining qualitative and quantitative methods. Journal of Mixed Methods Research, 1(1), 48-76. Retrieved from http://mmr.sagepub.com/content/1/1/48.short

Morgan, D. L. (2013). Integrating qualitative and quantitative methods: A pragmatic approach. Thousand Oaks, CA: Sage.

Morgan, D. L. (2014). Pragmatism as a paradigm for social research. Qualitative Inquiry, 20(8), 1045-1054. doi:10.1177/1077800413513733.

Nadelson, L. S., Boham, M. D., Conlon-Khan, L., Fuentealba, M. J., Hall, C. J., Hoetker, G. A., ... Zenkert, A. J. (2012). A shifting paradigm preservice teachers' 
multicultural attitudes and efficacy. Urban Education, 47(6), 1183-1208. doi: $10.1177 / 0042085912449750$

Nelson, S. W., \& Guerra, P. L. (2014). Educator beliefs and cultural knowledge: Implications for school improvement efforts. Educational Administration Quarterly, 5O(1), 67-95. doi:10.1177/0013161X13488595

Nespor, J. (1987). The role of beliefs in the practice of teaching, The Journal of Curriculum Studies, 19(4), 317-328.

Nylund, D. (2006). Critical multiculturalism, whiteness, and social work. Journal of Progressive Human Services, 17(2), 27-42. doi:10.1300/J059v17n02_03

Ogletree, Q. D. (2013). The relationship between elementary teachers' beliefs about diversity and their selections of multicultural materials for instructional practices in one urban school district. Available from ProQuest Dissertations \& Theses Global (1442390707). Retrieved from http://search.proquest.com.proxy.lib.pdx.edu/docview/1442390707/Record/8566B 5C361954B70PQ/1?accountid=13265\#

Olneck, M. R. (2011). Facing multiculturalism's challenges in Korean education and society. Asia Pacific Education Review, 12, 675-690.

Pajares, M. F. (1992). Teachers' beliefs and educational research: Cleaning up a messy construct. Review of Educational Research, 62(3), 307-322.

Palincsar, A.S. (1998). Social constructivist perspectives on teaching and learning. Annual Review of Psychology, 49, 345-375. 
Park, J. K. (2009). 'English fever' in South Korea: Its history and symptoms. English Today, 25(01), 50-57.

Park, S. (2007). A study of progress, mission, and performance analysis of multicultural educational policy in Korea. Research report. Seoul, South Korea: Jungang Multicultural Educational Center of Seoul National University.

Park, S. H. (2011). The cognition of primary and secondary school teachers on multicultural education in Daegu. Research of Social Studies. [Sahoegwa yeongu], 18(1), 1-17.

Pettus, A. M., \& Allain, V. A. (1999). Using a questionnaire to assess prospective teachers' attitudes toward multicultural education issues. Education, 119(4), 651. Retrieved from http://stats.lib.pdx.edu/proxy.php?url=http://search.ebscohost.com/login.aspx?dire ct=true $\& \mathrm{db}=$ tfh $\& A N=2130381 \&$ site $=$ ehost-live

Pohan, C. A. (1996). Preservice teachers' beliefs about diversity: Uncovering factors leading to multicultural responsiveness. Equity and Excellence in Education. 29(3), 62-69.

Pohan, C. A., \& Aguilar, T. E. (1994). Initial development and preliminary testing of two beliefs about diversity measures. Research monograph. Lincoln, NE: The University of Nebraska, Center for Curriculum and Instruction, Teachers College.

Pohan, C. A., \& Aguilar, T. E. (1995). The beliefs about diversity scale: User manual and scoring guide. Lincoln, NE: Department of Educational Psychology and the Center for Curriculum and Instruction, University of Nebraska-Lincoln. 
Pohan, C. A., \& Aguilar, T. E. (2001). Measuring educators' beliefs about diversity in personal and professional contexts. American Educational Research Journal, $38(1), 159-182$.

Pohan, C. A., Ward, M., Kouzekanani, K., \& Boatright, C. (2009). The impact of field placement sites on preservice teachers' beliefs about teaching diverse students. School-University Partnerships, 3(1), 43-53. Retrieved from http://eric.ed.gov/?id=EJ915860

Prawat, R. S., \& Floden, R. E. (1994). Philosophical perspectives on constructivist views of learning. Educational Psychologist, 29(1), 37.

Richardson, V. (1997). Constructivist teaching and teacher education: Theory and practice. In V. Richardson (Ed.), Constructivist teacher education: Building new understandings (pp. 3-14). Washington, DC: Falmer Press.

Rodriguez, A. J., \& Berryman, C. (2002). Using sociotransformative constructivism to teach for understanding in diverse classrooms: A beginning teacher's journey. American Educational Research Journal, 39(4), 1017-1045.

Schraw, G., \& Olafson, L. (2002). Teachers' epistemological world views and educational practices. Issues in Education, 8(2), 99-148.

Silverman, S. K. (2010). What is diversity? An inquiry into preservice teacher beliefs. American Educational Research Journal, 47(2), 292-329.

Sleeter, C. E. (1991). Introduction: Multicultural education and empowerment. In C. E. Sleeter (Ed.), Empowerment through multicultural education (pp. 1-23). Albany, NY: State University of New York Press. 
Sleeter, C. E., \& Grant, C. A. (2009). Making choices for multicultural education: five approaches to race, class, and genders ( $6^{\text {th }}$ ed.). Hoboken, NJ: Wiley.

Snyder, C. R. (1995). Conceptualizing, measuring, and nurturing hope. Journal of Counselling \& Development, 73(3), 355-361.

Teddlie, C., \& Tashakkori, A. (2010). Overview of contemporary issues in mixed methods research. In A. Tashakkori \& C. Teddlie (Eds.), SAGE handbook of mixed methods in social and behavioral sciences (2nd ed., pp. 1-44). Thousand Oaks, CA: Sage.

Torok, C. E., \& Aguilar, T. E. (2000). Changes in preservice teachers' knowledge and beliefs about language issues. Equity \& Excellence in Education, 33(2), 24-31.

Tschong, Y. (2009). Hankook damunhawa saheo gyoyukhakjuck sungchal [Educational reflection on the multiculturalization of the Korean society]. Gyoyouk cholhak [Educational Philosophy], 44, 113-137.

Van Hook, C. W. (2002). Preservice teachers' perceived barriers to the implementation of a multicultural curriculum. Journal of Instructional Psychology, 29(4), 254-264.

Vogt, W. P., Gardner, D. C., \& Haeffele, L. M. (2012). When to use what research design. New York, NY: Guilford Press.

Watson, I. (2010). Multiculturalism in South Korea: A critical assessment. Journal of Contemporary Asia, 40(2), 337-346.

Watson, S. L., Park, G. C., \& Lee, H. (2011). Pre-service teachers' awareness and attitudes on South Korea's increasing cultural and ethnic diversity and the role of 
multicultural education in K-12 Schools. International Journal of Education, 3(2), E3. doi:10.5296/ije.v3i2.709

Won, S. (2008). Damunhwa sidae sosuja jungchck chabyolguk posopgwa baejae [Differentiated inclusion and exclusion of policy for marginalized groups in multicultural age]. Hankuk hangjung hakbo [Korean Journal of Administration], 42(3), 29-49.

Yoon, I. (2009). The development of multiculturalism discourse and multicultural policy in South Korea: With a focus on the roles of the government and civil society. Trans-Humanities, 1, 1-36. 
Appendix A

Demographic and Experience Survey

TO THE RESPONDER: The demographic information requested below is necessary for the research process. Please be assured that this information and all of your responses on this instrument will be kept strictly confidential. Data will be reported in such a way that identification of individuals will be impossible.

Definition: In this survey, the terms "multicultural family" means family where one or both parents are a different ethnicity than Korean.

Directions: Please response to the following items by checking in the appropriate space.

1. Gender: (1) Male (2) Female

2. Age: (1) 24-30 years old (2) 31-40 years old (3) 41-50 years old (4) 51-62 years old

3. Years of teaching: (1) Below 5 years (2) 5-10 years (3) $11-15$ years

$$
\text { (4)16-20 years }
$$
(5) Above 20 years

4. Have you been worked with students from multicultural family?

(1) Yes (2) No

5. Have you ever attended courses of study (at University, inservice training, workshop or some other) which focused on multicultural education?

(1) Yes (if yes, please name the courses done)

(2) No 
6. Have you ever traveled foreign countries?

(1) I have not traveled (2) I have traveled 1-2 times

(3) I have traveled 3-5 times (4) I have traveled 6 or more times

7. Have you ever lived in foreign countries for than 6 months?

(1) Yes (2) No

8. Have you ever had friendships with people from countries? (e.g., exchange visits with a foreign friend, have a foreign friend on Facebook, engage in an international organization such as UNESCO, etc.)

(1) Yes ___ (if yes, please explain your experience)

(2) No 
Appendix B

Permission for Using Personal and Professional Beliefs about Diversity Scales

1 Gmail

Marie Yeo <mariejolie4u@gmail.com>

\section{Request a permission for using scales}

Cathy Pohan <cpohan@nu.edu>

Tue, Mar 10, 2015 at 12:50 PM

To: Marie Yeo <mariejolie4u@gmail.com>, "taguilarVPAA@nmhu.edu" <taguilarVPAA@nmhu.edu>

Dear Ms. Marie Yeo,

Sorry it has taken me a while to respond, but I was out of the office for about a week. We are happy to see that you are interested in investigating the beliefs of South Korean teachers with regard to diversity. You certainly have our permission to use the scales, but please understand that the cultural contexts in both countries are very different and many of the items may not make sense in the context of South Korea. The validity and reliability of the scales are based on using all items, so we do not advise removing items. We did not find evidence of separate subscales within the Personal and Professional Beliefs about Diversity Scales.

Attached it a copy of our Guidebook. Please note that the most reliable and valid scales are the 1998 versions - these are what we recommend you use.

This email serves as your permission to use the scales for the proposed research. Any translation of the items into a language other than English will require additional reliability tests.

Good luck in your research.

Dr. Cathy Pohan

From: Marie Yeo [mailto:mariejolie4u@gmail.com]

Sent: Wednesday, March 04, 2015 10:26 AM

To: Cathy Pohan; taguilarVPAA@nmhu.edu

Subject: Request a permission for using scales

Dear Drs. Pohan and Aguilar,

My name is Marie Yeo. I am a doctoral student in Portland State University, Oregon. I am developing a dissertation proposal titled "South Korean teachers' beliefs about diversity and their practice of multicultural education." As I reviewed the research literature, I found that your "Personal and Professional Beliefs about Diversity Scales (2001)" are appropriate instruments for my study. I would like your permission to use your scales in my research.

Please let me know if you have any questions. 
Appendix C

Personal Beliefs about Diversity Scale (modified)

The purpose of this survey is to examine Korean elementary teachers' beliefs about diversity in personal and professional context. The scale is adapted from Pohan and Aguilar's (2001) scale and is modified to Korean context.

Definition: In this survey, the terms "diversity" and "people different from me" to include people of different races, ethnic groups, cultures, religions, socio-economic classes, sexual orientations, and physical abilities.

Direction: Please check "V" the most appropriate answer to according to your belief about diversity in personal context. Each question has five levels of answer from "strongly disagree" to "strongly disagree." Please take a few minutes to fill out the questionnaire below completely.

Personal Beliefs about Diversity Scale (modified)

Key: SD: Strongly Disagree, D: Disagree, U: Undecided, A: Agree, SA: Strongly Agree

\begin{tabular}{|l|c|c|c|c|c|}
\hline & SD & D & U & A & SA \\
\hline $\begin{array}{l}\text { 1. There is nothing wrong with people from } \\
\text { different racial backgrounds having/raising } \\
\text { children. }\end{array}$ & & & & & \\
\hline $\begin{array}{l}\text { 2. Korea's immigrant and refugee policy has led to } \\
\text { the deterioration of Korea. }\end{array}$ & & & & & \\
\hline $\begin{array}{l}\text { 3. Making all public facilities accessible to the } \\
\text { disabled is simply too costly. }\end{array}$ & & & & & \\
\hline $\begin{array}{l}\text { 4. Accepting many different ways of life in Korea } \\
\text { will strengthen us as a nation. }\end{array}$ & & & & & \\
\hline $\begin{array}{l}\text { 5. It is not a good idea for same-sex couples to raise } \\
\text { children. }\end{array}$ & & & & & \\
\hline
\end{tabular}




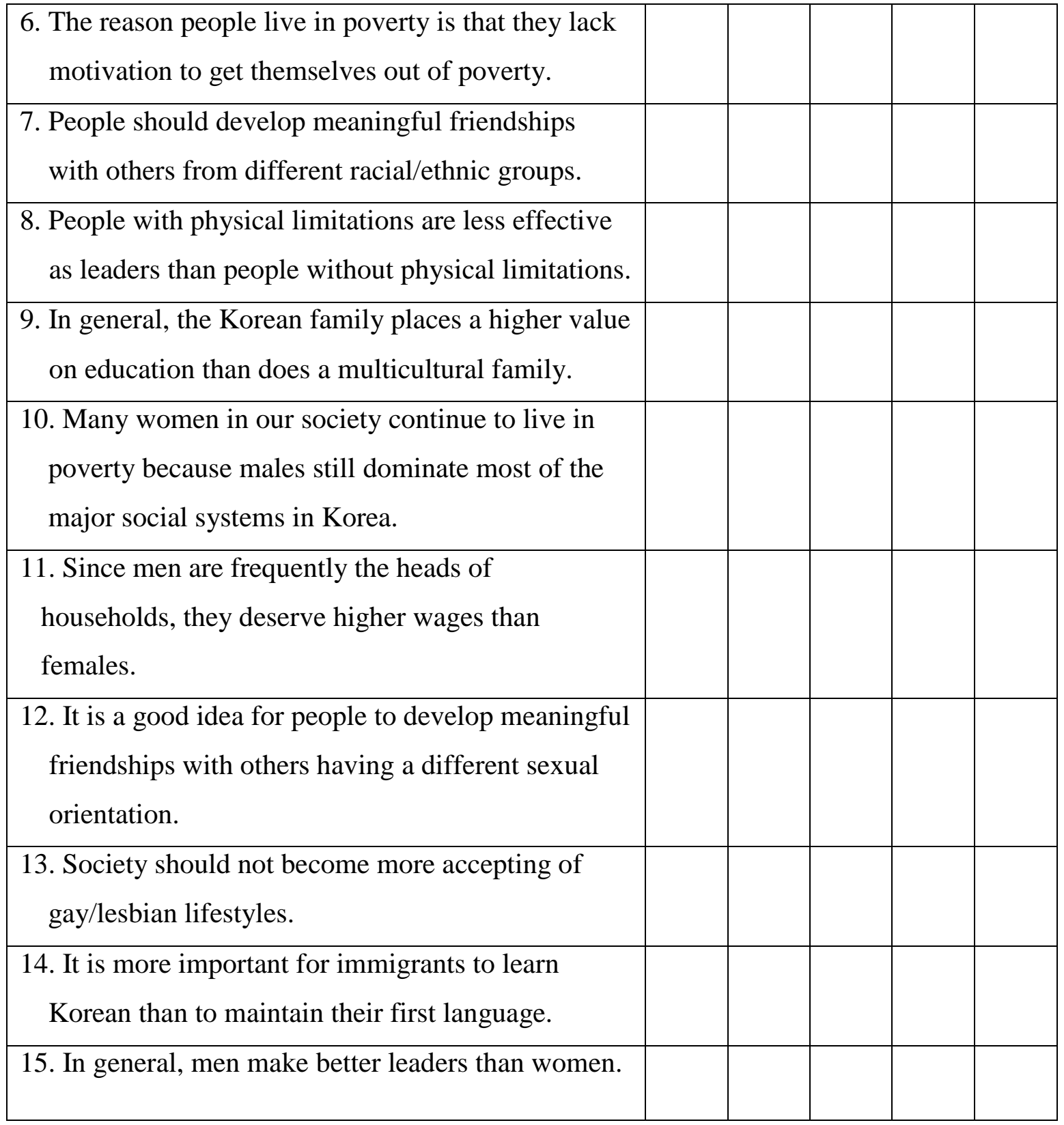




\section{Appendix D}

Professional Beliefs about Diversity Scale (modified)

Key: SD: Strongly Disagree, D: Disagree, U: Undecided, A: Agree, SA: Strongly Agree

\begin{tabular}{|c|c|c|c|c|c|}
\hline & $\begin{array}{l}\text { SD } \\
(1)\end{array}$ & $\begin{array}{l}\mathrm{D} \\
(2)\end{array}$ & $\begin{array}{c}\mathrm{U} \\
\mathrm{U} \\
(3)\end{array}$ & $\begin{array}{c}\mathrm{A} \\
(4)\end{array}$ & $\begin{array}{l}\text { SA } \\
(5)\end{array}$ \\
\hline \multicolumn{6}{|l|}{$\begin{array}{l}\text { 1. Teachers should not be expected to adjust their } \\
\text { preferred mode of instruction to accommodate the } \\
\text { needs of all students. }\end{array}$} \\
\hline \multicolumn{6}{|l|}{$\begin{array}{l}\text { 2. The traditional classroom has been set up to } \\
\text { support the middle-class lifestyle. }\end{array}$} \\
\hline \multicolumn{6}{|l|}{$\begin{array}{l}\text { 3. Gays and lesbians should not be allowed to teach } \\
\text { in public schools. }\end{array}$} \\
\hline \multicolumn{6}{|l|}{$\begin{array}{l}\text { 4. Students and teachers would benefit from having a } \\
\text { basic understanding of different (diverse) } \\
\text { religions. }\end{array}$} \\
\hline \multicolumn{6}{|l|}{$\begin{array}{l}\text { 5. Money spent to educate the severely disabled } \\
\text { would be better spent on programs for gifted } \\
\text { students. }\end{array}$} \\
\hline \multicolumn{6}{|l|}{$\begin{array}{l}\text { 6. All students should be encouraged to become } \\
\text { fluent in one foreign language. }\end{array}$} \\
\hline \multicolumn{6}{|l|}{$\begin{array}{l}\text { 7. Only schools serving multicultural students need a } \\
\text { racially, ethnically, and culturally diverse staff } \\
\text { and faculty. }\end{array}$} \\
\hline \multicolumn{6}{|l|}{$\begin{array}{l}\text { 8. The attention girls receive in school is comparable } \\
\text { to the attentions boys receive. }\end{array}$} \\
\hline \multicolumn{6}{|l|}{$\begin{array}{l}\text { 9. Tests, particularly standardized tests, have been } \\
\text { used to sort students (e.g., high or low grades). }\end{array}$} \\
\hline \multicolumn{6}{|l|}{$\begin{array}{l}\text { 10. People from diverse culture and races are } \\
\text { adequately represented in most textbooks today. }\end{array}$} \\
\hline \multicolumn{6}{|l|}{$\begin{array}{l}\text { 11. Students with physical limitations should be } \\
\text { placed in the regular classroom whenever } \\
\text { possible. }\end{array}$} \\
\hline $\begin{array}{l}\text { 12. Males are given more opportunities in math and } \\
\text { science than females. }\end{array}$ & & & & & \\
\hline
\end{tabular}




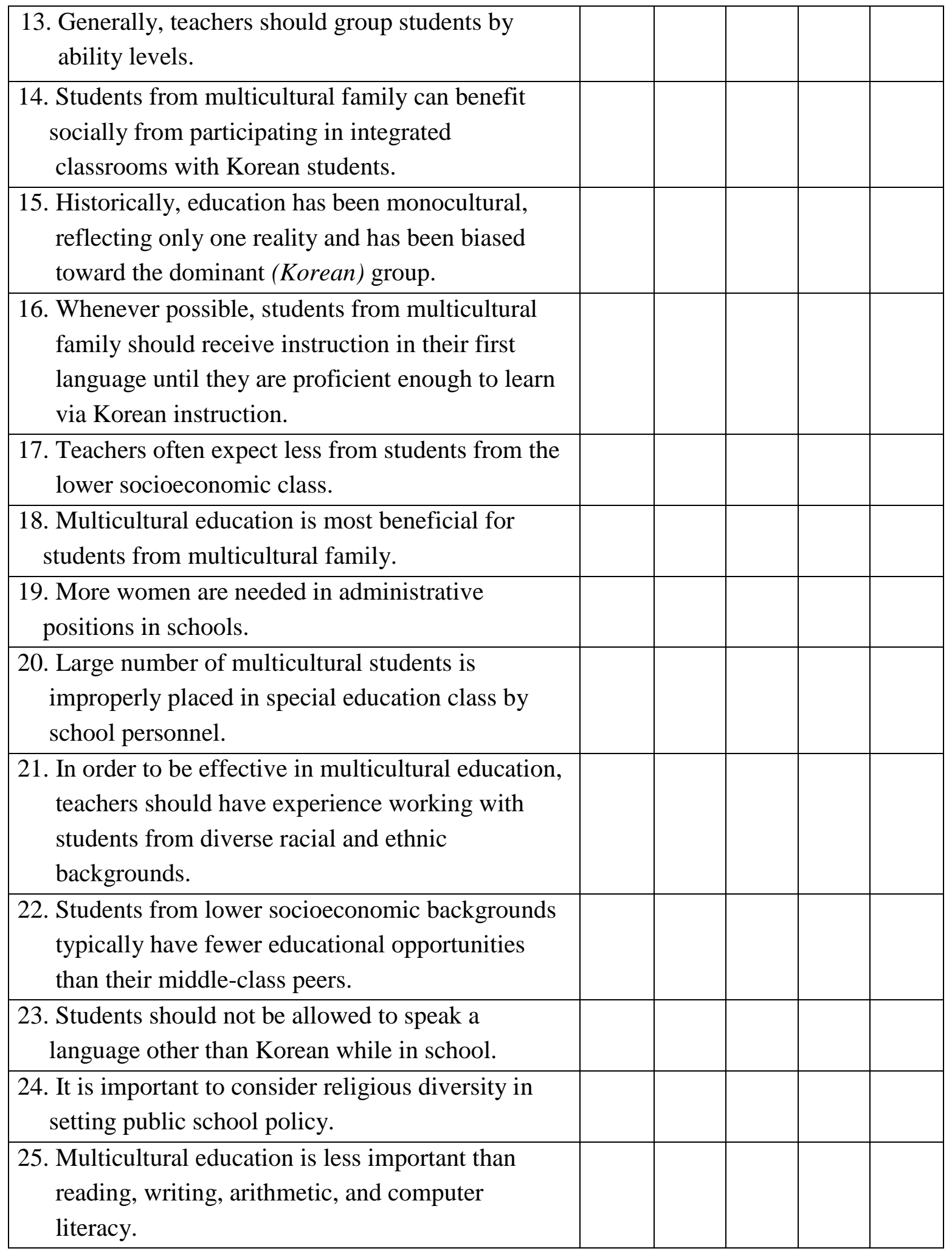




\author{
Appendix E \\ Interview Questions
}

1. Have you had any intercultural experience? Tell me about it.

2. How do your intercultural experiences influence your beliefs about diversity?

3. How do your beliefs about diversity influence your multicultural teaching?

4. What experiences have most prepared you to teach multicultural education?

5. What does multicultural education mean to you?

6. Have you taught students from multicultural family? Tell me about the experience.

7. What has or has not supported your multicultural teaching so far?

8. What do you think is the best model for multicultural teacher education program? 


\section{Appendix F}

Categories and Codes Identified from Coding Analysis

\begin{tabular}{|c|c|}
\hline Categories & Codes \\
\hline $\begin{array}{l}\text { Teachers' experiences with multicultural } \\
\text { family }\end{array}$ & $\begin{array}{ll}\text { - } & \text { Koreans' spectrum of racial preference } \\
\text { - } & \text { Hiding identity as multicultural } \\
\text { student/family } \\
\text { - } & \text { Prejudice and discrimination } \\
\text { - } & \text { Language issues }\end{array}$ \\
\hline Effects of intercultural experiences & $\begin{array}{l}\text { - Interest and understanding about diverse } \\
\text { cultures } \\
\text { - Becoming culturally sensitive } \\
\text { - Awareness about multicultural education } \\
\text { - Experiences as effective teaching } \\
\text { materials }\end{array}$ \\
\hline $\begin{array}{l}\text { Impact of teachers' beliefs on } \\
\text { multicultural education }\end{array}$ & $\begin{array}{l}\text { - Strong direct impact on teaching practice } \\
\text { - Understanding individual situation of } \\
\text { students } \\
\text { - Non-judgmental in communication with } \\
\text { parents }\end{array}$ \\
\hline Challenges in multicultural education & $\begin{array}{l}\text { - Stereotype and prejudice about } \\
\text { multicultural family } \\
\text { - } \quad \text { Multicultural students' low self-esteem } \\
\text { - } \\
\text { Superficial multicultural education for } \\
\text { - } \text { Korean students } \\
\text { - } \text { Nulticultural education is not a priority } \\
\text { - } \text { Insufficient support for mother language } \\
\text { - } \quad \text { Emphasis on Korea's homogeneity in } \\
\text { - } \text { textbooks } \\
\text { Keeping balance between multicultural } \\
\text { students and Korean students in need }\end{array}$ \\
\hline
\end{tabular}




\begin{tabular}{|c|c|}
\hline How to support multicultural education & $\begin{array}{l}\text { - Integrated class with multicultural } \\
\text { students } \\
\text { - } \text { Multicultural education specialist needed } \\
\text { - } \text { Human resources are useful } \\
\text { - } \text { Considering benefit of being a } \\
\text { multicultural student }\end{array}$ \\
\hline Teacher education program & $\begin{array}{l}\text { - Through experience } \\
\text { - Curriculum related } \\
\text { - Creating "we" concept among students, } \\
\text { parents, and teachers }\end{array}$ \\
\hline
\end{tabular}

